Pacific Northwest National Laboratory

Operated by Battelle for the

U.S. Department of Energy

\title{
Development of NEXRAD Wind Retrievals as Input to Atmospheric Dispersion Models
}

\author{
J. D. Fast ${ }^{(1)}$ \\ R. K. Newsom ${ }^{(1)}$ \\ K. J. Allwine ${ }^{(1)}$ \\ Q. $\mathrm{Xu}^{(2)}$ \\ P. Zhang ${ }^{(2)}$ \\ J. H. Copeland ${ }^{(3)}$ \\ J. $\operatorname{Sun}^{(3)}$ \\ (1) Pacific Northwest National Laboratory, Richland, WA \\ (2) NOAA National Severe Storms Laboratory, Norman, OK \\ (3) National Center for Atmospheric Research, Boulder, CO
}

February 2007

Prepared for the U.S. Department of Energy under Contract DE-AC05-76RL01830 


\title{
DISCLAIMER
}

This report was prepared as an account of work sponsored by an agency of the United States Government. Neither the United States Government nor any agency thereof, nor Battelle Memorial Institute, nor any of their employees, makes any warranty, express or implied, or assumes any legal liability or responsibility for the accuracy, completeness, or usefulness of any information, apparatus, product, or process disclosed, or represents that its use would not infringe privately owned rights. Reference herein to any specific commercial product, process, or service by trade name, trademark, manufacturer, or otherwise does not necessarily constitute or imply its endorsement, recommendation, or favoring by the United States Government or any agency thereof, or Battelle Memorial Institute. The views and opinions of authors expressed herein do not necessarily state or reflect those of the United States Government or any agency thereof.

\author{
PACIFIC NORTHWEST NATIONAL LABORATORY \\ operated by \\ BATTELLE \\ for the \\ UNITED STATES DEPARTMENT OF ENERGY \\ under Contract DE-ACO5-76RL01830
}

Printed in the United States of America
Available to DOE and DOE contractors from the
Office of Scientific and Technical Information,
P.O. Box 62, Oak Ridge, TN 37831-0062;
ph: (865) 576-8401
fax: (865) 5765728
email: reports@adonis.osti.gov

\footnotetext{
Available to the public from the National Technical Information Service, U.S. Department of Commerce, 5285 Port Royal Rd., Springfield, VA 22161 ph: (800) 553-6847 fax: (703) 605-6900

email: orders@nits.fedworld.gov online ordering: http://www.ntis.gov/ordering.htm
} 


\title{
Development of NEXRAD Wind Retrievals as Input to Atmospheric Dispersion Models
}

\author{
J. D. Fast ${ }^{(1)}$ \\ R. K. Newsom ${ }^{(1)}$ \\ K. J. Allwine ${ }^{(1)}$ \\ Q. $\mathrm{Xu}^{(2)}$ \\ P. Zhang ${ }^{(2)}$ \\ J. H. Copeland ${ }^{(3)}$ \\ J. Sun ${ }^{(3)}$ \\ (1) Pacific Northwest National Laboratory, Richland, WA \\ (2) NOAA National Severe Storms Laboratory, Norman, OK \\ (3) National Center for Atmospheric Research, Boulder, CO
}

March 2007

Prepared for the U.S. Department of Energy

under Contract DE-AC05-76RL01830

Pacific Northwest National Laboratory

Richland, WA 99352 


\section{Summary}

Two techniques that derive spatially varying wind fields from operational radar measurements have been evaluated in this study. Based on results, we propose that one technique be implemented operationally in a phased approach. The other technique would be suitable for operational implementation only after additional modifications have been made and evaluated. These two techniques would require additional funding to implement, maintain operational versions of these codes, and perform additional research to improve their accuracy.

Atmospheric dispersion models (ADMs) are used by emergency-response organizations to address the consequences of potential airborne releases of harmful materials. The wind fields in ADMs are based on meteorological measurements and forecasts made by atmospheric models. In the United States, routine meteorological measurements from surface stations, towers, rawinsondes, and radar wind profilers are available to drive ADMs. Large metropolitan areas usually have a network of surface stations; however, the wind-speed and direction measurements from these stations are usually not representative of conditions above the surface. There are currently relatively few measurements that can characterize the winds above the surface. One potentially rich, yet untapped, source of meteorological data for routine use in ADMs is from the Next Generation Weather Radar (NEXRAD) systems with 141 nearly identical WSR-88D Doppler radar units installed throughout the United States.

The objective of this study is to determine the feasibility that routinely collected data from the Doppler radars can appropriately be used in ADMs for emergency response. We have evaluated the computational efficiency and accuracy of two variational mathematical techniques that derive the u- and v-components of the wind from radial velocities obtained from Doppler radars. A review of the scientific literature indicated that the techniques employ significantly different approaches in applying the variational techniques: 2-D Variational (2DVar), developed by the National Oceanic and Atmospheric Administration's National Severe Storms Laboratory and Variational Doppler Radar Analysis System (VDRAS), developed by the National Center for Atmospheric Research. We designed a series of numerical experiments in which both models employed the same horizontal domain and resolution encompassing Oklahoma City for a 2-week period during the summer of 2003 so that the computed wind retrievals could be fairly compared. Both models ran faster than real-time on one typical dual-processor computer, indicating that they could be used to generate wind retrievals in near real-time. The simpler approach of 2DVar allowed it to execute $~ 2.5$ faster than VDRAS. The simpler approach of 2DVar allowed it to execute $\sim 2.5$ times faster than VDRAS.

The accuracy of 2DVar and VDRAS is quantified by comparing the derived wind components with independent, meteorological measurements made by radar wind profilers. Both systems qualitatively reproduced the observed diurnal and multi-day trends in the wind speeds and direction. The wind speeds

were often within a few meters per second of radar wind-profiler data. While these differences may seem large, the wind retrievals likely provide useful information when no other observations are available. The periods in which differences exceeded $5 \mathrm{~m} \mathrm{~s}^{-1}$ were usually relatively short. Both models had the tendency to over-estimate the wind speeds associated with the nocturnal low-level jet by as much as $\sim 5 \mathrm{~m} \mathrm{~s}^{-1}$ when the observed winds were $\sim 20 \mathrm{~m} \mathrm{~s}^{-1}$. Farther aloft from 1 to $2 \mathrm{~km}$ above the ground, either the 2DVar or VDRAS wind retrieval would be closer to the profiler data. Above $2 \mathrm{~km}$, the wind retrievals and radar wind-profiler data were often very different; therefore, the wind retrievals should not be used at these altitudes. 
The statistical performance (bias, root-mean-square error, index of agreement, and correlation coefficient) of both systems was similar as well when evaluated against the radar wind-profiler data. Statistically, 2DVar performed better at certain locations and altitudes while VDRAS performed better at other locations and altitudes. Thus, neither system out-performed the other. Considering that the accuracy of radar wind-profiler measurements is from 0.5 to $1 \mathrm{~m} \mathrm{~s}^{-1}$, the statistical measures suggest that the uncertainties of the wind retrievals are higher than those found in conventional instrumentation. The simulated spatial variations in wind speed and direction were similar to the measurements from the radar wind-profiler network during periods with large spatial variability in the observed winds; however, the observed spatial-velocity differences were usually below the accuracy of the radar wind-profiler measurements during the sampling period. For emergency-response ADM applications, the windretrieval uncertainties need to be weighed against having no other wind information aloft. For example, the wind retrievals were shown to often provide better information aloft than simply interpolating standard rawinsonde information in time.

The effect of the additional wind information aloft on transport and dispersion is examined by performing a series of sensitivity simulations using a widely used ADM. The results of the dispersion simulations indicated the wind fields based on wind retrievals from 2DVar and VDRAS, and the radar wind-profiler data produced similar dispersion patterns. This suggests that the operational NEXRAD data could provide valuable information for a location that does not have any radar wind-profiler data or other routine wind-profile measurements aloft, even if it did contain somewhat larger uncertainties than other remote sensing instruments.

An important consideration for using NEXRAD wind retrievals for ADMs is availability of the data since the range of the radar depends on the size, number-density, and physical properties of scattering material in the atmosphere. The availability of radial-velocity data was computed for five radars near large metropolitan areas, including Los Angeles, Salt Lake City, Oklahoma City, Boston, and Washington DC. The total amount of data that passed quality-control checks over the total possible number of data points within $\sim 230 \mathrm{~km}$ of the radar was typically from 10 to $40 \%$. The good data were usually located closest to the radar; therefore, measurements were often available over adjacent urban areas. Even if wind retrievals were not produced directly over the urban areas, the upper-air information would likely be representative of the region and provide useful information to better describe the local three-dimensional wind fields. The availability also varied by season with the highest availability during the summer. Lack of targets for the radar in clear-air is the main reason for lower availability in winter since insects are less active during the cold periods.

Finally, we weighed the advantages and disadvantages of both 2DVar and VDRAS based on quantitative, operational, and system-capability considerations. Despite being a relatively new algorithm, we recommend that 2DVar be implemented operationally, first to produce routine wind fields associated with NEXRAD radar data. We based our decision on the fact that the wind retrievals from the technique in 2DVar can be considered a type of observation that is similar to other types of data (e.g., radar wind profiler). Its simplicity also makes it easier to implement computationally. VDRAS is a more sophisticated model and is therefore more computational expensive. Despite the complexity of VDRAS's four-dimensional variational approach, the wind retrievals were not significantly better than 2DVar at the profiler sites. Nevertheless, we recommend that additional research be performed to refine the system before it is used operationally in the future. VDRAS is more flexible than 2DVar, and the capability of VDRAS to assimilate a wide range of conventional meteorological information could reduce current uncertainties associated with the NEXRAD wind retrievals. An updated version of VDRAS has the potential to produce significantly better wind fields than the present version, but additional research is 
needed so that the model does not require "tuning” for each location. The costs associated with making NEXRAD wind retrievals available operationally would also be significantly less than deploying additional standard instrumentation.

A preliminary plan has been developed that describes how the wind-retrieval software should be implemented so that wind fields derived from NEXRAD data can be used routinely to drive ADM applications throughout the United States. We propose a phased approach of making NEXRAD wind retrievals available in real time that is summarized as 1) developing the NEXRAD data center, 2) evaluating an operational beta version of 2DVar, 3) implementing 2DVar operationally, 4) maintaining operational NEXRAD wind-retrieval products, 5) further developing VDRAS, 6) evaluating an operational beta version of VDRAS, and 7) implementing VDRAS operationally. Implementing this plan would depend on future funding by the Department of Homeland Security and other organizations. 



\section{Acronyms and Abbreviations}

2DVar

$\mathrm{ADM}$

AGL

ANL

BWIC

CALMET

CALPUFF

CPU

DTRA

EPA

HPAC

IA

IMAAC

JU 2003

LST

NASA

NEXRAD

NCAR

NCDC

NCEP

NOAA

NSSL

NWS

$\mathrm{OU}$

OSSE

PNNL

QC

$\mathrm{R}$

RMSE

RTFDDA
Two-Dimensional Variational

atmospheric dispersion model

above ground level

Argonne National Laboratory

Biological Warning and Incident Characterization

CALifornia METeorological model

CALifornia PUFF model

central processing unit

Defense Threat Reduction Agency

U.S. Environmental Protection Agency

hazard prediction and assessment capability

index of agreement

Interagency Modeling and Atmospheric Assessment Center

Joint Urban 2003 Atmospheric Dispersion Study

local standard time

National Aeronautics and Space Administration

next generation weather radar

National Center for Atmospheric Research

National Climatic Data Center

National Center for Environmental Prediction

National Oceanic and Atmospheric Administration

National Severe Storms Laboratory

National Weather Service

Oklahoma University

observing system simulation experiment

Pacific Northwest National Laboratory

quality control

correlation coefficient

root-mean-square error

real time four dimensional data assimilation 
SCIPUFF

TDWR

UTC

VAD

VCP

VDRAS
Second-order Closure Integrated PUFF

Terminal Doppler Weather Radar

coordinated universal time

velocity azimuth display

volume coverage pattern

Variational Doppler Radar Analysis System 


\section{Acknowledgments}

This research was supported by the U.S. Department of Homeland Security through the Science and Technology Directorate, Office of Systems Engineering and Development, under a related services agreement with the U.S. Department of Energy (DOE) under Contract DE-AC05-76RL01830. Pacific Northwest National Laboratory is operated by Battelle for DOE. We thank Jeremy Rishel and Fred Rutz for their assistance with CALMET operations and with adapting CALMET fields for use by SCIPUFF. 



\section{Contents}

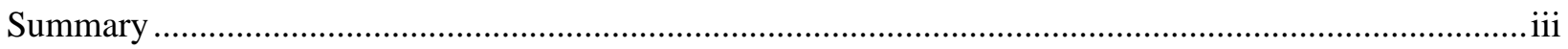

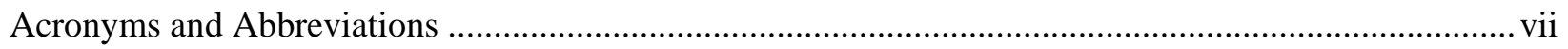

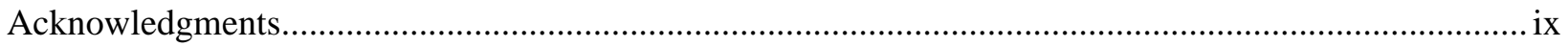

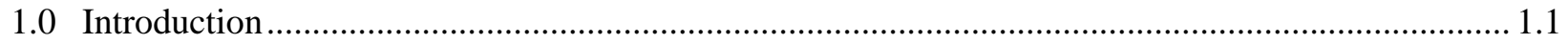

1.1 Operational Meteorological Measurements ........................................................................ 1.1

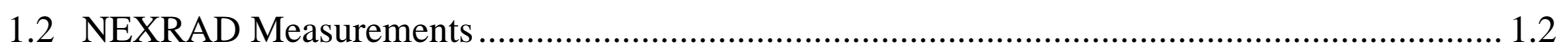

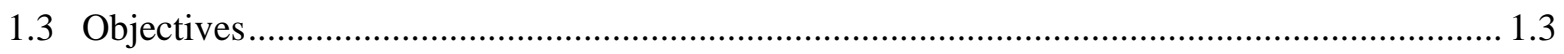

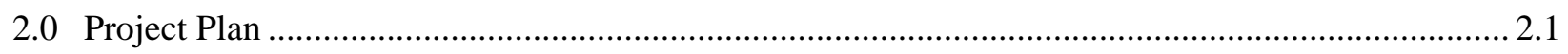

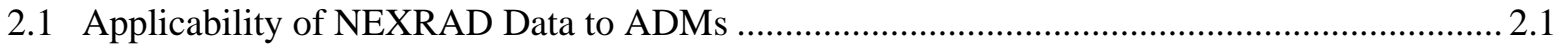

2.2 Evaluation of Data-Center Concepts ....................................................................................... 2.1

2.3 Feasibility of a NEXRAD ADM Data Center..................................................................... 2.1

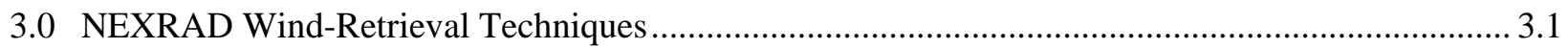

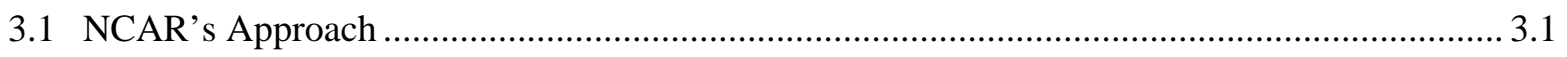

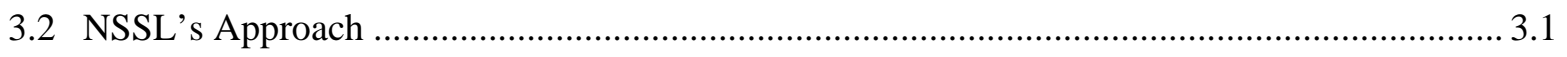

4.0 Evaluation of NEXRAD Wind Retrievals .................................................................................. 4.1

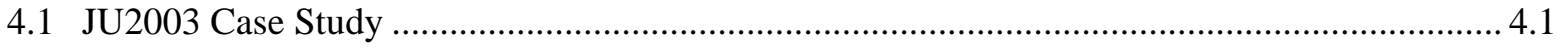

4.2 Configuration and Execution of 2DVar for JU2003 Case Study ........................................... 4.2

4.3 Configuration and Execution of VDRAS for JU2003 Case Study ......................................... 4.3

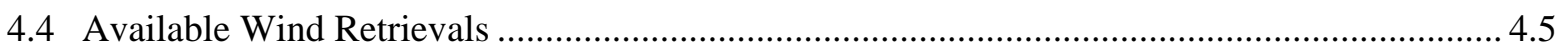

4.5 Evaluation of Wind Retrievals at Radar Wind-Profiler Sites................................................ 4.7

4.6 Evaluation of Spatial Variations in the Wind Retrievals....................................................... 4.12

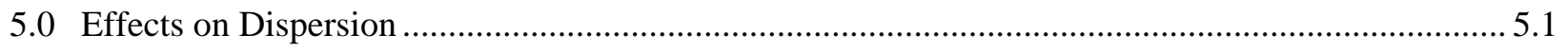

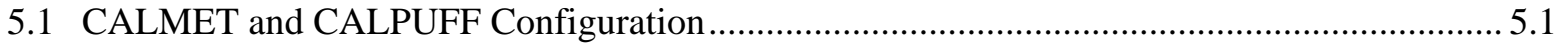

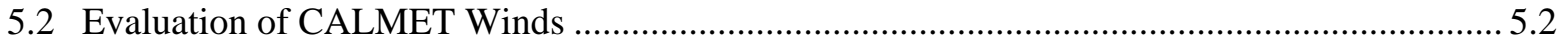

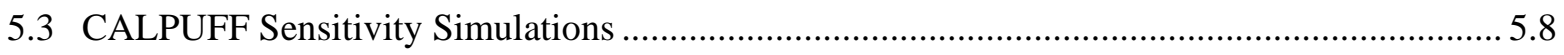

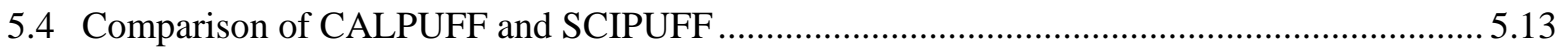

5.5 Effect of Temporal Resolution of Meteorology …............................................................. 5.14

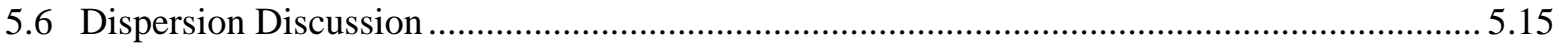




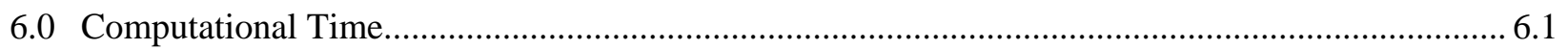

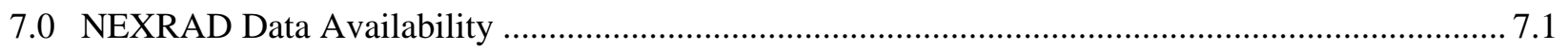

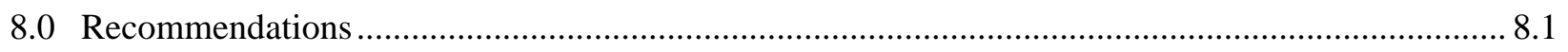

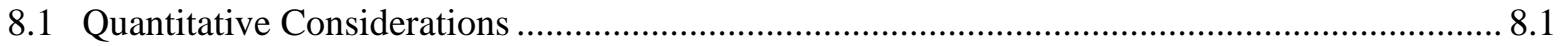

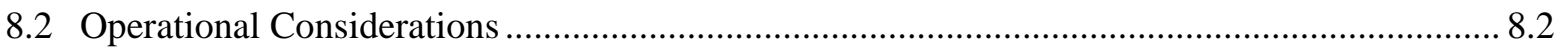

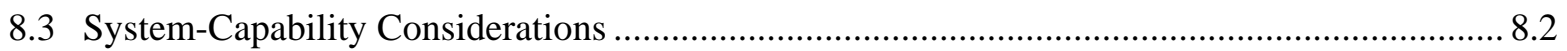

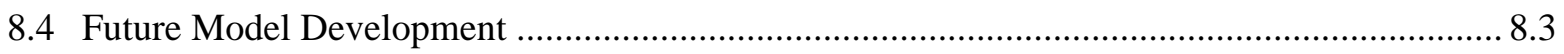

8.5 Wind Retrieval Versus Additional Instrumentation Considerations ....................................... 8.4

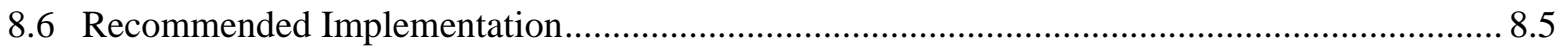

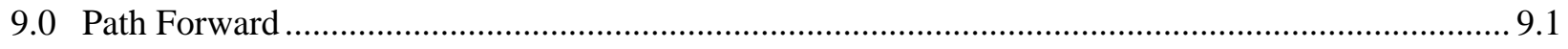

9.1 Phase 1: Development of the NEXRAD Data Center ............................................................. 9.2

9.2 Phase 2: Evaluation of an Operational Beta Version of 2DVar .............................................. 9.3

9.3 Phase 3: Implementation of 2DVar Operationally ................................................................. 9.3

9.4 Phase 4: Maintenance of Operational NEXRAD Wind-Retrieval Products ............................ 9.4

9.5 Phase 5: Further Development of VDRAS …......................................................................... 9.4

9.6 Phase 6: Evaluation of an Operational Beta Version of VDRAS.............................................. 9.5

9.7 Phase 7: Implementation of VDRAS Operationally …......................................................... 9.6

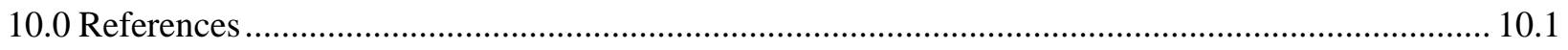

Appendix A: Additional Description of VDRAS ….............................................................................. A.1

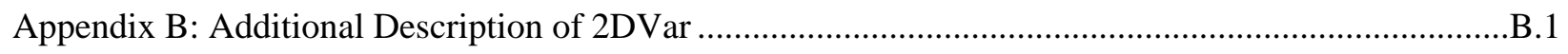

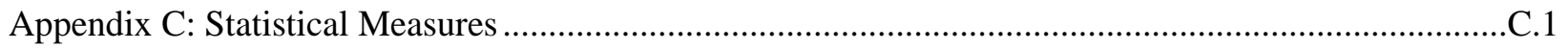

Appendix D: CALMET Configuration ....................................................................................... D.1 


\section{Figures}

1.1. Locations of the NEXRAD Radar Systems in the Continental United States (dots) and the Distance from the NEXRAD Sites $(\sim 80 \mathrm{~km})$ Where the Lowest Elevation Scan is less than 1 km AGL (open circles)

4.1. Wind-Retrieval Locations (light blue crosses) from (a) 2DVar and (b) VDRAS Along with the Locations of Surface Meteorological Stations (red squares), Rawinsonde (green dot), Radar Wind Profilers (blue dots), and the KTLX NEXRAD (black dot).

4.2. East-West Vertical Cross Section Through the KTLX NEXRAD Site Depicting (a) 2DVar Elevation-Angle and (b) VDRAS Constant-Elevation Surfaces; Example Wind Retrievals at 1330 UTC July 12, 2003 from 2DVar along the (c) $0.5^{\circ}$ and (d) $2.5^{\circ}$ Elevation Scans; and Example Wind Retrievals from VDRAS along the (e) $188 \mathrm{~m}$ and (f) $2062 \mathrm{~m}$ AGL Surfaces

4.3. Fraction of Valid Winds from the (a) 2DVar Wind Retrievals and (b) VDRAS Wind Retrievals for a 2-Week Period in July During the JU2003 Field Campaign.

4.4. Time Series of ANL Radar Wind-Profiler Wind Speed and Direction (blue dots) Compared to Values from (a) 2DVar (red dots) at the 357-m Range Gate and (b) VDRAS (red dots) at the 192-m Range Gate

4.5. Time Series of ANL Radar Wind-Profiler Wind Speed and Direction (blue dots) Compared to Values from (a) 2DVar (red dots) at the 1897-m Range Gate and (b) VDRAS (red dots) at the 1677-m Range Gate

4.6. Time Series of ANL Radar Wind Profiler and VDRAS Wind-Retrieval Wind Speeds at the

(a) 577-m and (b) 1677-m AGL and Wind Directions at (c) 577-m and (d) 1677-m AGL

4.7. Mean (dots) and Standard Deviation (lines) of the Bias Obtained from the 2DVar (red) and VDRAS (blue) Wind Retrievals Using Only the NEXRAD Data

4.8. Mean (dots) and Standard Deviation (lines) of the Bias Obtained from VDRAS for Wind Retrievals Based on only the NEXRAD Data (blue) and NEXRAD with Operational Data (red)

4.9. Correlation Coefficient of the Wind Speed and Direction Obtained from the 2DVar (red) and VDRAS (blue) Wind Retrievals

4.10. Difference in the u- and v- Components of the Wind Speed at $550 \mathrm{~m}$ AGL Between the PNNL and NOAA Radar Wind Profiler Sites for the (a) 2DVar and (b) VDRAS Wind Retrievals.....

5.1. Observed (blue) and Simulated (red) Wind Profiles over the ANL Site on July 5, 2003, from Six CALMET Simulations that Employed the Following Meteorological Fields: (a) Standard Observations, (b) Standard Observations and Radar Wind Profilers, (c) Standard Observations and 2DVar Retrievals, (d) Standard Observations and VDRAS Retrievals, (e) Standard 
Observations, 2DVar Retrievals, and Radar Wind Profilers, and (f) Standard Observations, VDRAS Retrievals, and Radar Wind Profilers.

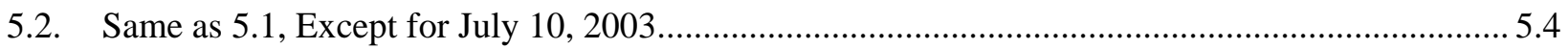

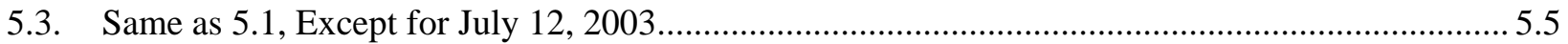

5.4. Wind Fields from Two CALMET Simulations at Two Altitudes on 04 LST (10 UTC)

July 5, 2003

5.5. Same as 5.4, except at 10 LST (16 UTC) July 5, 2003

5.6. 12-h Integrated Concentration on July 5, 2003, from Six CALPUFF Simulations with the Following Meteorology: (a) Standard Observations, (b) Standard Observations + Profiler, (c) Standard Observations + 2DVar Retrievals, (d) Standard Observations + VDRAS Retrievals, (e) Standard Observations + 2DVar Retrievals + Profiler, and (f) Standard Observations + VDRAS Retrievals + Profiler.

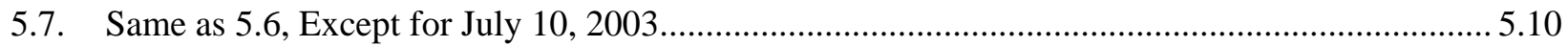

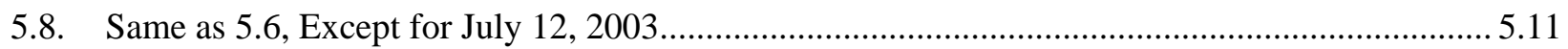

5.9. Direction of the Plume Produced by CALMET/CALPUFF Simulations Using Either Standard Observations (blue), Standard Observations + Profiler (light blue), Standard Observations + 2DVar Wind Retrievals (red), and Standard Observations + VDRAS Wind Retrievals (dashed red) for (a) July 5, (c) July 10, and (e) July 12. Plume widths for July 5, 10 , and 12 are shown in (b), (d), and (f), respectively.....

5.10. Comparison of CALPUFF and SCIPUFF Exposures for (a) July 5, (b) July 10, and (c) July 12 Using StdObs + 2DVar CALMET Wind Fields.

5.11. Comparison of CALPUFF and SCIPUFF Exposures for (a) July 5, (b) July 10, and (c) July 12 Using StdObs + VDRAS CALMET Wind Fields

7.1. Availability of Radial Velocities from the KBOX and KLWX Radars as a Function of Time of Day and Season

7.2. Same as 7.1, Except for KSOX and KMTX Radars

7.3. Same as 7.1, Except for KTLX Radar 7.5 


\section{Tables}

4.1. Characteristics of Radar Profilers Used in this Study, Where $\mathrm{z}_{\min }$ and $\mathrm{z}_{\max }$ are the Minimum and Maximum Range Gate Heights, $\Delta \mathrm{z}$ is the Distance Between Range Gates, and D is the Distance Between the Profiler Sites in Kilometers

4.2. Constant Elevation Levels Employed by VDRAS …................................................................... 4.4

4.3. KTLX Elevation Angles for Precipitation and Clear Modes During July 2003............................ 4.7

4.4. Distances Between Radar Profilers and the Nearest Horizontal Grid Point from the VDRAS and 2DVar Retrievals

4.5. 2DVar Vertical Levels at Grid Points Nearest Each Profiler

6.1. Computational Time Required to Execute 2DVAR and VDRAS for the JU2003

Configuration for a One Hour Period Staring at 2300 UTC July 4

7.1. Sampling Period of NEXRAD Data to Compute Available Coverage from Five Radars......

7.2. Availability of NEXRAD Data Expressed as Percentage of the Volume Scans Containing Valid Radial Velocities that Pass QC Checks During each Sampling Period ( $\left.\mathrm{A}_{\text {time }}\right)$ and Average Percentage of the Lowest Elevation Scan Containing Valid Radial Velocities During each Sampling Period $\left(\mathrm{A}_{\text {space}}\right)$......

C.1. Radar Wind-Profiler Range Gates and Model Levels Used to Evaluate 2DVar NEXRAD Wind Retrievals.

C.2. Radar Wind-Profiler Range Gates and Model Levels Used to Evaluate VDRAS NEXRAD Wind Retrievals.

C.3. Statistics that Quantify the Performance of the 2DVar Wind Retrievals Using Radar WindProfiler Measurements

C.4. Statistics that Quantify the Performance of the VDRAS Wind Retrievals Using Radar WindProfiler Measurements

C.5. Correlation Coefficients Between Time Series of Velocity Differences at Locations of the NOAA-Purcel and PNNL Profilers

C.6. Statistics that Quantify the Performance of the CALMET Wind Fields for the Six Cases Using Radar Wind-Profiler Measurements at the PNNL and ANL sites

C.7. Comparisons of the Maximum Surface Exposure Between SCIPUFF and CALPUFF During the Final Hour of Simulation as Well as the Percent Difference (D), Root Mean Squared Difference (RMSD), Index of Agreement (IA), and Correlation (R) Between the SCIPUFF and CALPUFF Results 
C.8. Comparisons of the Maximum Surface Exposure During the Final Hour of Simulation Between the CALPUFF Simulations that Employ Wind Fields at Either the 15-min or 1-h Intervals as Well as the Percent Difference (D), Root Mean Squared Difference (RMSD), Index of Agreement (IA), and Correlation (R) Between the Two CALPUFF Simulations

D.1. Execution Times of CALMET for Different Compilers, Resolution, and Number of Input

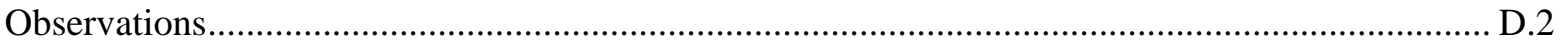




\subsection{Introduction}

\subsection{Operational Meteorological Measurements}

Atmospheric dispersion models (ADMs) are essential tools that address the consequences of potential airborne release of harmful materials. These models allow emergency management, law enforcement, and intelligence personnel to plan for, train for, and respond to potential terrorist attacks and accidental releases of harmful materials in the atmosphere. To accurately represent the dispersion and fate of airborne materials in ADMs requires the availability of real-time meteorological observations such as winds, precipitation, and temperature. Wind fields in and around many major U.S. urban areas (highterrorist threat areas) can be complex because of the direct influence of the urban area on the winds, the influence of their geographic settings leading to mesoscale circulations (e.g., land-sea breezes, terraininduced flows), and the interaction of mesoscale circulations and synoptic weather systems.

In the United States, routine meteorological measurements from surface stations, towers, rawinsondes, and radar wind profilers are available to drive ADMs. Most urban areas have a number of surface stations that describe the spatial variations in the wind field. However, these observations are not representative of conditions above the surface, especially within the nighttime stable boundary layer. Instrumentation deployed on towers obtains information within 200 meters above the ground, but relatively few towers are equipped with meteorological instrumentation. Vertical profiles of winds, temperature, and humidity are usually obtained from rawinsondes launched twice a day at 00 and 12 coordinated universal time (UTC) from $\sim 85$ sites across the country. The frequency of these measurements cannot describe temporal variations in the meteorological conditions near the surface. Only a fraction of the rawinsonde sites is located adjacent to large urban areas, and meteorological measurements above many large urban areas are not available. A network of 35 radar wind profilers provides wind profiles at hourly intervals up to several kilometers above the ground. Most of the profilers have been deployed in rural areas of the central United States to obtain information needed to improve model forecasts of severe weather. Radar wind profilers are relatively expensive and therefore have not been deployed in most urban areas. Nor are data from radar wind profilers typically used by ADMs for real-time operations.

ADMs employ two approaches to fill gaps in the available meteorological information. The first approach is to simply interpolate spatially and temporally between available observations using massconservation. The second approach is to supplement the available measurements using gridded output from a forecast model. Both approaches have advantages and disadvantages. One disadvantage of the first approach is that interpolation of meteorological data does not accurately represent the state of the atmosphere, especially for strong wind shears and rapidly changing meteorological conditions. Additional meteorological instrumentation can be deployed to fill in the gaps so that interpolation provides a reasonable approximation of the true atmospheric conditions; however, deploying large amounts of instrumentation is costly. An advantage of the second approach is that governing equations of the atmosphere can produce realistic wind shears and rapidly changing conditions; however, these models contain uncertainties in the predicted conditions that can be large at times. 


\subsection{NEXRAD Measurements}

One potentially rich, yet untapped, source of meteorological data for routine use in ADMs is from the Next Generation Weather Radar (NEXRAD) systems with 141 nearly identical WSR-88D Doppler radar units installed throughout the United States as shown in Figure 1.1 (Crum and Alberty 1993; Brown and Lewis 2005; Crum et al. 1998). The WSR-88D Doppler radar employs an S-band transmitter that produces output at wavelengths from 10 to $11 \mathrm{~cm}$, with pulse repetition frequencies from 318 to $452 \mathrm{~Hz}$. The pulse duration is $1.57 \mu \mathrm{s}$, corresponding to a range resolution of $\sim 250 \mathrm{~m}$. The $3 \mathrm{~dB}$ beam-width of the main lobe is $\sim 0.95^{\circ}$ (Crum and Alberty 1993). Range-resolved estimates of radial velocity, the flow towards or away from the radar, are computed by spectral processing of a heterodyne signal that is obtained by mixing the atmospheric return with a reference signal of known frequency.

The Doppler radars are operated in either a clear-air mode or a precipitation mode. The clear-air mode is the normal mode of operation and is used when there is no significant precipitation in the area. When the radar detects significant precipitation, it automatically switches to the precipitation mode. The major difference between these two modes of operation is in the scan strategies.

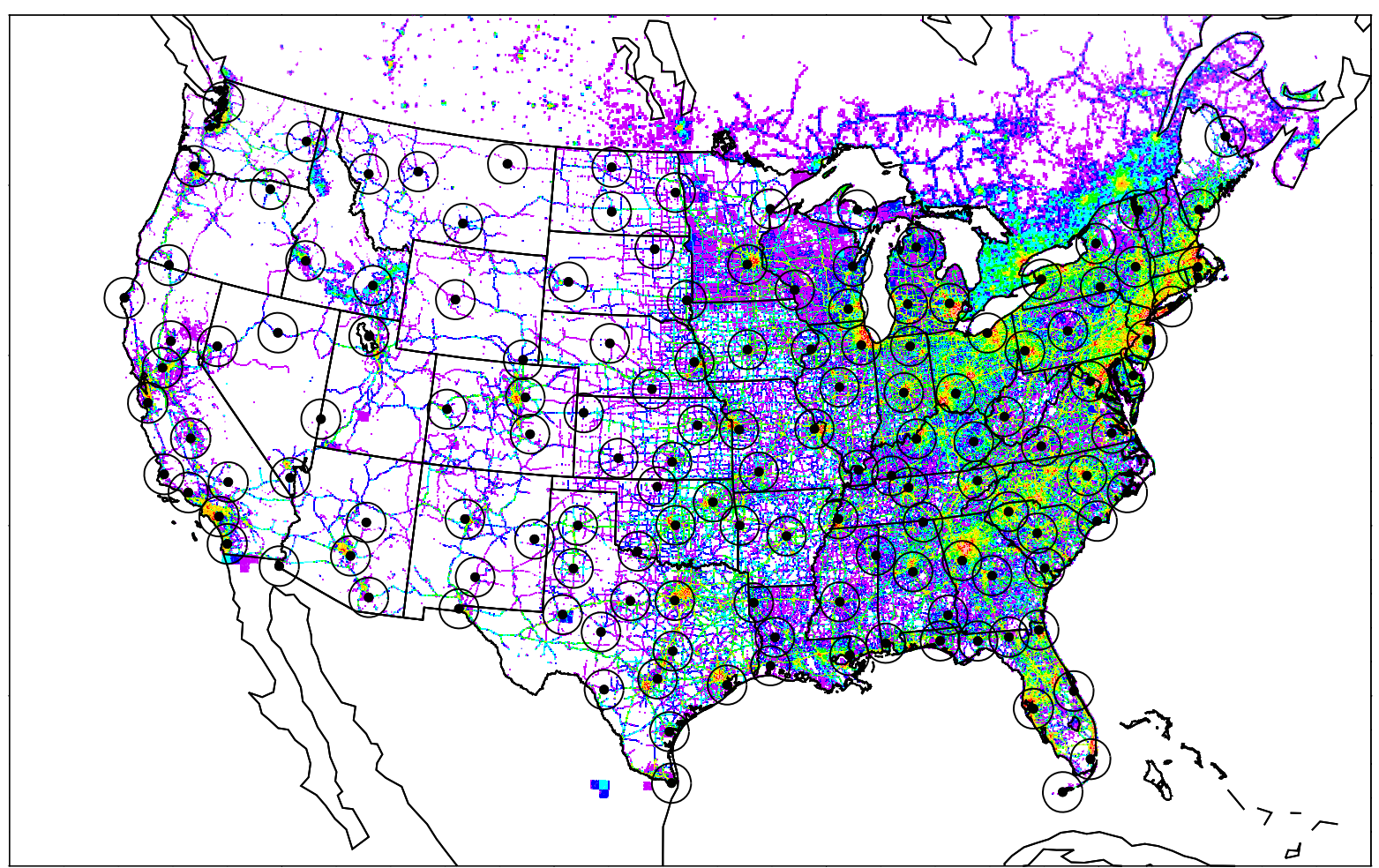

Figure 1.1. Locations of the NEXRAD Radar Systems in the Continental United States (dots) and the Distance from the NEXRAD Sites $(\sim 80 \mathrm{~km})$ Where the Lowest Elevation Scan is less than $1 \mathrm{~km}$ AGL (open circles). Color shading denotes carbon monoxide emission rates (red $=$ high, purple $=$ low) that are proportional to human activities, where red indicates large cities. 
The clear-air mode has the slowest antenna rotation rate, which permits the radar to sample a given volume of the atmosphere longer, resulting in improved sensitivity. In this mode, the radar performs a sequence of 360-degree azimuth scans at five elevation angles ranging from 0.5 to 4.5 degrees. In the precipitation mode, the radar performs a sequence of 360-degree azimuth scans at nine elevation angles ranging from 0.5 to 19.5 degrees. In clear-air mode, each volume coverage pattern (VCP) takes 10 minutes to complete, whereas in precipitation mode each VCP takes 6 minutes to complete (Brown et al. 2000). Some radar sites use clear-air mode even if there is light snow in the area. The added sensitivity of this mode allows the detection of snow showers since snow generally reflects much less energy than other forms of precipitation.

NEXRAD data from the clear-air mode of operation is desired for deriving winds for ADMs (because of its better sensitivity); otherwise, winds would be produced only when and where precipitation occurred. The range of the radar depends on the size, number-density, and physical properties of scattering material in the atmosphere and varies in time and among NEXRAD sites. For example, the range is usually shorter during winter than during summer because of the lack of insects and reduced particulate loading. Another consideration for ADMs is the sampling altitude. The NEXRAD elevation scans obtain near-surface information close to the radar site, but data are located at increasingly higher altitudes at farther distances. For example, the 0.5-degree-elevation angle scan becomes $\sim 1 \mathrm{~km}$ above ground level (AGL) at $\sim 80 \mathrm{~km}$ from the NEXRAD site. As shown in Figure 1.1, the horizontal extent of data from the NEXRAD radars within $1 \mathrm{~km}$ AGL encompasses most large urban areas, assuming the presence of sufficient scatterers in the atmosphere. Even though ADM applications often focus on dispersion within a few hundred meters of the surface, wind data at these altitudes are needed because winds aloft influence near-surface meteorological conditions.

If the true two-dimensional wind components (east/west and north/south components) can be derived from the measured radial velocities, then an unprecedented amount of data would be available to drive ADMs and more accurately predict the transport of atmospheric contaminants.

\subsection{Objectives}

The primary objective of this study is to determine the feasibility of whether routinely collected data from the NEXRAD weather radar system can appropriately be used in ADMs for emergency response. We have therefore evaluated the accuracy and computational efficiency of two variational mathematical techniques that derive the two-dimensional wind components from NEXRAD radial velocity fields. After reviewing the scientific literature, we chose to evaluate the variational techniques developed by the National Center for Atmospheric Research (NCAR) and the National Oceanic and Atmospheric Administration's (NOAA's) National Severe Storms Laboratory (NSSL). The accuracy of the variational techniques is quantified by comparing the derived wind components with independent, standard meteorological measurements. The effect of the additional information available on transport and dispersion is examined by performing a series of sensitivity simulations with a widely used ADM. Computational speed is also quantified because winds derived from NEXRAD data need to be available in near-real time for emergency-response applications. A preliminary plan that recommends how to implement the software so that wind fields derived from NEXRAD data can be used routinely to drive ADMS for applications throughout the United States has been developed.

After describing our overall objectives in Section 2, a review of the details and previous applications of the two variational techniques is presented in Section 3. The results of our evaluation of the NEXRAD-derived wind fields are presented in Section 4, and the effects of the NEXRAD-derived wind 
fields on dispersion are shown in Section 5. Section 6 presents the computational requirements of both techniques in relation to their proposed real-time operation. The availability of NEXRAD data at select locations is quantified in Section 7. Section 8 discusses the overall advantages and disadvantages of both techniques that form the basis of our recommendation of which system should be implemented operationally. A path forward that describes how NEXRAD-derived wind fields should be developed for operational use is proposed in Section 9. Finally, Section 10 presents the overall conclusions of this study. 


\subsection{Project Plan}

This study consisted of three major tasks that are described in the following sub-sections.

\subsection{Applicability of NEXRAD Data to ADMs}

The focus of this task was to evaluate the applicability and advantages of using wind fields derived from NEXRAD data in ADMs used for emergency response. The specific steps required to complete this task include:

1) identifying what type of software is available that processes NEXRAD data and obtains products suitable for ADMs

2) assessing the accuracy and robustness of the derivations of the three-dimensional wind fields derived from radars

3) determining the compatibility of the spatial and temporal resolution of the NEXRAD data with the spatial and temporal resolutions of ADMs

4) assessing the efforts of implementing NEXRAD products routinely in ADMs versus the benefits of improved performance of ADMs in using NEXRAD data.

The most promising capabilities were employed for this task with collaboration of scientists at NCAR and NSSL. The results for Steps 2 to 4 are described in Sections 3 to 6.

Our overall strategy was to compare the NCAR and NSSL variational techniques using similar domains and the same NEXRAD location so that the derived wind fields could be directly compared with one another and with independent measurements. To our knowledge, no such study like this has been performed.

\subsection{Evaluation of Data-Center Concepts}

The focus of this task was to evaluate the current status and availability of NEXRAD data products being routinely available in a form for use in emergency-response ADMs. Several organizations within the United States currently process NEXRAD data and make the data available in various forms accessible on the Internet or other data feeds. The most promising approach and/or organization for potentially providing NEXRAD products to emergency-response ADMs will be identified in this task as described in Sections 7 and 8.

\subsection{Feasibility of a NEXRAD ADM Data Center}

The focus of this task was to determine the feasibility and procedure for bringing the promising NEXRAD ADM data center concepts identified in Section 2.2 to a fully operational data feed of appropriate NEXRAD products to ADM emergency-response centers and users. A path forward for implementing an ADM data center is described in Section 9. The path forward of implementing and operating a nationwide data center will include estimating the required computational cost, data storage, communication speed, and man-power. 


\subsection{NEXRAD Wind-Retrieval Techniques}

We evaluate two entirely different methods for retrieving three-dimensional fields of horizontal winds from NEXRAD radar radial-velocity observations. The first method, developed at NCAR, uses a physical algorithm based on four-dimensional variational data assimilation. The second method, developed at NSSL, uses a statistical technique based on an analytic formulation of the background error covariance. Additional details are described in Appendices A and B.

\subsection{NCAR’s Approach}

The Variational Doppler Radar Analysis System (VDRAS) was developed at NCAR and is used in this study to retrieve wind fields from NEXRAD data. VDRAS uses four-dimensional variational data assimilation to retrieve three-dimensional time-varying wind and temperature fields from a sequence of radar volume scans. At a minimum, the system requires radial velocity data from a single Doppler radar as well as temperature soundings. The system can also be configured to assimilate radar reflectivity, surface mesonet data, and data from multiple Doppler radars. The basic concept behind the VDRAS wind-retrieval scheme is to fit the output of a prognostic model to spatially and temporally resolved observations. The model's boundary conditions are prescribed so that the initial conditions uniquely determine the model solution. Thus, the fit is performed by variational adjustment of the model's initial state. The initial conditions are iteratively adjusted to optimize the agreement between the model solution and the available observations within the computational domain over a given assimilation cycle. The duration of the assimilation cycle typically includes two or three complete radar volume scans.

An early prototype of VDRAS was developed and demonstrated by Sun et al. (1991) using simulated single-Doppler radar data. The technique was later applied to a dry-gust front case using Doppler radar data (Sun and Crook 1994), and then adapted to study the structure and dynamics of convective storms (Sun and Crook 1997; Sun and Crook 1998). More recently, various versions of VDRAS have been run operationally and in real time for demonstration projects, including the 2000 summer Olympics in Sydney, Australia (Sun and Crook 2001; Crook and Sun 2004), a 2-year period for the Weather Forecast Office in Sterling, Virginia (Crook and Sun 2004), and the 2004 Pentagon Shield experiment (Warner 2006).

For this study, an operational version of VDRAS is used so that the prognostic model (i.e., the forward model) simulates dry, shallow incompressible flow. Although a moist version exists (Sun and Crook 1997), it is computationally too expensive to run in real-time (Crook and Sun 2004). The coordinate system in VDRAS does not include variations in terrain. Therefore, model physics and parameterization schemes in the operational version of VDRAS are simpler than those implemented in most mesoscale models. These simplifications are essential to reduce the complexity of the adjoint code and the resulting computational expense of the cost-function-minimization algorithm.

\subsection{NSSL's Approach}

The wind-field retrieval method implemented by NSSL in this study (Xu et al. 2007) is based on the statistical interpolation technique (Daley 1991) and can be regarded as an extension of the traditional Velocity Azimuth Display (VAD) technique (Browning and Wexler 1968). This technique, referred to here as the 2-D Variational (2DVar) algorithm, uses radial velocity data from a conical radar scan to 
apply an optimal correction to a predefined background field using assumed analytic forms for the error covariance of the background field. The background field, in this case, is determined from a VAD analysis of the conical scan data.

The 2DVar algorithm represents years of research at NSSL in developing fast and efficient radar wind-retrieval methods. Examples of past research include the simple adjoint method (Qiu and Xu 1992; Xu et al. 1995; Xu et al. 2001a; Xu et al. 2001b). The simple adjoint method retrieves the unobserved cross-beam winds by tracking, using a system involving the time integration of a two-dimensional advection equation and its adjoint. However, Xu et al. (2007) points out that this method tends to be severely impacted by the data voids in the analysis domain, and the computational cost is high (but not as high as 4DVar).

The 2DVar method is appealing from an operational point of view because of its relative simplicity, its capability to retrieve velocities on a single conical scan surface, its capability to handle data voids, and its data requirements. For example, it only needs the radial velocity data from the radar. The 2DVar algorithm executes much faster than real-time because of its simplicity.

Because the 2DVar technique developed by NSSL is relatively new, it has not been "road tested" to the extent that VDRAS has. As with VDRAS, the algorithm's capability to handle processes influenced by complex terrain has not been developed. Currently, the method assumes that the canonical form of the background error covariance tensor function is homogeneous and isotropic in the horizontal following a constant height above the sea level or a flat ground surface. In the presence of complex terrain, the assumed horizontal homogeneity and isotropy may need modification to follow a constant (or s-coordinate) height above the terrain (instead of the sea level). The effectiveness of this modification needs to be tested in future development. Another concern is with the sensitivity of the retrieved wind fields to changes in the prescribed de-correlation length parameters, although these parameters should and can be estimated in principle from radar innovation data (Xu et al. 2007). 


\subsection{Evaluation of NEXRAD Wind Retrievals}

\subsection{JU2003 Case Study}

The NEXRAD wind retrievals from 2DVar and VDRAS were evaluated using radar wind-profiler data obtained during the 2003 Joint-Urban (JU2003) field campaign in the vicinity of Oklahoma City (Allwine et al. 2004). This period was chosen because of the special meteorological instruments that were deployed (surface meteorological stations, sodars, radar wind profilers, radiosondes, and lidars) to support a series of $\mathrm{SF}_{6}$ tracer experiments in the downtown area of Oklahoma City. The closest

NEXRAD to Oklahoma City is KTLX, located $\sim 20 \mathrm{~km}$ to the southeast at $35.333^{\circ}$ latitude and $-97.277^{\circ}$ longitude.

Our evaluation employs data from July 3 to 14, 2003, from the four radar wind profilers shown in Figure 4.1 and listed in Table 4.1. Pacific Northwest National Laboratory (PNNL), Argonne National Laboratory (ANL), and the University of Oklahoma (OU) deployed three of the profilers. The ANL profiler was located about $6 \mathrm{~km}$ north of downtown Oklahoma City, and the PNNL profiler was located just south of downtown. The OU profiler was located in Norman, Oklahoma, in the vicinity of the National Weather Service (NWS) rawinsonde about $25 \mathrm{~km}$ south of downtown Oklahoma City. An existing radar wind profiler operated by NOAA was located about $50 \mathrm{~km}$ south of Oklahoma City. The PNNL, ANL, and OU profilers measured 30-min average wind speed and direction profiles up to $\sim 4 \mathrm{~km}$ AGL, and the NOAA profiler measured hourly average wind-speed and direction profiles up to $\sim 10 \mathrm{~km}$ AGL. Figure 4.1 also shows the location of surface meteorological stations that obtain routine data in the region. The locations of the other special instrumentation deployed during JU2003 are not shown since they are not used in this study.

The 2DVar and VDRAS techniques were set up to compute wind retrievals over an area centered over KTLX that encompasses Oklahoma City and the surrounding region using a grid spacing of $\sim 2 \mathrm{~km}$. The extent of the model domains and locations where winds were obtained is shown in Figure 4.1 along with the meteorological instrumentation sites. The spatial extent of the domains differs slightly because of the projections. The $2 \mathrm{DV}$ ar technique has $80 \times 80$ points over a $160-\times 160-\mathrm{km}$ domain, and VDRAS has $75 \times 75$ points over a $150-\times 150-k m$ domain. 
(a)

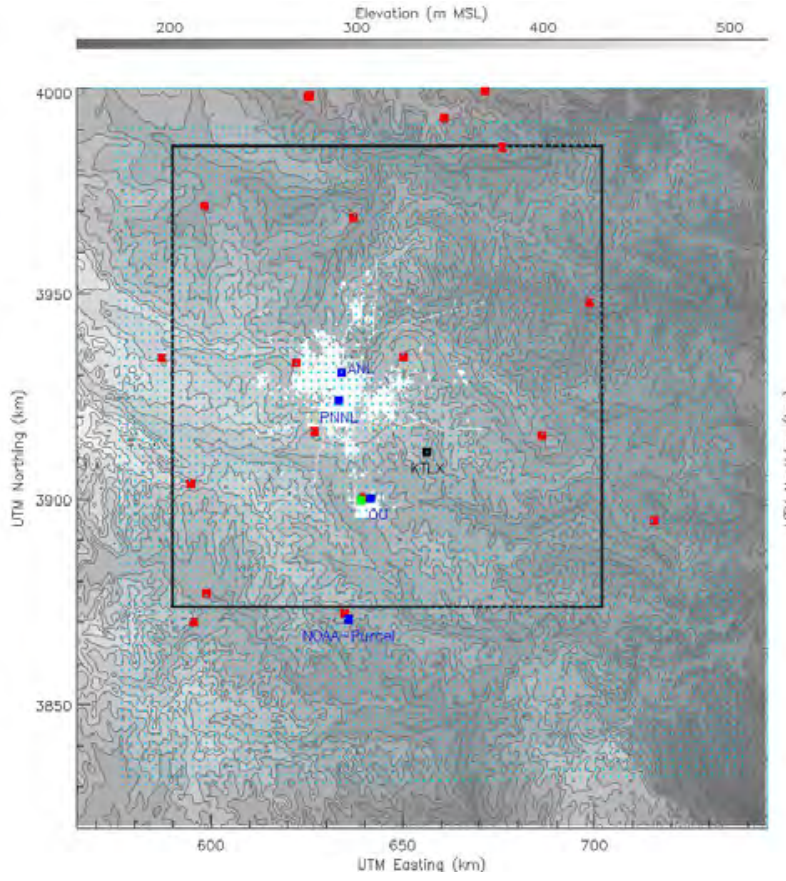

(b)

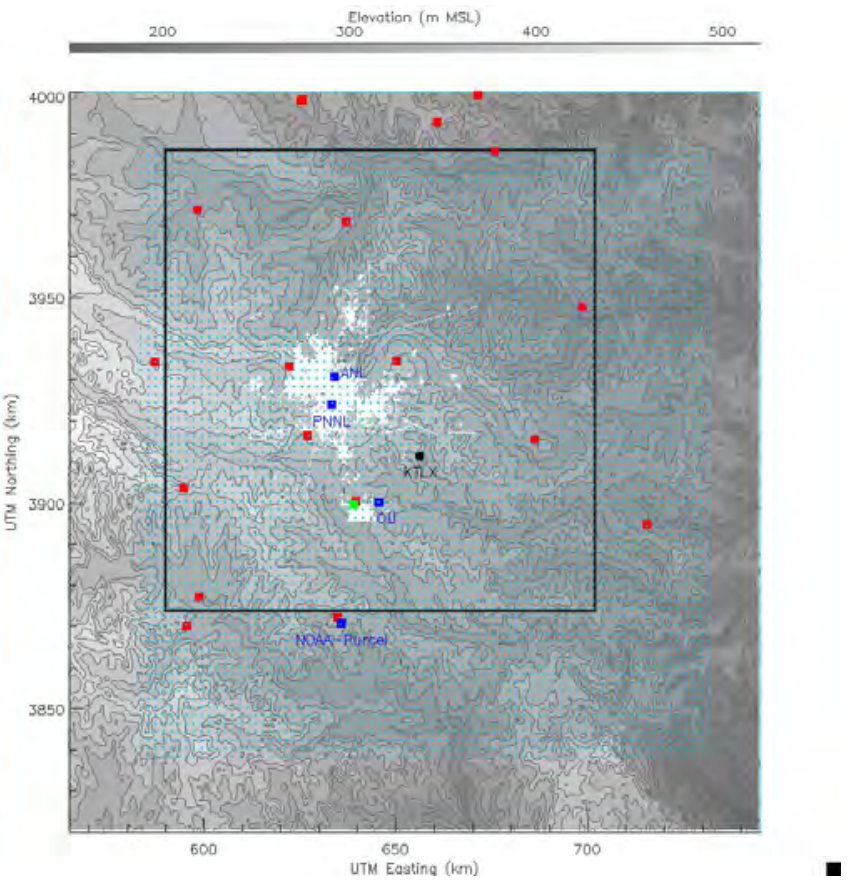

Figure 4.1. Wind-Retrieval Locations (light blue crosses) from (a) 2DVar and (b) VDRAS Along with the Locations of Surface Meteorological Stations (red squares), Rawinsonde (green dot), Radar Wind Profilers (blue dots), and the KTLX NEXRAD (black dot). Gray shading denotes topography, white shading denotes urban areas, and the modeling domain of the CALifornia METeorological model/CALifornia PUFF model (CALMET/CALPUFF) is denoted by the large black square.

Table 4.1. Characteristics of Radar Profilers Used in this Study, Where $z_{\min }$ and $z_{\max }$ are the Minimum and Maximum Range Gate Heights, $\Delta \mathrm{z}$ is the Distance Between Range Gates, and $\mathrm{D}$ is the Distance Between the Profiler Sites in Kilometers

\begin{tabular}{|c|c|c|c|c|c|c|c|c||}
\hline Profiler & Type & $\mathbf{z}_{\min }(\mathbf{m})$ & $\mathbf{z}_{\mathbf{m a x}}(\mathbf{m})$ & $\Delta \mathbf{z}$ & $\mathbf{D}_{\text {ANL }}$ & $\mathbf{D}_{\text {PNNL }}$ & $\mathbf{D}_{\text {OU }}$ & $\mathbf{D}_{\text {NOAA }}$ \\
\hline ANL & $915 \mathrm{MHz}$ & 137 & 2392 & 55 & - & 6.7 & 30.9 & 59.59 \\
\hline PNNL & $915 \mathrm{MHz}$ & 302 & 2777 & 55 & 6.7 & - & 24.6 & 53.3 \\
\hline OU & $915 \mathrm{MHz}$ & 124 & 2213 & 55 & 30.9 & 24.6 & - & 29.7 \\
\hline NOAA & $404 \mathrm{MHz}$ & 500 & 16000 & 250 & 59.9 & 53.3 & 29.7 & - \\
\hline
\end{tabular}

\subsection{Configuration and Execution of 2DVar for JU2003 Case Study}

Three steps were performed for each volume of the KTLX radar scans. For Step 1, the NSSLNational Center for Environmental Prediction (NCEP) quality control (QC) package (Gong et al. 2003; Liu et al. 2003, 2005; Zhang et al. 2005) was applied to the entire volume of level-II raw data. For Step 2, the VAD wind produced from the three-step dealiasing algorithm (Gong et al. 2003) in the QC package was taken as the background field to derive the radial-wind-innovation field (observation minus 
background) at radar observation points. The innovation field was then thinned to the super-innovation field by using the superobbing (averaging the observations) algorithm. Finally, the 2DVar vector windretrieval algorithm (Xu et al. 2007) was applied to the super-innovation field to obtain the incremental vector winds on each conical surface of the volume scan as part of Step 3. Steps 1 to 3 were completed for one volume in about 1 or 2 minutes, so the central processing unit (CPU) time was about 4 times as fast as the real-time data flow.

For Steps 2 and 3, the retrievals were tested with different superobbing resolutions (2, 3, 6, and $12 \mathrm{~km}$ ). The retrievals were found to be nearly the same as long as the superobbing resolution of $\leq 6 \mathrm{~km}$, so $6 \mathrm{~km}$ was used. Step 3 in 2DVar differs from that of Xu et al. (2007) by including the vertical correlation in the background error covariance. The upgraded 2DVar is thus applicable to all the elevation angles (rather than limited to very low elevation angles as the previous 2DVar). The vertical correlation was modeled by the Gaussian function with the de-correlation depth set to $L_{\mathrm{Z}}=3 \mathrm{~km}$. The horizontal correlation was the same as Equations (2.4) and (2.5) of Xu et al. (2007). In particular, the horizontal de-correlation length was set to $L_{\mathrm{h}}=30 \mathrm{~km}$ for both the rotational and divergent parts, and the background error variance was equally partitioned between the rotational and divergent parts (that is, $a=0$ and $b=1$ in Equations [2.4] and [2.5] of Xu et al. [2007]). The background error variance was estimated "real-time" for each tilt by the spatially averaged variance of the super-innovation fields. The observation-error standard deviation was set to $\sigma_{\mathrm{ob}}=2 \mathrm{~m} \mathrm{~s}^{-1}$.

\subsection{Configuration and Execution of VDRAS for JU2003 Case Study}

As shown in Figure 4.1, a 2-km horizontal grid spacing was employed over a 150- × 150-km domain. Fourteen vertical levels, listed in Table 4.2, were used up to $5.06 \mathrm{~km}$. The height of the first level was at $187.5 \mathrm{~m}$, and a grid spacing of $375 \mathrm{~m}$ was used for subsequent vertical levels. A time step of $15 \mathrm{~s}$ was employed.

Two QC procedures were performed on the KTLX radar scans obtained from the National Climatic Data Center (NCDC) archive: one was velocity dealiasing performed during the data ingest, and the other was a generalized quality check to eliminate remaining noisy and spatially inconsistent data before they were used in the data assimilation. The generalized quality check was performed using a software package imbedded in VDRAS and was based on the local standard deviation computed at each grid point using data from 25 sounding points and a threshold value of $8 \mathrm{~m} \mathrm{~s}^{-1}$. Another step in the generalized QC was to clean any remaining clutter-contaminated data that have a small velocity value. A threshold value of $0.5 \mathrm{~m} \mathrm{~s}^{-1}$ was used to remove data associated with clutter contamination.

The radar data were interpolated from the two-dimensional polar sampling to the two-dimensional Cartesian grid along the conic surface before the data were assimilated by VDRAS. Another step in radar data pre-processing was the extraction of super-observations from the finer-resolution data to match the model resolution. Data filtering was performed before the extraction to remove high-frequency features that cannot be represented by a coarser grid, using a local-least-square fitting method. 
Table 4.2. Constant Elevation Levels Employed by VDRAS

\begin{tabular}{|c|c|}
\hline Level & Height (km AGL) \\
\hline 1 & 0.1875 \\
\hline 2 & 0.5625 \\
\hline 3 & 0.9375 \\
\hline 4 & 1.3125 \\
\hline 5 & 1.6875 \\
\hline 6 & 2.0625 \\
\hline 7 & 2.4575 \\
\hline 8 & 2.8125 \\
\hline 9 & 3.1875 \\
\hline 10 & 3.5625 \\
\hline 11 & 3.9375 \\
\hline 12 & 4.3125 \\
\hline 13 & 4.6875 \\
\hline 14 & 5.0625 \\
\hline
\end{tabular}

Background wind and potential temperature profiles are necessary to run VDRAS. For each analysis cycle, a VAD wind profile from the KTLX was computed by an algorithm in VDRAS and used as the background first-guess wind field. Since the VAD wind profile can only provide winds below $\sim 3 \mathrm{~km}$, the upper level winds were set to a constant value available from the highest level of the VAD wind profile.

The background potential-temperature profile cannot be obtained directly from the radar data, so an alternative is required. Historically, a climatological sounding appropriate for the month has been employed. A nearby rawinsonde could be used to provide the sounding. However, rawinsondes available only twice a day may not represent the environmental conditions at the radar-analysis times. An alternative is to use a forecast model sounding, such as those produced by the Real Time Four Dimensional Data Assimilation (RTFDDA) system that been run in real time at NCAR for a number of years to provide short-term forecasts for U.S. Army range operations. Since RTFDDA produced hourly output, VDRAS has been set up to look back for 1 hour to find the sounding closest to the analysis time.

Two experiments were performed to evaluate the performance of VDRAS, including 1) the assimilation of radar data only and 2) the assimilation of radar data with the addition of standard synoptic information. For Experiment 1, the VAD wind profile from the radar provided the first guess of winds, and the climatological potential temperature sounding was used for the first guess of temperatures. For Experiment 2), the synoptic information included surface-station observations (Oklahoma mesonet, NWS stations) and hourly upper-air soundings. The background potential temperature was based on potential temperature soundings from RTFDDA for Experiment 2 when available; otherwise, climatology was used for 12 to 15 UTC July 2, 8 UTC July 3, 16 to 23 UTC July 4, and 00 to 09 UTC July 5. The time resolution of radar data ( $\sim 5$ minutes) was much higher than those of conventional data ( $\sim$ a few hours). As a result, all types of observations are not available at all times. The synoptic data were used to provide background and first-guess fields for each cycle of the radar data assimilation.

The time window for each analysis cycle was 12 minutes in which two or three volumes of radar data from KTLX were used. Each radar volume was assumed to be instantaneous at a single time step to 
reduce the computational time. All analysis cycles used the cold-start option so that the previous forecast was not used as a first guess.

\subsection{Available Wind Retrievals}

An example of the spatial varying winds from the two types of retrievals at 1330 UTC July 12, 2003, is shown in Figure 4.2. The 2DVar method computes winds directly on the radar elevation scans (Figure 4.2a); therefore, vertical wind profiles at five levels extend up to $0.5 \mathrm{~km}$ AGL at $\sim 10 \mathrm{~km}$ from the NEXRAD site. The radar beams continue to diverge with distance from the radar so that the five levels are spaced out between the surface and $5 \mathrm{~km}$ AGL at $60 \mathrm{~km}$ from the NEXRAD site.

The exact elevation angles changed slightly during July 2003 so that there were two modes of operation for the KTLX radar as listed in Table 4.3. In contrast, VDRAS employs a constant elevation vertical coordinate for the wind retrievals (Figure 4.2b) with 14 levels up to 5-km AGL.

The winds produced by 2DVar (Figure 4.2c,d) and VDRAS (Figure 4.2e,f) are different because of their vertical coordinate. Higher wind speeds are often produced by 2DVar farther away from the NEXRAD site since the beam is sampling air at a higher altitude, and wind speeds aloft are usually higher than at the ground. Therefore, the $2.5^{\circ}$ elevation surface (Figure $4.2 \mathrm{~d}$ ) has higher wind speeds closer to the NEXRAD site than does the $0.5^{\circ}$ elevation surface (Figure $4.2 \mathrm{c}$ ). In contrast, the winds on the VDRAS levels show less spatial variability along the constant elevation surfaces. As expected, winds from VDRAS near the surface (Figure 4.2e) are lower in general than those aloft (Figure 4.2f). A closer inspection of the wind fields indicates that both retrieval techniques produced westerly winds over Oklahoma City at this time. The accuracy of these wind fields is quantified later as described in Sections 4.5 and 4.6.

Figure 4.3 shows the periods of wind retrievals obtained from 2DVar and VDRAS. There were periods of missing data, but this was a small percentage of the total time. The lack of radar scans produces the gaps in the wind retrievals during the 2-week period. Even though both 2DVar and VDRAS employ the same radar data, the data gaps are somewhat different, presumably because of the different quality-assurance techniques that each model employs. For 2DVar, winds are only obtained for those grid points with valid data. The fraction of valid data points in Figure 4.3a reflects that the range of good data from the radar varies in time and is a function of the meteorological conditions and amount of scatterers in the atmosphere. During this 2-week period, the fraction of data availability on the 2DVar grid ranged from 0.35 to 0.85 . Since VDRAS employs 4DVar, it fills in information for all the grid points when pieces of the radar scans are missing. Therefore, the fraction of valid points for VDRAS is always 1.0 (Figure 4.3b). 

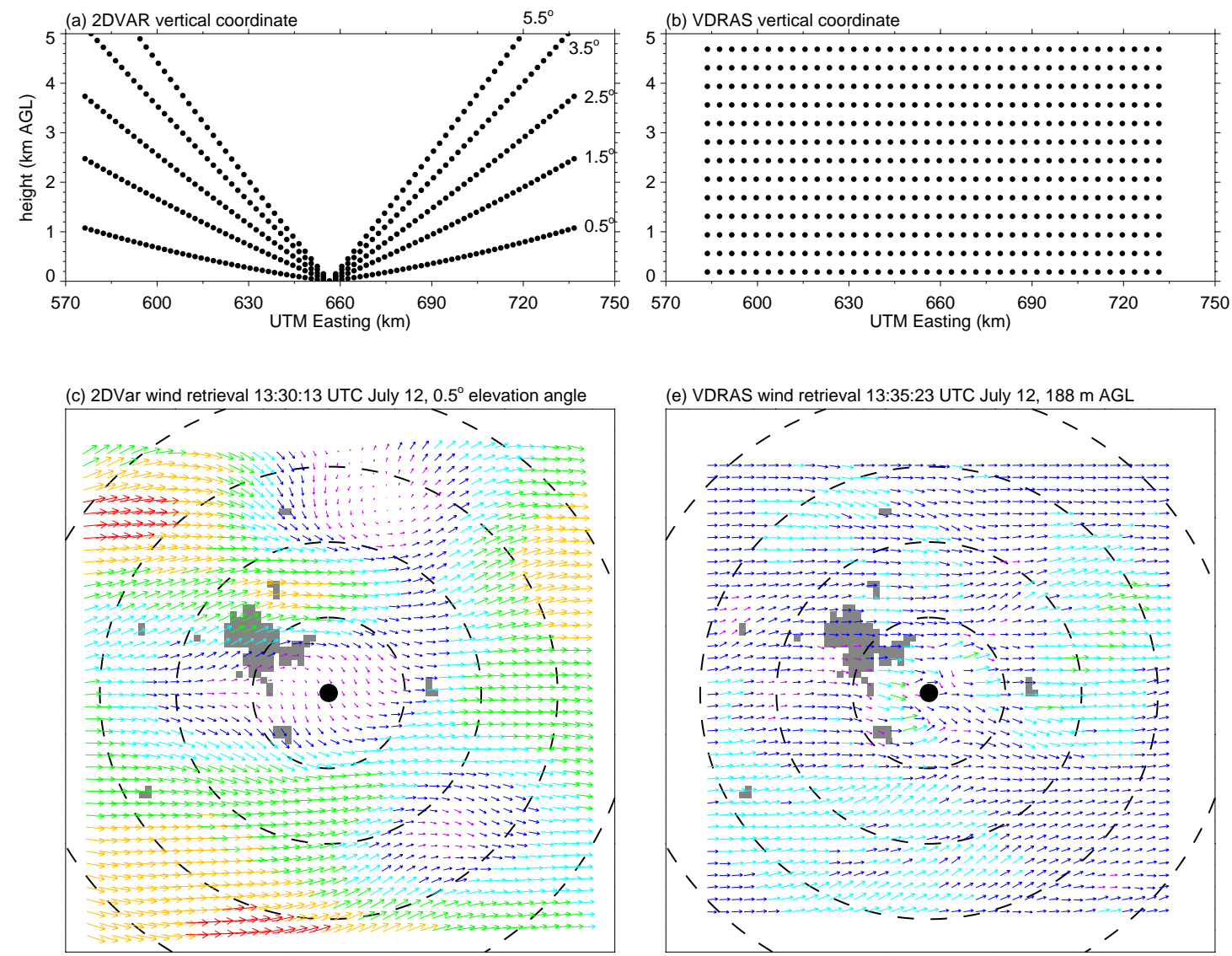

(d) 2DVar wind retrieval 13:30:13 UTC July $12,2.5^{\circ}$ elevation angle
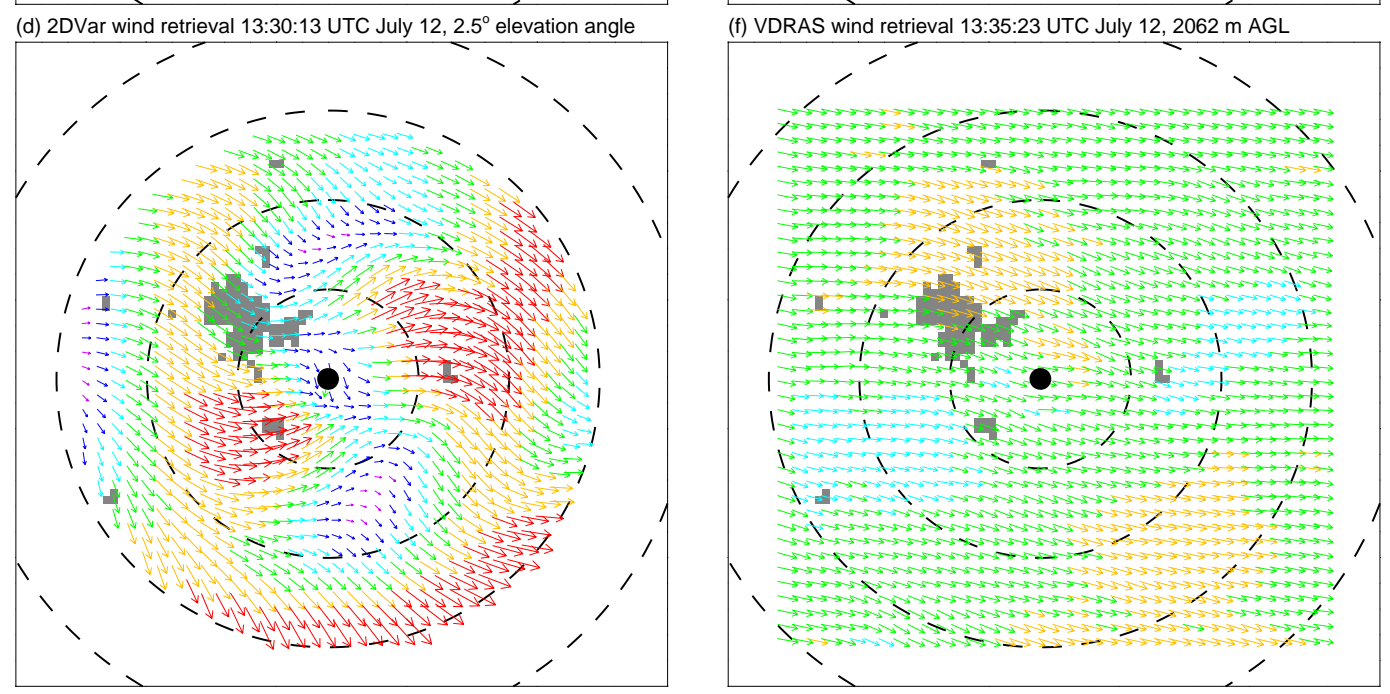

$<6 \mathrm{~m} \mathrm{~s}^{-1}$

$<6-9 \mathrm{~m} \mathrm{~s}^{-1}$

$<12-15 \mathrm{~m} \mathrm{~s}^{-1}$

$>18 \mathrm{~m} \mathrm{~s}^{-1}$

Figure 4.2. East-West Vertical Cross Section Through the KTLX NEXRAD Site Depicting (a) 2DVar Elevation-Angle and (b) VDRAS Constant-Elevation Surfaces; Example Wind Retrievals at 1330 UTC July 12, 2003 from 2DVar along the (c) $0.5^{\circ}$ and (d) $2.5^{\circ}$ Elevation Scans; and Example Wind Retrievals from VDRAS along the (e) $188 \mathrm{~m}$ and (f) $2062 \mathrm{~m}$ AGL Surfaces. Gray shading denotes urban areas, and dashed lines denote distances of $25 \mathrm{~km}$ from the KTLX NEXRAD site (large dot). Every other wind vector and node is shown in (a) to (f). 
Table 4.3. KTLX Elevation Angles for Precipitation and Clear Modes During July 2003. The five lowest elevation angles were employed by 2DVar.

\begin{tabular}{||c|c|c|c|c|c|c|c|c|c||}
\hline \multirow{2}{*}{ Mode } & \multicolumn{10}{c||}{ KTLX PPI Scan Elevation Angles (degrees) } \\
\cline { 2 - 11 } & $\boldsymbol{\theta}_{\mathbf{1}}$ & $\boldsymbol{\theta}_{\mathbf{1}}$ & $\boldsymbol{\theta}_{\mathbf{4}}$ & $\boldsymbol{\theta}_{\mathbf{4}}$ & $\boldsymbol{\theta}_{\mathbf{5}}$ & $\boldsymbol{\theta}_{\mathbf{6}}$ & $\boldsymbol{\theta}_{\mathbf{7}}$ & $\boldsymbol{\theta}_{\mathbf{8}}$ & $\boldsymbol{\theta}_{\mathbf{9}}$ \\
\hline Precipitation & 0.5 & 1.45 & 2.4 & 3.35 & 4.3 & 6.0 & 9.9 & 14.6 & 19.5 \\
\hline Clear Air & 0.5 & 1.5 & 2.5 & 3.5 & 4.5 & - & - & - & - \\
\hline \hline
\end{tabular}
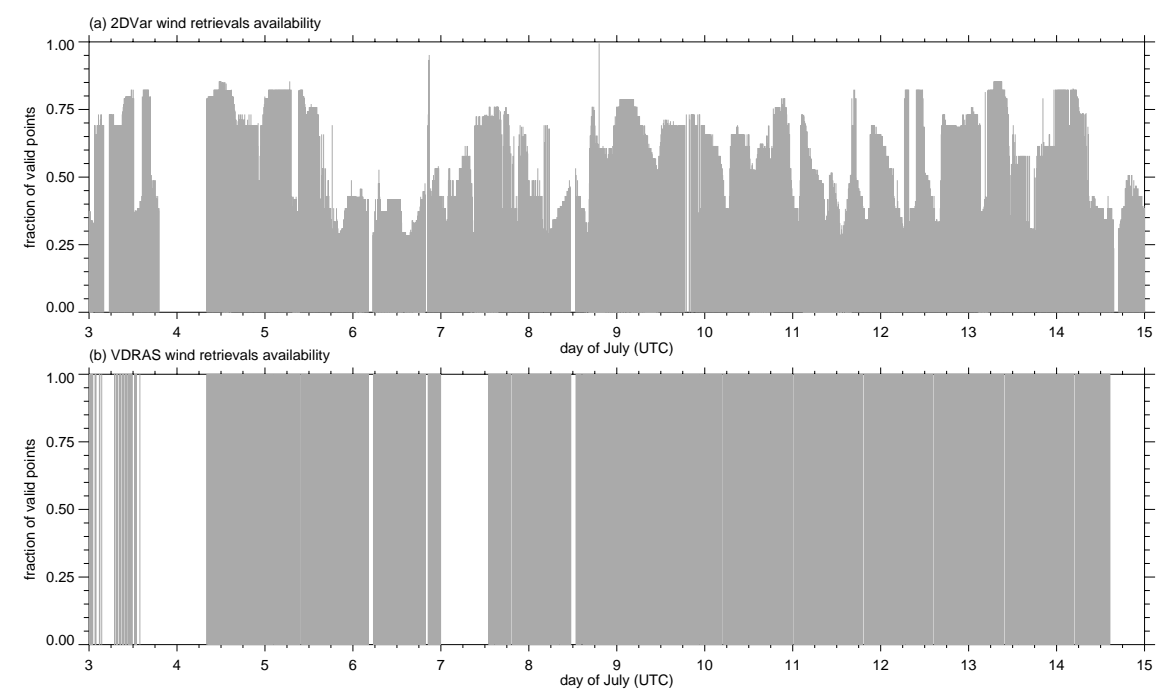

Figure 4.3. Fraction of Valid Winds from the (a) 2DVar Wind Retrievals and (b) VDRAS Wind Retrievals for a 2-Week Period in July During the JU2003 Field Campaign

\subsection{Evaluation of Wind Retrievals at Radar Wind-Profiler Sites}

The 2DVar and VDRAS wind retrievals were evaluated using measurements obtained from the four radar wind profilers in the vicinity of Oklahoma City (Figure 4.1). The range gate closest to the windretrieval levels was chosen for the comparisons, rather than vertically interpolating either the wind retrievals to the profiler range gates or the profiler winds to the wind-retrieval levels. Tables C.1 and C.2 in Appendix C list the range gates closest to each wind-retrieval level for 2DVar and VDRAS, respectively. For the PNNL, ANL, and OU profilers, the largest difference in the altitude of the windprofiler range gates and retrieval levels was $34 \mathrm{~m}$. The difference at the NOAA profiler was as large as 146 and $97 \mathrm{~m}$ for 2DVar and VDRAS, respectively, since the range gate spacing for that profiler was larger. It is important to note that both the radar wind profiler and the radar sample volumes of air, so that the height differences shown in Tables C.1 and C.2 should not significantly affect the conclusions regarding the differences between the radar wind profiler and NEXRAD wind retrievals.

While qualitative comparisons were made for all corresponding pairs of radar wind-profiler and windretrieval data, we present only a select set of comparisons. Figure 4.4 shows an example comparison of the wind retrievals near the surface at the ANL radar wind-profiler measurements. The 2DVar $0.5^{\circ}$ level over the ANL site was closest to the 357-m range gate (Figure 4.4a), and the lowest VDRAS level was closest to the 192-m range gate (Figure 4.4b). The radar wind-profiler measurements show a diurnal 
variation in wind speed and direction, primarily from the development of a low-level jet nearly every night. Both wind-retrieval techniques reproduce this feature, although the retrieval nighttime wind speeds were frequently higher than observed. The daytime values were usually closer to the profiler measurements, perhaps because of the stronger backscattering during the day. At times, the radar windprofiler measurements exhibited strong variations in wind direction when the wind speeds were the lowest. Neither wind-retrieval technique reproduced this feature.

(a)

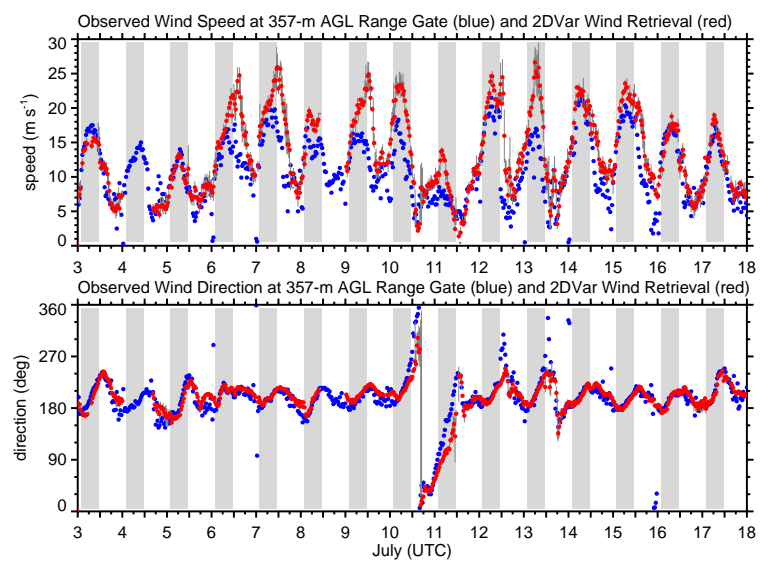

(b)

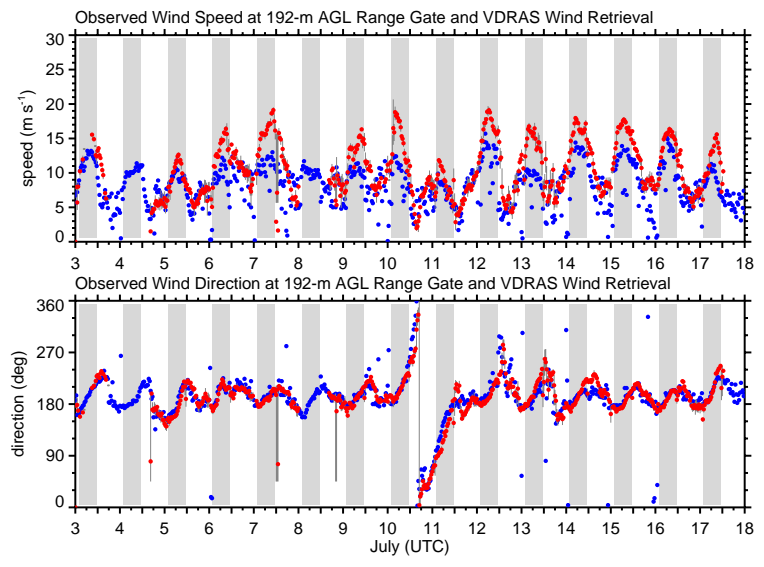

Figure 4.4. Time Series of ANL Radar Wind-Profiler Wind Speed and Direction (blue dots) Compared to Values from (a) 2DVar (red dots) at the 357-m Range Gate and (b) VDRAS (red dots) at the 192-m Range Gate. Dots denote 30-min averages, and vertical gray lines denote the range of wind-retrieval values within a 30-min averaging period. Gray shading denotes night.

Another example comparison at a higher altitude is shown in Figure 4.5. The 2DVar $2.0^{\circ}$ level over the ANL site was closest to the 1897-m range gate (Figure 4.5a), and the fifth VDRAS level was closest to the $1677-\mathrm{m}$ range gate (Figure 4.5b). At this altitude, which is above the nighttime low-level jets, the radar wind-profiler measurements indicate much smaller diurnal variations in speed and direction. Both retrieval techniques reproduce the temporal variation in wind speed and direction over the 2-week period. In contrast to the comparison closer to the surface (Figure 4.4), the retrievals do not overestimate the nighttime wind speeds. The VDRAS wind speeds were usually somewhat lower than the radar windprofiler measurements, and both retrievals differed from the profiler wind directions more frequently than closer to the ground.

Since VDRAS was run with two types of input data (radar, radar + standard observations), a time series of both retrievals at the 577-m and 1677-m range gates are shown in Figure 4.6. The retrieval that includes the additional information from operational surface stations and rawinsondes produced wind speeds at the 577-m range gate that were lower than both the other retrievals based on radar data only and the radar wind-profiler measurements. At the 1677-m range gate, both retrievals produced similar wind speeds. The wind directions for both retrievals were nearly identical at all altitudes. These results suggest that the weighting in VDRAS for the surface meteorological observations likely extends too far aloft. 
(a)

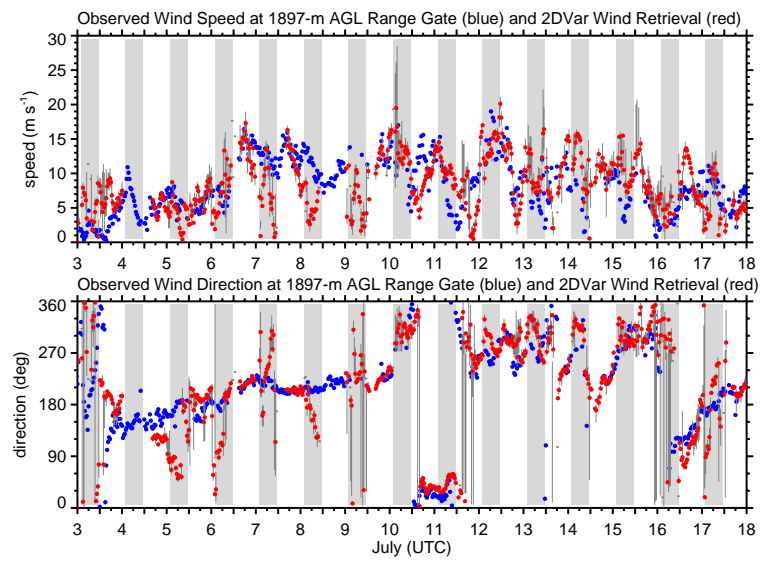

(b)

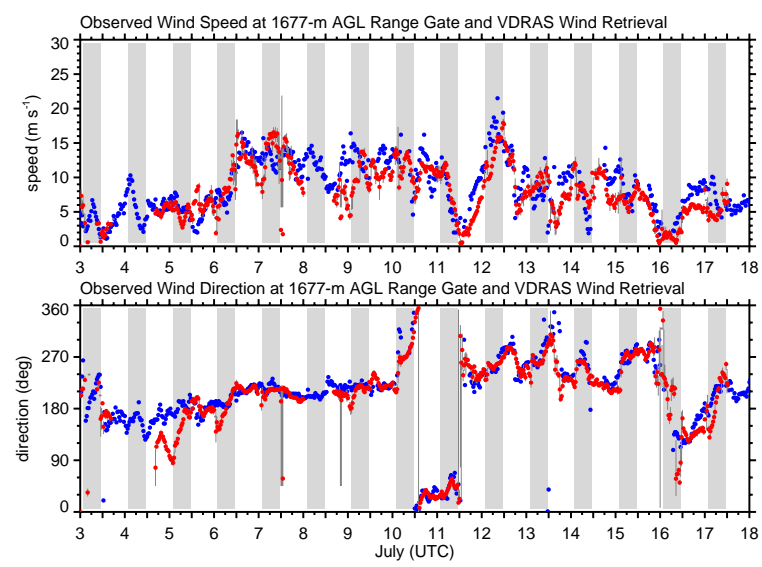

Figure 4.5. Time Series of ANL Radar Wind-Profiler Wind Speed and Direction (blue dots) Compared to Values from (a) 2DVar (red dots) at the 1897-m Range Gate and (b) VDRAS (red dots) at the 1677-m Range Gate. Dots denote 30-min averages, and vertical gray lines denote the range of wind-retrieval values within a 30 -min averaging period. Gray shading denotes night.
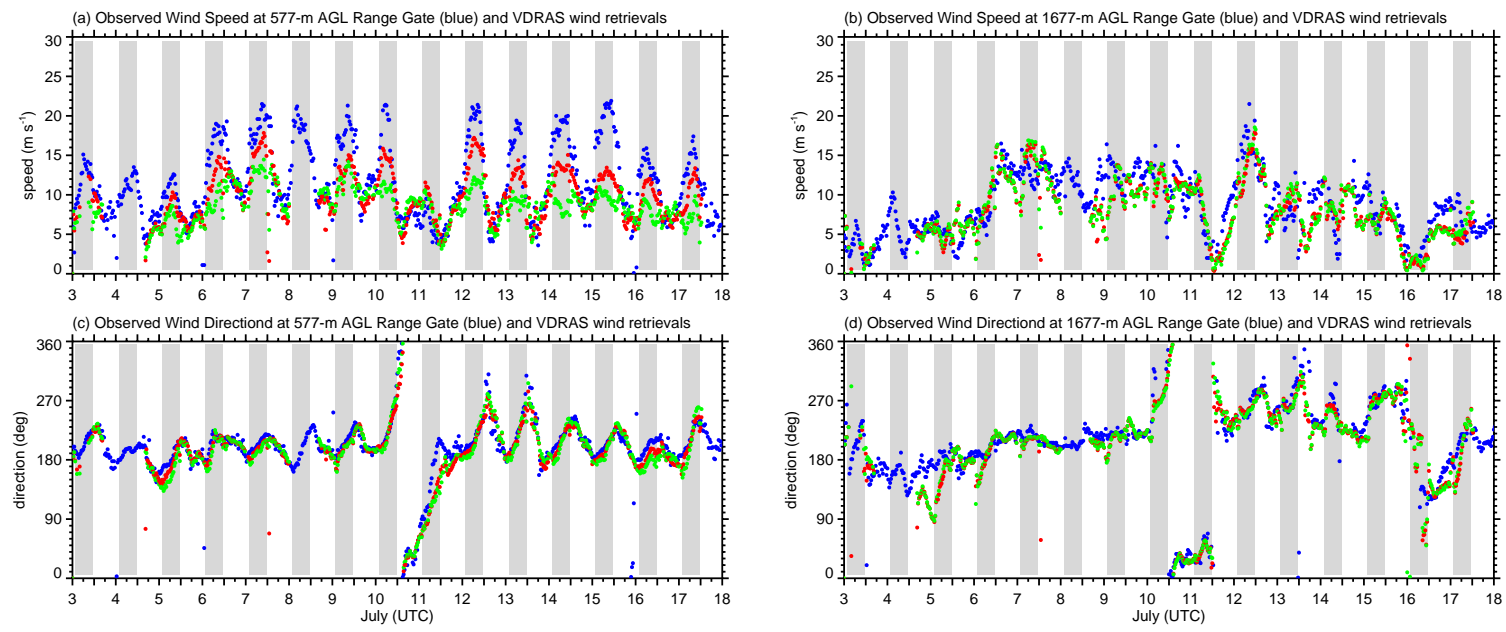

Figure 4.6. Time Series of ANL Radar Wind Profiler and VDRAS Wind-Retrieval Wind Speeds at the (a) 577-m and (b) 1677-m AGL and Wind Directions at (c) 577-m and (d) 1677-m AGL. VDRAS wind retrievals are based on NEXRAD data only (red dots) and NEXRAD and operational data (green dots).

Statistics that quantify the performance of the wind retrievals are listed in Tables C.3 and C.4 in Appendix C for 2DVar and VDRAS, respectively. The average values, bias, root-mean-square error (RMSE), index of agreement (IA), and correlation coefficient (R) were computed as defined in Appendix C. The number of available retrievals to compare with the radar wind-profiler measurements decreased with height for two reasons. First, radar wind-profiler data are relatively complete near the 
surface but not at the upper range gates. Second, the range of the wind retrievals from 2DVar varies in time (Figure 4.3a) so that valid data may not extend to the profiler sites at times. Nevertheless, a sufficient number of comparisons are available aloft to evaluate the performance of the wind retrievals at altitudes aloft.

As shown in Table C.3, the wind-speed bias for 2DVar at the ANL, PNNL, and OU sites ranged from -3.8 to $2.7 \mathrm{~m} \mathrm{~s}^{-1}$, and the RMSE ranged from 2.4 to $4.7 \mathrm{~m} \mathrm{~s}^{-1}$. While the bias at the NOAA profiler was only $0.7 \mathrm{~m} \mathrm{~s}^{-1}$ near the surface, a bias of $\sim 5 \mathrm{~m} \mathrm{~s}^{-1}$ and an RMSE of $\sim 8 \mathrm{~m} \mathrm{~s}^{-1}$ was produced above 2800-m AGL. These altitudes were higher than available from the other radar wind profilers. The wind-direction bias at all profiler sites ranged from -16 to 7 degrees, and the RMS ranged from 18 to 67 degrees. The IA and $\mathrm{R}$ for both speed and direction that was often greater than 0.8 suggests that the wind retrieval produced temporal variations that were similar to the radar wind-profiler measurements. In general, IA and $\mathrm{R}$ were lower at the higher altitudes, so that the wind retrieval had more skill near the surface than aloft. The statistics at the OU profiler (closest to KTLX) were generally good at all altitudes since the radar elevation angles passed over this site within $\sim 1700 \mathrm{~m}$ of the ground. As shown in Table C.4, the wind-speed bias for VDRAS at all profilers ranged from -0.1 to $3.2 \mathrm{~m} \mathrm{~s}^{-1}$, and the RMSE ranged from 2.2 to $5.2 \mathrm{~m} \mathrm{~s}^{-1}$. The wind direction bias ranged from -26 to 18 degrees, and the RMS ranged from 15 to 69 degrees. As with 2DVar, the IA and R for both wind speed and direction was often greater than 0.8 , and the values near the surface were greater than those at higher altitudes.

To directly compare the statistics of 2DVar and VDRAS on the same scale, the biases in the wind speed and direction are shown in Figure 4.7 for each radar wind profiler. At the OU profiler, the wind speed and direction bias from 2DVar was closer to zero than from VDRAS. At the PNNL and ANL sites, both retrievals usually overestimated the wind speeds near the surface and underestimated the wind speeds from 0.5 to $2 \mathrm{~km}$ AGL. Further aloft, both retrievals had higher wind speeds than the profiler measurements. At the NOAA site, the bias from VDRAS was closer to zero than from 2DVar at all altitudes. While both retrievals produced wind speeds larger than the profiler measurements above $2.5 \mathrm{~km}$ AGL, the bias from 2DVar was much larger than from VDRAS. Both retrievals produced a larger range in the bias for speed and direction at higher altitudes, indicating a larger uncertainty in wind speeds and directions aloft.

Figure 4.8 compares the bias as a function of altitude for the two retrieval types from VDRAS. The bias for wind direction is similar at all altitudes for all profilers. However, the magnitude of the bias in wind speed for the retrieval that included operational data was greater than the retrieval that included only the radar data within about $1.5 \mathrm{~km}$ of the ground.

The correlation coefficient for wind speeds and direction as a function of altitude shown in Figure 4.9 indicate that both the retrieval techniques produce winds that are similar to the radar wind-profiler data close to the surface and not as correlated aloft. Wind speed from VDRAS has a value of $\mathrm{R}$ greater than 0.7 up to an altitudes ranging from 2.4 to $2.8 \mathrm{~km}$. Wind speed from 2DVar decreases with altitude faster than from VDRAS so that $\mathrm{R}$ became less than 0.7 at altitudes ranging from 1.0 to $1.4 \mathrm{~km}$. The correlation of wind direction from 2DVar and VDRAS was similar at the OU, PNNL, and ANL sites, but the wind directions obtained from VDRAS at the NOAA site were closer to the radar-profiler measurements. As with the bias shown in Figure 4.6, the correlation coefficients from VDRAS that included standard observation data were poorer than those from the retrieval that was based only on the radar data within $1.5 \mathrm{~km}$ of the ground with the largest decrease in performance at the PNNL and ANL sites located in Oklahoma City. 

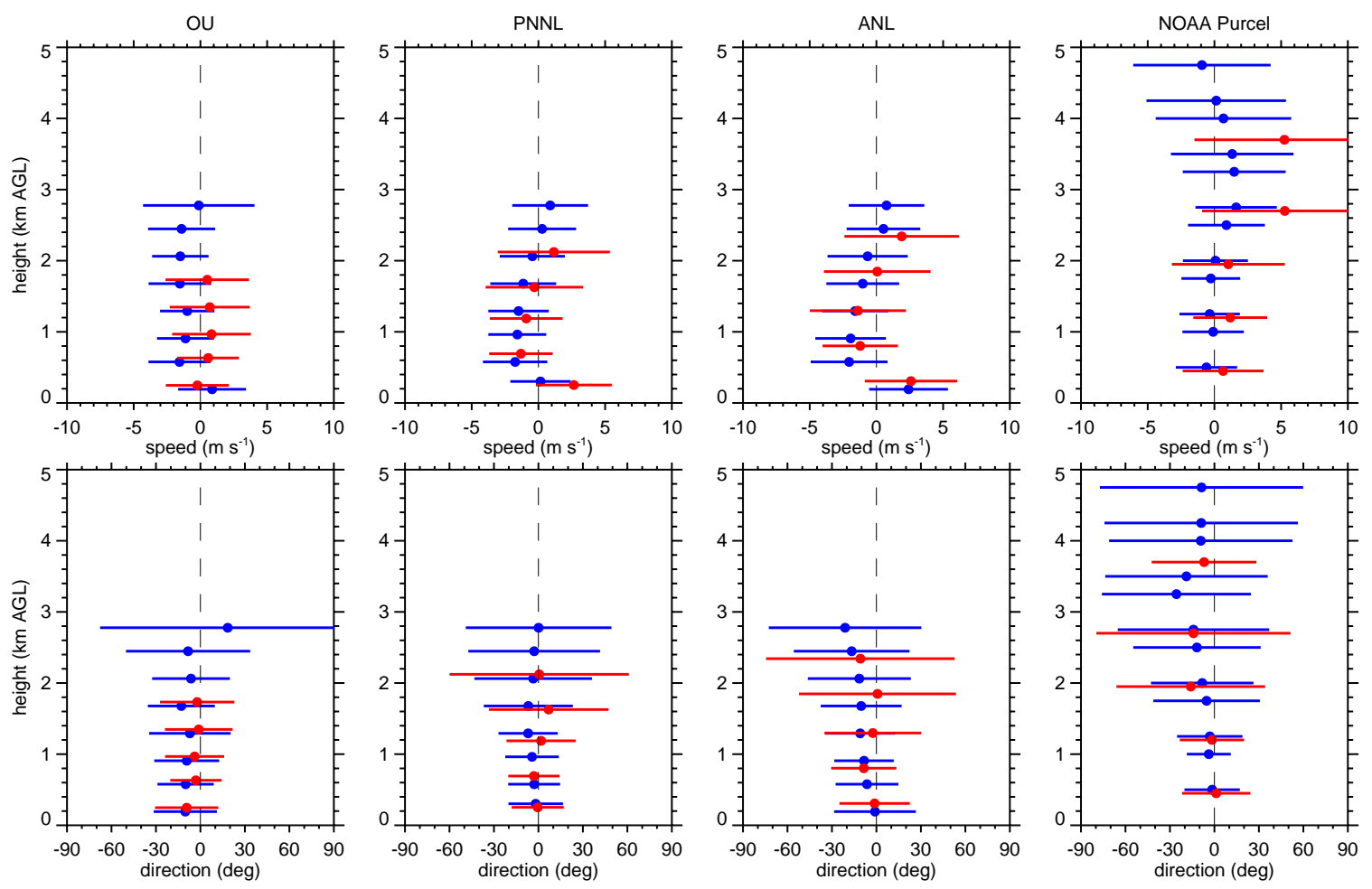

Figure 4.7. Mean (dots) and Standard Deviation (lines) of the Bias Obtained from the 2DVar (red) and VDRAS (blue) Wind Retrievals Using Only the NEXRAD Data

The differences in the performance of the two retrieval techniques can be attributed to the different approaches employed by 2DVar and VDRAS. In general, the performance of VDRAS was better aloft because it is based on a three-dimensional mesoscale model. The first guess of the meteorological fields is based on a VAD wind profile and a potential temperature profile predicted by another operational model. This permits the dynamic and thermodynamic fields to adjust realistically. The first guess in 2DVar is based solely on the VAD wind profile. Despite the differences in the level of complexity in the variational techniques between 2DVar and VDRAS, both retrievals produced similar results within 1 to $2 \mathrm{~km}$ of the surface. While one model may have performed better than another at a specific place or time, one model did not out-perform the other in terms of statistical measures. 

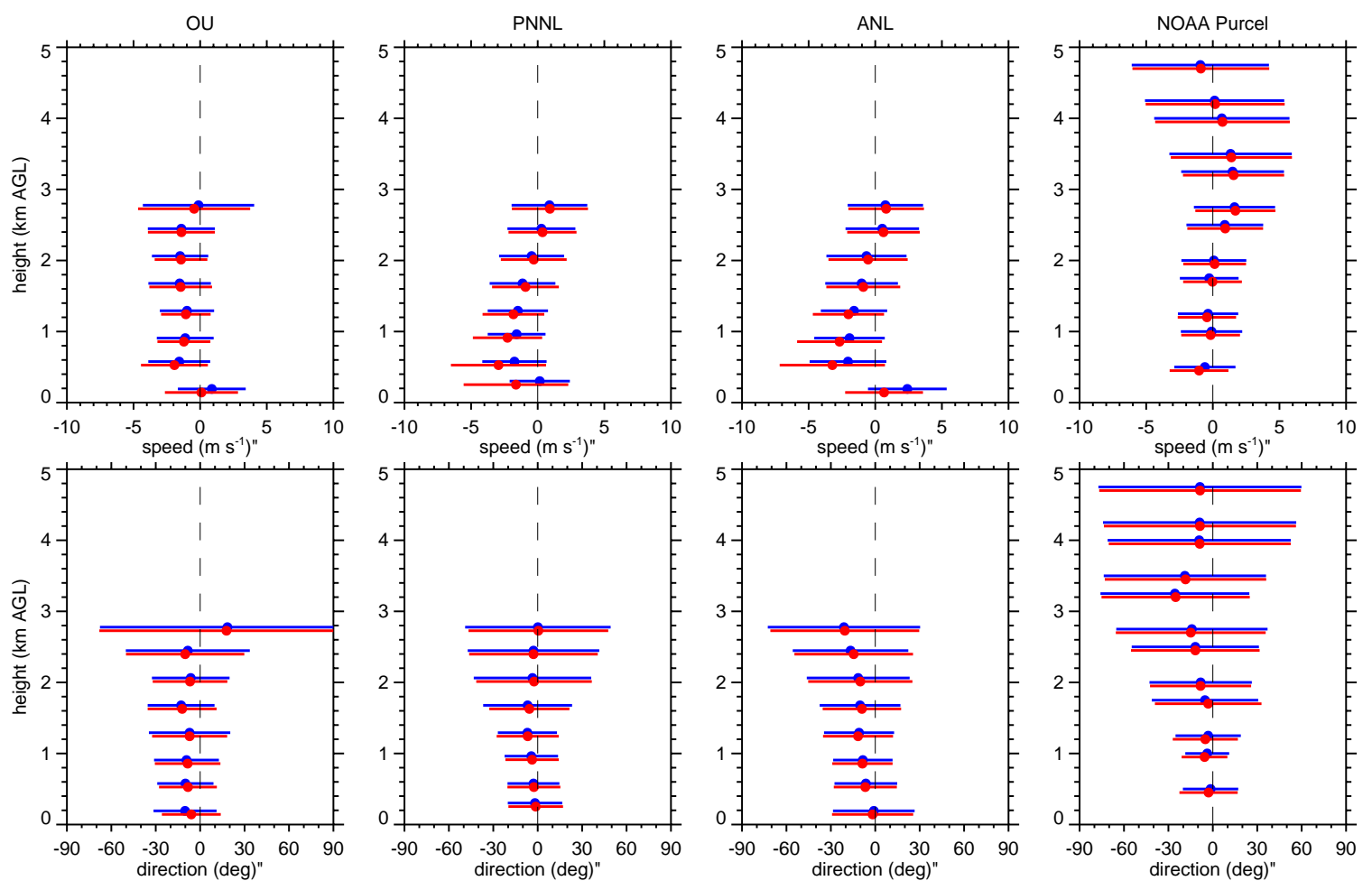

Figure 4.8. Mean (dots) and Standard Deviation (lines) of the Bias Obtained from VDRAS for Wind Retrievals Based on only the NEXRAD Data (blue) and NEXRAD with Operational Data (red)

\subsection{Evaluation of Spatial Variations in the Wind Retrievals}

In addition to evaluating the performance of the wind retrievals in reproducing the wind speed and directions at the radar wind-profiler sites, we also quantified how well the wind retrievals reproduced the spatial variations in the winds between the different radar wind-profiler sites. As listed in Table 4.1, the ANL and PNNL profilers are the closest to one another and are separated by $\sim 7 \mathrm{~km}$, and the ANL and NOAA profilers are the farthest from one another and are separated by $\sim 60 \mathrm{~km}$.

The spatial variation evaluation was computed at three altitudes: 550, 900, and $1400 \mathrm{~m}$. First, the radar wind-profiler data were interpolated to the three altitudes and to the time of the retrieved wind field. Then, the retrieved wind profile, nearest to the radar wind profilers (Table 4.4), was interpolated to the three altitudes. In this way, the radar wind-profiler measurements and the wind retrievals were referenced to the same times and the same vertical levels. The vertical levels were selected based on constraints imposed by both the vertical extent of the radar wind-profiler measurements (Table 4.1) and the wind retrievals (Table 4.5). 

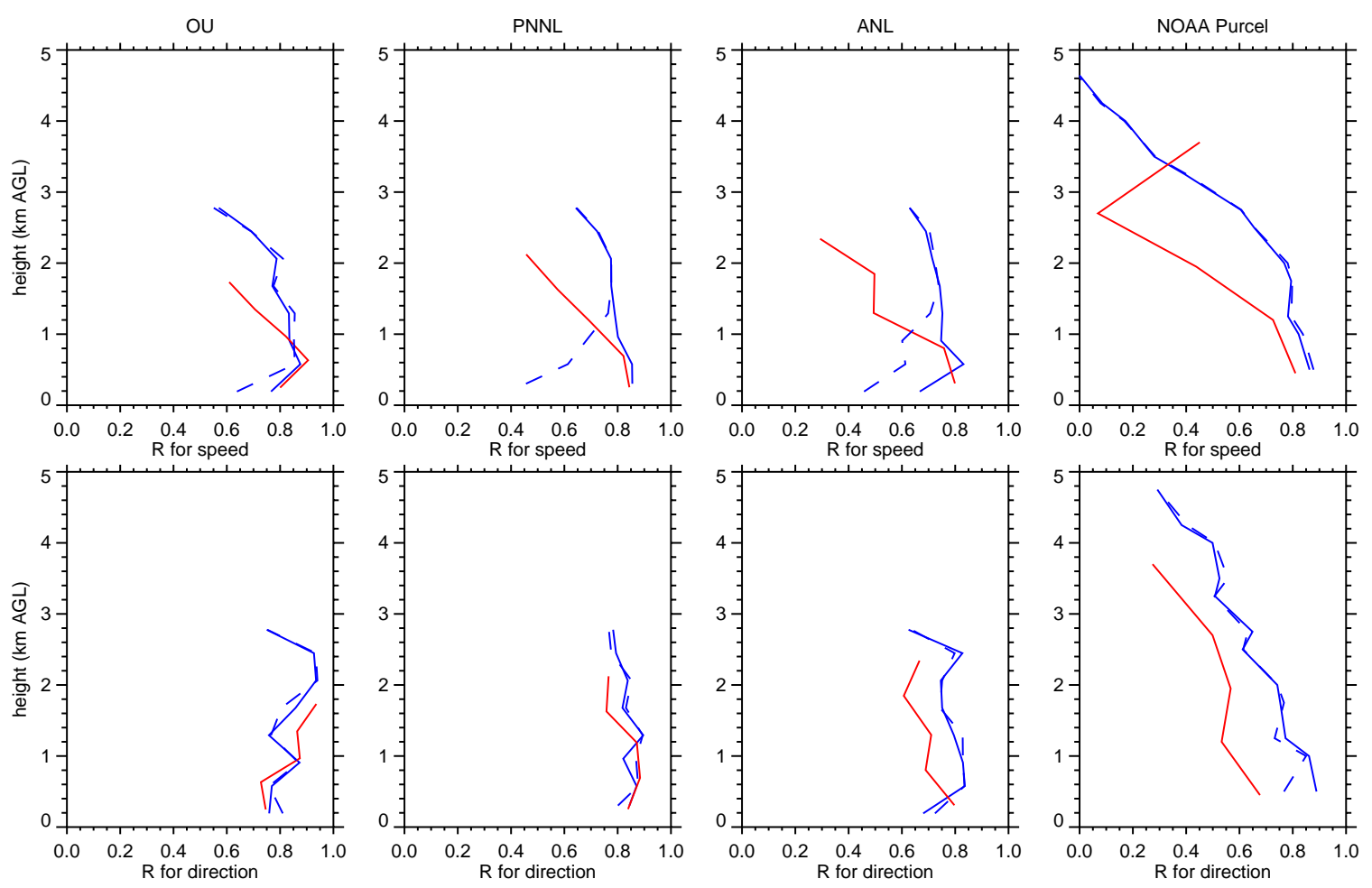

Figure 4.9. Correlation Coefficient of the Wind Speed and Direction Obtained from the 2DVar (red) and VDRAS (blue) Wind Retrievals. The dashed line indicates results from VDRAS using both NEXRAD and operational data.

Figure 4.10 shows an example of the difference in the $\mathrm{u}$ - and v-components of the wind at the $550-\mathrm{m}$ level between the PNNL and NOAA sites. In general, the differences in the wind components from the radar wind profilers were within $3 \mathrm{~m} \mathrm{~s}^{-1}$. The differences from 2DVar and VDRAS usually do not follow the temporal variations in the wind-profiler differences when the wind-profiler differences are less than $3 \mathrm{~m} \mathrm{~s}^{-1}$. There were a few instances in which the radar wind profilers indicated strong horizontal variations in the winds (e.g., July 10, 12, 13). On July 10, a front moved through the region that produced differences between the PNNL and NOAA sites as large as $10 \mathrm{~m} \mathrm{~s}^{-1}$. The wind retrievals from 2DVar and VDRAS both produced larger spatial variations in the winds, although the magnitude and evolution in time was not exactly the same as the radar wind-profiler measurements. In general, the peak differences in the wind components were larger than observed, especially after July 10. The 2DVar method produced larger peak spatial variations in both the u- and v-components than VDRAS.

The correlation coefficients between velocity differences in profiler observations and the corresponding velocity differences in the retrieved wind fields is listed in Table C.5 in Appendix C. The results of the velocity-difference correlation analysis depend upon the distance between the various profiler sites. Generally, the correlations improve slightly with larger separations, i.e., between PNNL and NOAA or between ANL and NOAA. By contrast, the distance between the PNNL and ANL profilers is relatively small $(\sim 7 \mathrm{~km})$. Velocity differences between these two sites were very noisy and, thus, velocity differences are poorly correlated. One would expect the velocity differences between the sites to be small (especially aloft) because of their proximity. 
Table 4.4. Distances Between Radar Profilers and the Nearest Horizontal Grid Point from the VDRAS and 2DVar Retrievals

\begin{tabular}{||c|c|c||}
\hline & \multicolumn{2}{|c|}{ Distance to Nearest Horizontal Grid Point (km) } \\
\hline Profiler & VDRAS & 2DVar \\
\hline ANL & 0.68 & 0.32 \\
\hline OU & 0.20 & 1.27 \\
\hline PNNL & 0.44 & 1.31 \\
\hline NOAA & 0.58 & 1.03 \\
\hline
\end{tabular}

Table 4.5. 2DVar Vertical Levels at Grid Points Nearest Each Profiler. Mode 2 levels are given in parentheses.

\begin{tabular}{||c|c|c|c|c|c||}
\hline & \multicolumn{5}{|c|}{ 2DVar vertical levels ( m AGL) } \\
\hline Profiler & $\mathbf{z}_{\mathbf{1}}$ & $\mathbf{z}_{2}$ & $\mathbf{z}_{\mathbf{3}}$ & $\mathbf{z}_{\mathbf{4}}$ & $\mathbf{z}_{\mathbf{5}}$ \\
\hline ANL & 311.9 & 831.8 & $1300.1(1352.2)$ & $1821.3(1873.5)$ & $2291.3(2395.9)$ \\
\hline PNNL & 267.9 & 723.9 & $1134.6(1180.3)$ & $1591.7(1637.5)$ & $2003.9(2095.7)$ \\
\hline OU & 185.8 & 515.7 & $812.9(846.0)$ & $1143.6(1176.7)$ & $1441.9(1508.2)$ \\
\hline NOAA & 521.6 & 1319.9 & $2039.1(2119.1)$ & $2839.5(2919.6)$ & $3561.4(3722.1)$ \\
\hline
\end{tabular}

(a)
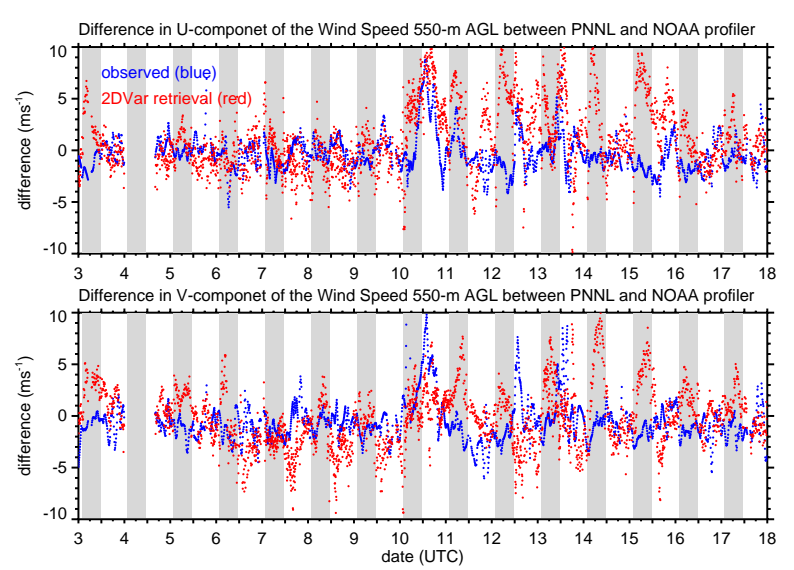

(b)

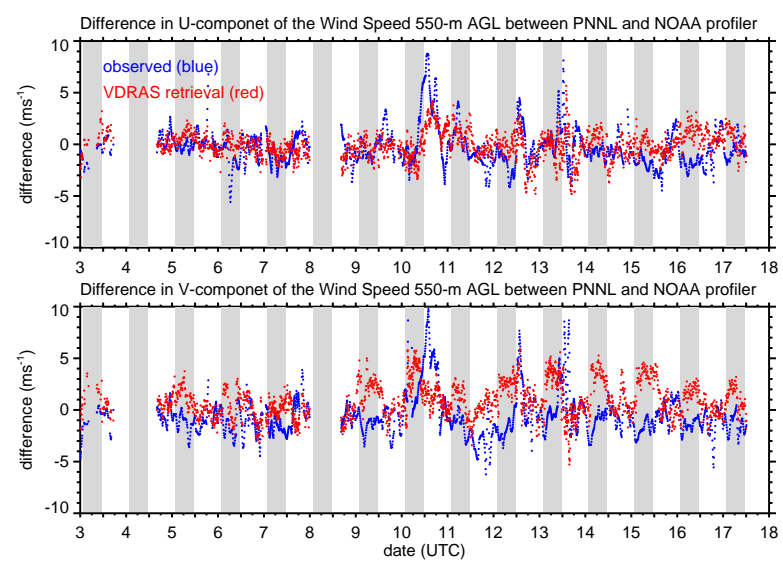

Figure 4.10. Difference in the u- and v-Components of the Wind Speed at $550 \mathrm{~m}$ AGL Between the PNNL and NOAA Radar Wind Profiler Sites for the (a) 2DVar and (b) VDRAS Wind Retrievals 


\subsection{Effects on Dispersion}

It is clear from the previous section that the winds obtained from 2DVar and VDRAS wind retrievals differ from radar wind-profiler measurements and from each other at times. If these wind retrievals are ingested into ADMs, simulated dispersion patterns will differ to some extent. Dispersion will be affected not only by different wind speeds and directions, but also the amount and distribution of data that are produced by the retrievals in the vertical. To determine the impact of the wind retrievals on dispersion, we employed the CALMET/CALPUFF modeling system to examine the sensitivity of the simulated transport and mixing of a passive scalar in the vicinity of Oklahoma City when the 2DVar and VDRAS wind retrievals are used as input.

\subsection{CALMET and CALPUFF Configuration}

CALMET/CALPUFF was chosen because it is an ADM that is widely used in the air-quality community, and the ingestion of meteorological data and its treatment of dispersion are similar to other emergency-response models (e.g., HPAC). CALMET (Scire et al. 1997) is a meteorological model that generates hourly or sub-hourly wind and temperature fields on a three-dimensional grid from standard, routinely available meteorological observations. CALMET includes a diagnostic wind-field generator with objective analysis and parameterized treatment of slope flows, kinematic terrain effects, terrainblocking effects, a divergence minimization procedure, and a micro-meteorological model for boundary layers over land and water surfaces. The diagnostic wind-field model within CALMET contains options that allow wind fields produced from prognostic models to be used as first-guess fields. CALPUFF (Scire et al. 2000) is a non-steady-state Lagrangian Gaussian puff model that uses meteorological fields generated by CALMET to transport puffs of material. CALPUFF contains modules for complex terrain effects, transport over water, coastal-interaction effects, building downwash, wet and dry removal, and simple chemical transformation.

The domain for the CALMET/CALPUFF computations is shown in Figure 4.1 along with the locations of the observations in the vicinity of Oklahoma City. The domain is $110 \mathrm{~km}$ wide and encompasses Oklahoma City and the four radar wind-profiler sites. A 2-km horizontal grid spacing was used so that the spatial resolution was similar to the NEXRAD wind retrievals. However, NEXRAD retrievals from every other grid point from the 2DVar and VDRAS domains were employed to reduce the overall computational time required by CALMET as described in Appendix D. Additional details on how the wind retrievals were incorporated into CALMET are also discussed in Appendix D.

A series of 12-h simulations were performed for each day from July 3 to 17, which started at 03 local standard time (LST) and ended at 15 LST. CALMET wind fields were created for six cases:

1) StdObs:

2) StdObs + profiler:

3) StdObs + 2DVar:

4) StdObs + VDRAS:

5) StdObs + profiler + 2DVar:

6) StdObs + profiler + VDRAS: standard observations (surface station and rawinsonde)

standard observations and radar wind-profiler measurements

standard observations and 2DVar wind retrievals

standard observations and VDRAS wind retrievals

standard observations, radar wind-profiler measurements, and 2DVar

wind retrievals

standard observations, radar wind-profiler measurements, and VDRAS

wind retrievals. 
Case 1) represents the three-dimensional wind fields that would be produced using operational data that are normally available at most urban areas in the United States. Case 2) represents a situation in which an urban area happens to have additional meteorological information aloft, such as those produced by a radar wind profiler. For both Cases 1) and 2), spatial variability in the wind fields is produced by interpolation between the measurement sites and adjustments to satisfy conservation of mass. Cases 3 and 4 were made to demonstrate how the contribution of the wind retrievals to the overall wind field could affect the prediction of near-surface dispersion when they are compared to Cases 1 and 2. Cases 5 and 6 include all of the data and were made to determine whether the large amount of data produced by the wind retrievals overwhelms the influence of the radar wind-profiler data in the diagnostic model predictions.

\subsection{Evaluation of CALMET Winds}

Before examining the effect of the six cases on the predicted dispersion, it is useful to quantify the difference between the observed winds and the winds derived from CALMET. As with any diagnostic model, adjustment and interpolation techniques will result in wind fields that are similar to, but not exactly the same as, the input data. Figure 5.1 shows an example of the CALMET wind fields for the six cases compared to the ANL wind profiler data on July 5. For this comparison, the profiler winds have been interpolated to the CALMET vertical levels.

For Case 1 (Figure 5.1a), the simulated winds from CALMET were qualitatively similar to the radar wind profiler on this day because the observed winds did not change significantly during this period. Therefore, the temporal interpolation of the twice-daily rawinsonde wind profiles was a reasonable approximation of the observed variation. However, the temporal interpolation did not contain a sufficient amount of information to properly represent the evolution of the low-level jet. The simulated wind speeds for the low-level jet during the early morning before 06 LST were lower than observed, and the wind direction aloft differed by as much as 50 degrees.

For Case 2 (Figure 5.1b), the CALMET winds closely follow the profiler winds as expected since those winds were employed by CALMET. This indicates that the interpolation and mass adjustment within CALMET results in a wind field that does not deviate significantly from the observed winds at this location. For Cases 3 and 4 that employ the wind retrievals (Figure 5.1c,d), the wind speeds and directions were close to the radar wind-profiler measurements within $2 \mathrm{~km}$ AGL and are similar to Case 2. This suggests that the wind retrievals provided information comparable to the radar wind profiler. Yet, the wind speeds and directions above $2 \mathrm{~km}$ AGL were often very different from the profiler. Cases 5 and 6 (Figure 5.1e,f) produced winds that were very similar to Cases 3 and 4, and the incorporation of radar wind-profiler data did not reduce the large differences between the observed and simulated winds above $2 \mathrm{~km}$ AGL. The similarity between Cases 5 and 6 with Cases 3 and 4 occurred because CALMET weights all of the input data equally, and there were far more wind-retrieval profiles near the radar windprofiler site.

A second example, shown in Figure 5.2, compares the winds from the six cases and the ANL windprofiler measurements on July 10 when the observed winds were stronger and a front moved through the region so that the westerly winds during the morning shifted to northeasterly by the afternoon. In contrast to Figure 5.1a, the CALMET and observed winds aloft were very different for Case 1 (Figure 5.2b) because the temporal interpolation did not work well for the rapidly changing meteorological conditions associated with the front. The simulated winds were in better agreement with the profiler data close to the surface since CALMET employed the hourly surface observations. As expected, a reasonable agreement 
between the observed and simulated winds was produced for Case 2 (Figure 5.2b). The CALMET fields that employed the wind retrievals for Cases 3 and 4 (Figure 5.2c,d) were better than those from Case 1, but relatively large errors in both speed and direction still occurred at the time of the frontal passage. On this day, VDRAS produced better winds above 2 km AGL than 2DVar. Cases 5 and 6 (Figure 5.2e.f) were again nearly identical to those produced by Cases 3 and 4, respectively.
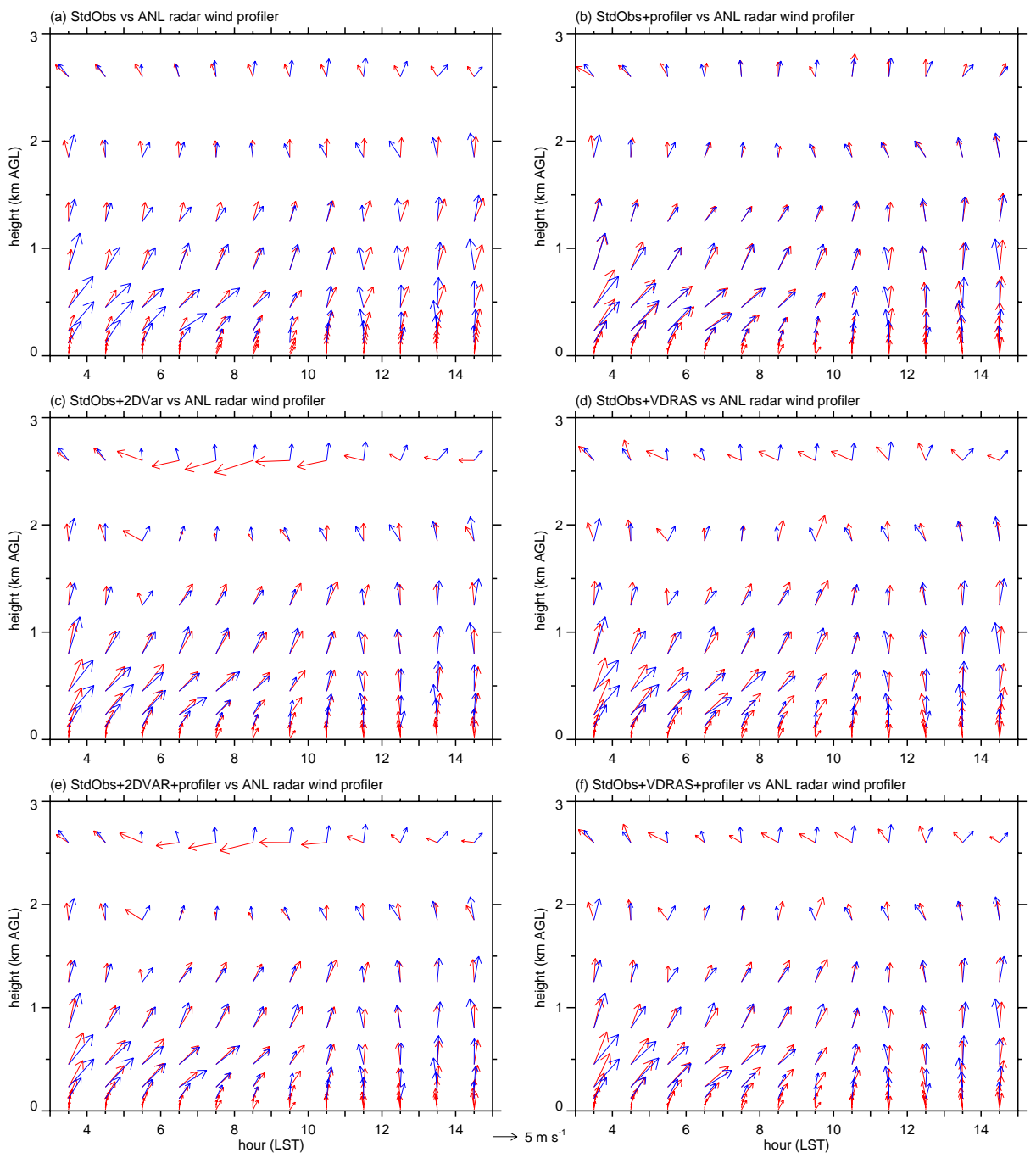

Figure 5.1. Observed (blue) and Simulated (red) Wind Profiles over the ANL Site on July 5, 2003, from Six CALMET Simulations that Employed the Following Meteorological Fields: (a) Standard Observations, (b) Standard Observations and Radar Wind Profilers, (c) Standard Observations and 2DVar Retrievals, (d) Standard Observations and VDRAS Retrievals, (e) Standard Observations, 2DVar Retrievals, and Radar Wind Profilers, and (f) Standard Observations, VDRAS Retrievals, and Radar Wind Profilers 

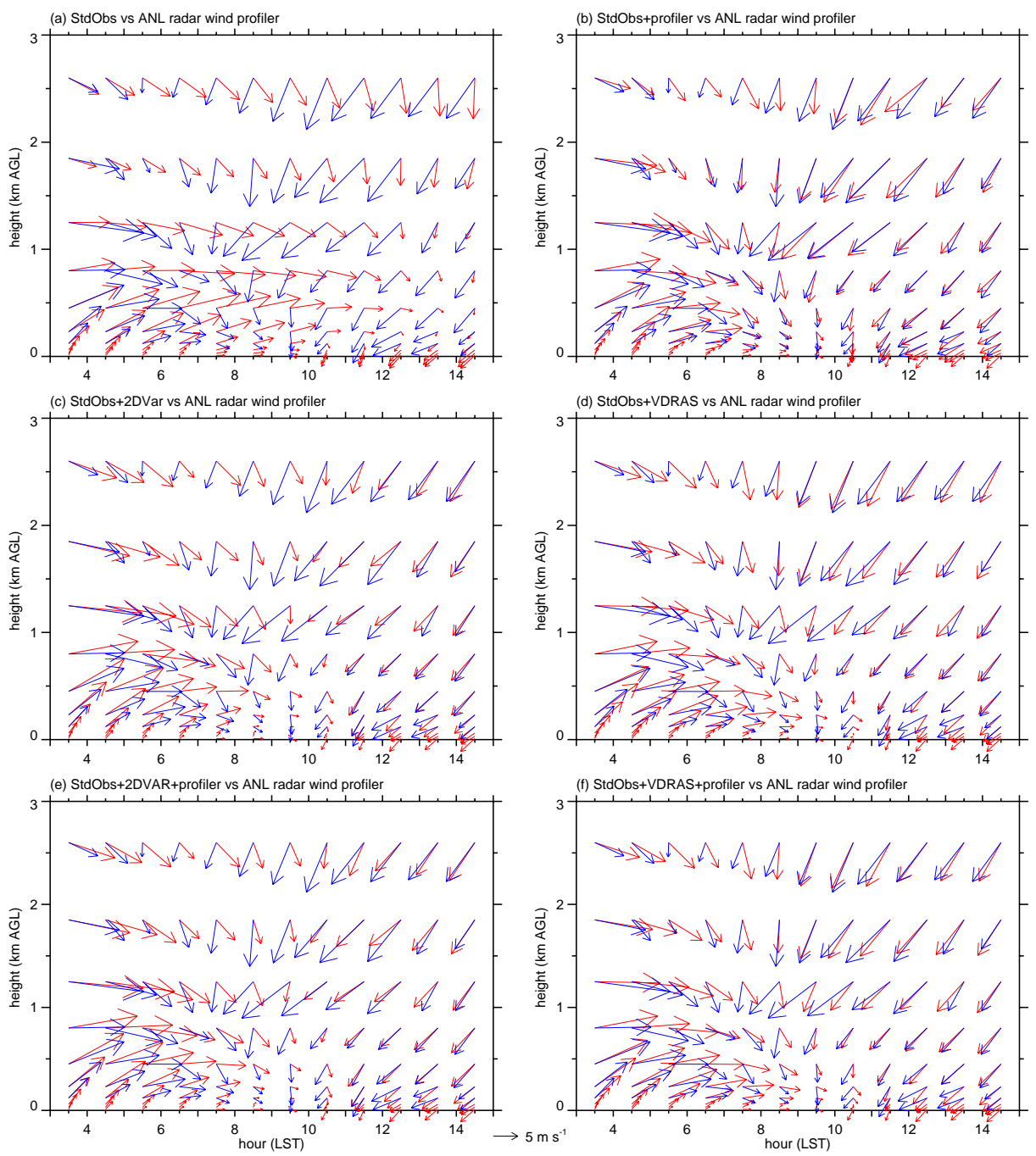

Figure 5.2. Same as Figure 5.1, Except for July 10, 2003

The third example of the CALMET wind fields is shown in Figure 5.3 for July 12 when a stationary front was located north of Oklahoma City. The behavior of the six CALMET wind fields was similar to the July 10 period shown in Figure 5.2. While the observed upper-air directions remained westerly throughout the period, the wind speeds decreased so that the temporal interpolation between the twicedaily rawinsonde profiles did not work well. The cases that employed the NEXRAD wind retrievals were better than Case 1, but not as good as Case 2.

Table C.6 lists statistics that summarize the performance of the CALMET wind fields for the six cases and the 11 simulation periods when compared with the PNNL and ANL radar wind-profiler data. As with the graphical depictions shown in Figure 5.1b, Figure 5.2b, and Figure 5.3b, Case 2, which employs the radar wind-profiler data, has the best performance, as expected. The index of agreement and correlation coefficient was usually close to 1 , and biases and root-mean-square errors were usually less than a few tenths of a meter per second within $2 \mathrm{~km}$ of the ground. For Case 1, which employed only the 
standard observations, the bias, RMSE, IA, and R range from -1.5 to $0.99,1.38$ to $3.91,0.76$ to 0.91 , and 0.66 to 0.88 , respectively. The statistics for Cases 3 to 6 that include the NEXRAD wind retrievals were better than from Case 1. The differences in the statistics between Cases 3 and 5 and between Cases 4 and 6 were small, but the statistics for Cases 5 and 6, which included the radar wind profiler data, were slightly better. This indicates that the inclusion of the radar wind-profiler data does affect the CALMET fields despite the large volume of NEXRAD wind retrievals. These differences are usually too small to detect graphically.
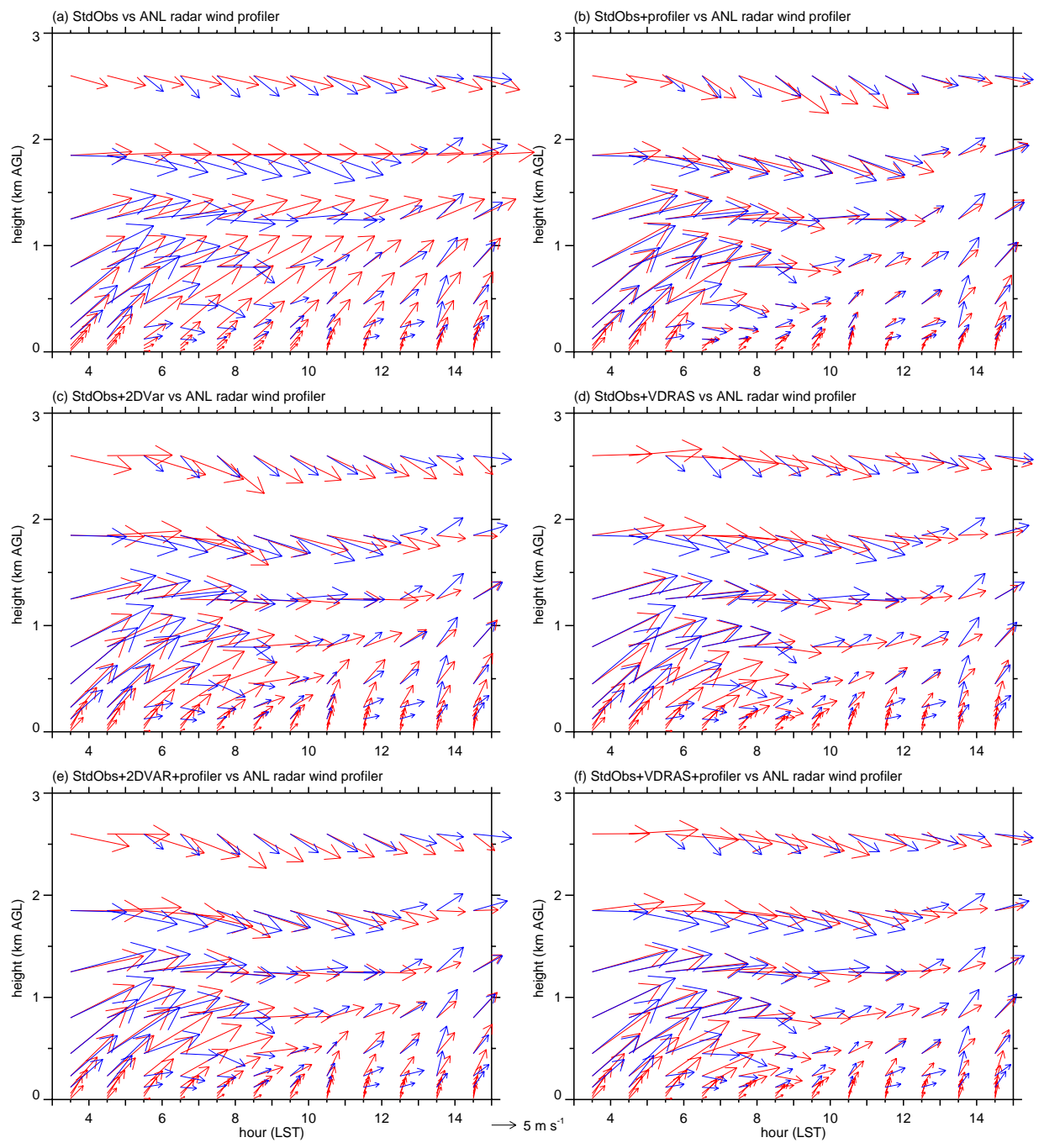

Figure 5.3. Same as Figure 5.1, Except for July 12, 2003 
Because of the different vertical coordinates employed by 2DVar and VDRAS, it is difficult to directly compare the horizontally-varying wind fields as was shown previously in Figure 4.2. We have used CALMET to examine the qualitative differences in the spatial wind fields, and examples are shown in Figure 5.4 and Figure 5.5. The wind fields from 2DVar and VDRAS were usually similar, except that wind fields derived from 2DVar exhibited more spatial variations over the 110-km-wide CALMET domain than did wind fields derived from VDRAS.
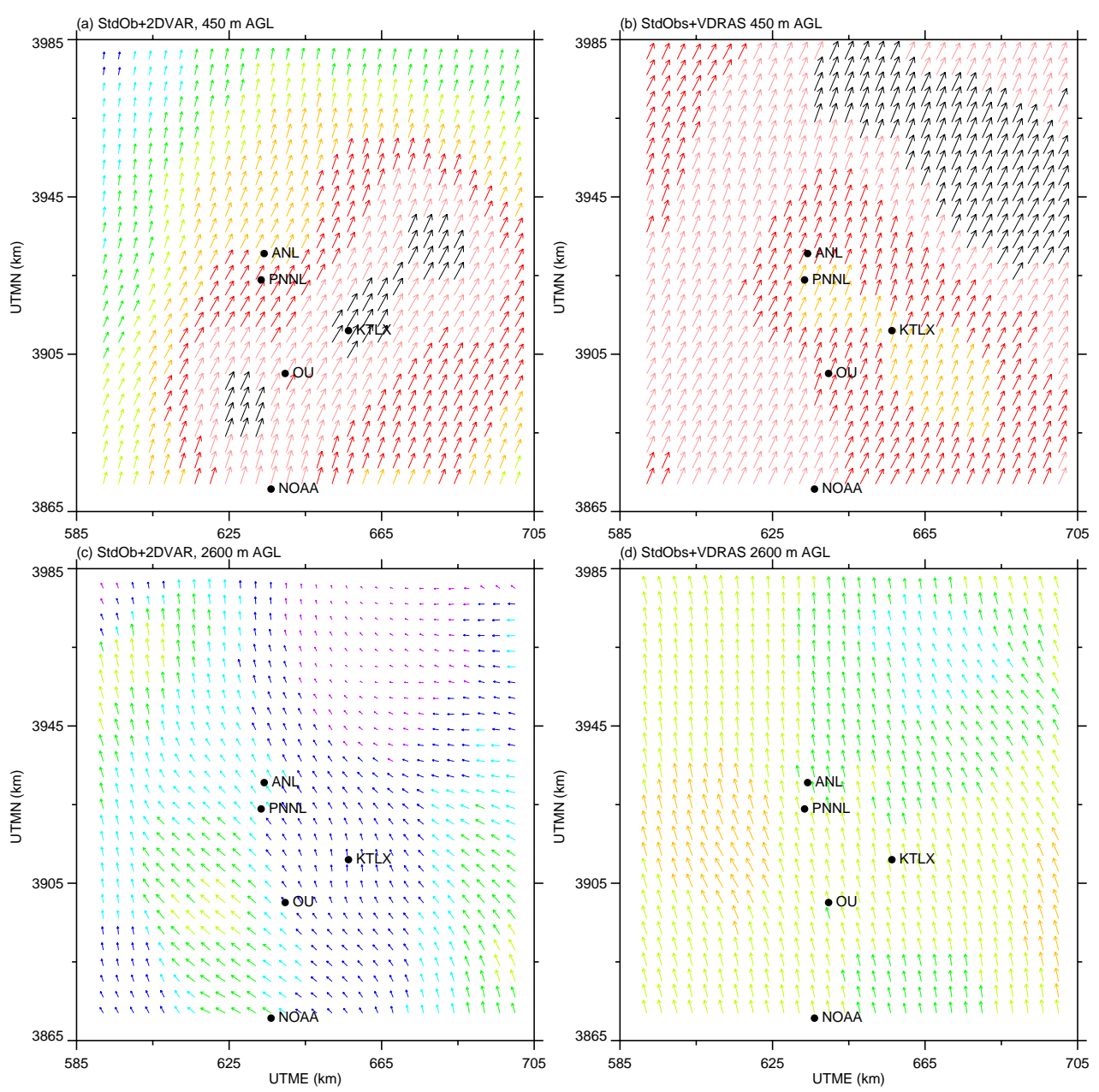

Figure 5.4. Wind Fields from Two CALMET Simulations at Two Altitudes on 04 LST (10 UTC) July 5, 2003. Color of arrow denotes wind speed where purple $=<3$, blue $=3-4$, light blue $=4-5$, green $=5-6$, light green $=6-7$, orange $=7-8$, red $=8-9$, pink $=9-10$, and black $>10 \mathrm{~m} \mathrm{~s}^{-1}$.

An example of when the wind fields derived from 2DVar varied more spatially than VDRAS is shown in Figure 5.4 at 04 LST (10 UTC) on July 5. Both models produced higher wind speeds at $450 \mathrm{~m}$ AGL (Figure 5.4a,b) than aloft at $2600 \mathrm{~m}$ AGL (Figure 5.4c,d) as a result of the nocturnal low-level jet. Wind speeds over the domain at $450 \mathrm{~m}$ AGL ranged from 3 to $10 \mathrm{~m} \mathrm{~s}^{-1}$ from 2DVar and 7 to $10 \mathrm{~m} \mathrm{~s}^{-1}$ for VDRAS. The locations of the peak wind speeds were different as well; however, the wind speed and 
direction at the profiler sites were quite similar. The wind fields further aloft at $2600 \mathrm{~m}$ AGL were qualitatively similar, except that the wind speeds derived from VDRAS were 1 to $2 \mathrm{~m} \mathrm{~s}^{-1}$ higher than from 2DVar.
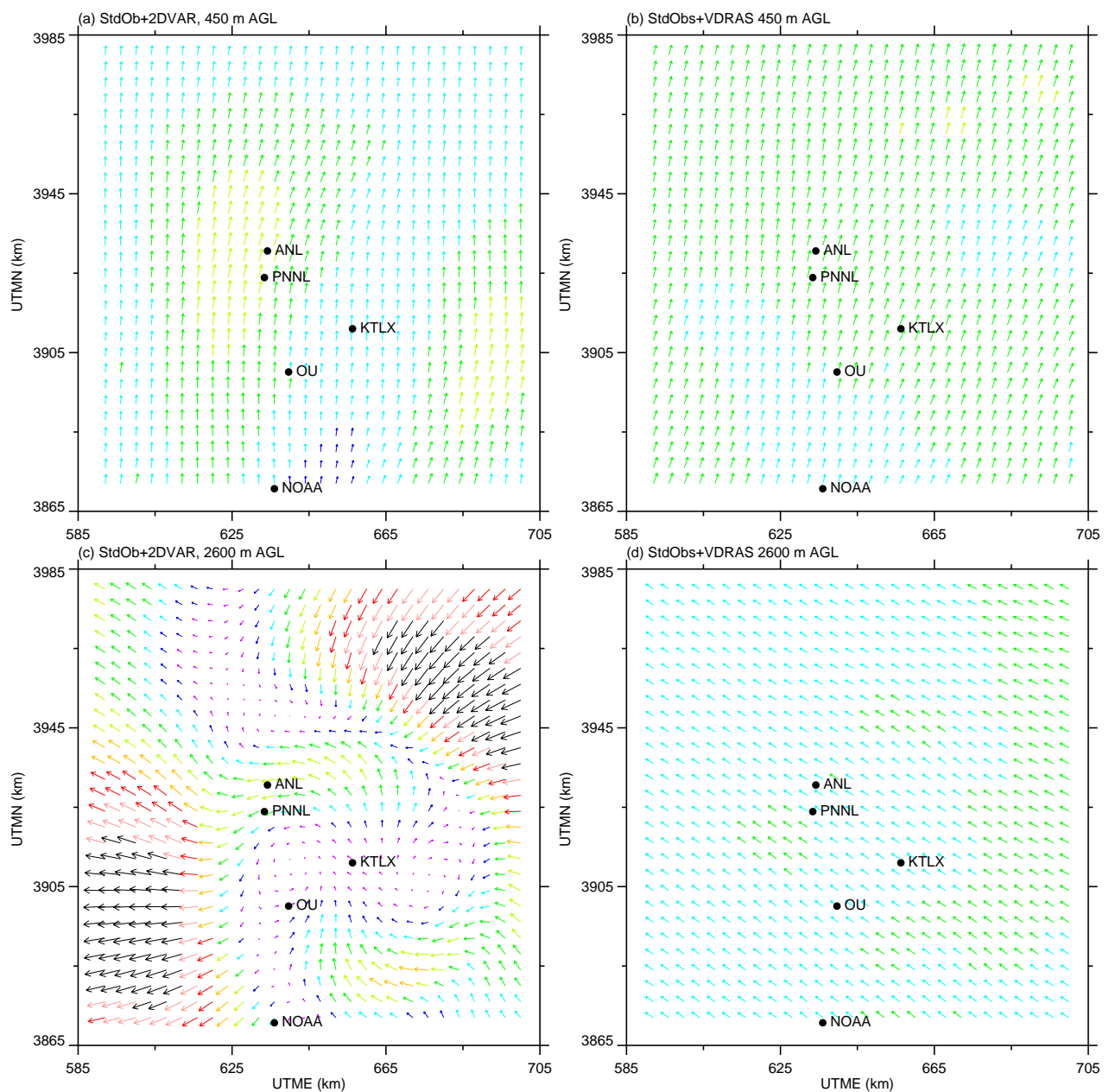

Figure 5.5. Same as Figure 5.4, except at 10 LST (16 UTC) July 5, 2003

Figure 5.5 shows the winds $6 \mathrm{~h}$ later at 10 LST (16 UTC) on July 5. At this time, the winds at $450-\mathrm{m}$ AGL (Figure 5.5a,b) between 2DVar and VDRAS were quite similar. In contrast with Figure 5.4, spatial variations from 2DVar were only $\sim 1 \mathrm{~m} \mathrm{~s}^{-1}$ greater than from the VDRAS at this time. The shift from large to small spatial wind-speed variations between 04 and 10 LST was also evident at the ANL profiler for the time series shown in Figure 4.10. The quasi-symmetrical perturbation pattern in the wind speed and direction at $2600 \mathrm{~m}$ AGL (Figure 5.5c) is an example of an artifact produced by 2DVar that was usually produced only at high altitudes. This artifact also explains the larger errors in the wind speeds and directions when compared with the radar wind-profiler data above $2 \mathrm{~km}$ AGL (e.g., Table C.3, Figure 4.7). The 2DVar wind field at this time was unrealistic because there were no sudden shifts in the ambient synoptic conditions, and one would expect horizontally homogenous winds aloft like the wind 
field produced from VDRAS (Figure 5.5d). A rapid decrease in the available data occurred between 04 and 10 LST, July 5, as shown in Figure 4.3; therefore, the variational approach in 2DVar may produce unrealistic results when relatively few NEXRAD radial-velocity data points are available.

\subsection{CALPUFF Sensitivity Simulations}

CALPUFF simulations were performed that employed the six CALMET wind-field cases. A constant release rate $\left(10 \mathrm{~g} \mathrm{~s}^{-1}\right)$ of material between 03 and $15 \mathrm{LST}$ was made close to the OU profiler site (Figure 4.1) from a stack. The release height, exit velocity, and temperature were 40-m AGL, $5 \mathrm{~m} \mathrm{~s}^{-1}$, and $355 \mathrm{~K}$, respectively. This release site was chosen because the southerly to southwesterly winds usually observed during the 2-week period would transport the plume through a large fraction of the modeling domain. In this way, the impact of differences in the simulated wind field would accumulate over time.

We compute a time-integrated concentration, or exposure, defined as the time integral of the concentration at a point on the surface, to demonstrate the differences in dispersion among the cases. Figure 5.6 shows the 12-h accumulated concentration of the predicted plumes on July 5 for the six cases. The plume for Case 1 was transported to the northeast during the 12-h period.

When the radar wind-profiler data were included in CALMET, the plume was transported further to the east, and the footprint's bifurcation indicates a wind shift during the period that transported material towards the north for a short period of time. The northward transport occurred between 1130 and 1230 when winds from Case 1 were southwesterly (Figure 5.1a), and the observed winds and winds from Case 2 were southerly (Figure 5.1b). The wind retrievals in CALMET resulted in bifurcations in the footprints for Cases 3 and 4 (Figure 5.6c,d) that were qualitatively similar to the footprint from Case 2 . The shapes of the downwind plume from 2DVar and VDRAS differ somewhat, but the results suggest that the choice of wind retrieval would not significantly affect the predicted dispersion. The plume footprint from Cases 5 and 6 (Figure 5.6e,f) were similar to Cases 3 and 4 since the wind fields in CALMET were also very similar.

The dispersion of the downwind plume during the frontal passage on July 10 is shown in Figure 5.7. The footprint of the plume from Case 1 (Figure 5.7a) shows that the variable winds transported the tracer over a wide region towards the east and south during the 12-h period. Before 09 LST, the simulated winds were southwesterly so that the plume was transported towards the northeast. As the front moved through the region, new material as well as previously released material over the northeastern portion of the domain were transported to the south and southwest. The footprint from Case 2 (Figure 5.7b) was remarkably similar to Case 1, even though there were large differences in the wind fields as shown in Figure 5.2a,b. The results suggest that transport was governed more by the winds within a few hundred meters of the surface than the winds aloft. After a frontal passage, the air would likely be more stable and would result in less coupling with the wind aloft. The simulated winds from 09 to 15 LST from Case 2 better represented the northeasterly near-surface winds and transported more material further to the southwest than from Case 1. Cases 3 and 4 produced footprints (Figure 5.7c,d) that were qualitatively similar to both Case 1 and 2; however, the 2DVar wind fields in Case 3 produced some transport to the north that was not seen in Cases 1, 2, and 4. The plume footprint from Cases 5 and 6 (Figure 5.7e,f) were similar to Cases 3 and 4 for the same reason as on July 5. 

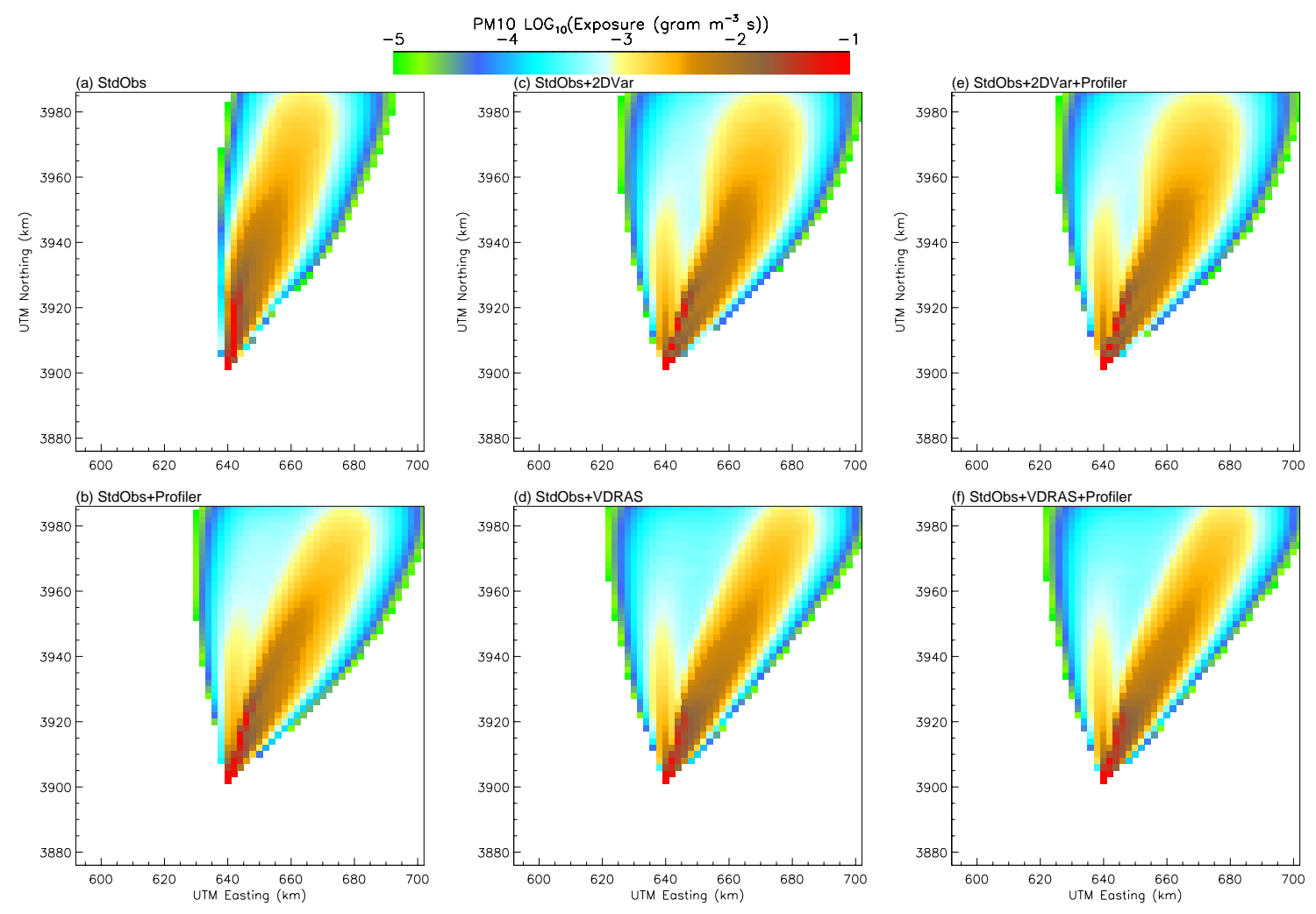

Figure 5.6. 12-h Integrated Concentration on July 5, 2003, from Six CALPUFF Simulations with the Following Meteorology: (a) Standard Observations, (b) Standard Observations + Profiler, (c) Standard Observations + 2DVar Retrievals, (d) Standard Observations + VDRAS Retrievals, (e) Standard Observations + 2DVar Retrievals + Profiler, and (f) Standard Observations + VDRAS Retrievals + Profiler

Figure 5.8 shows the footprint of the downwind plume predicted on July 12 for the six cases. The stronger and near-constant wind directions in the CALMET fields using the standard observations in Case 1 (Figure 5.8a) produced a downwind plume that was straight and narrow. The footprint produced by Case 2 (Figure 5.8b) was wider as a result of transport to the east from 7 to 12 LST (Figure 5.3b). While Cases 3 and 4 also produced downwind transport towards the northeast (Figure 5.8c,d), both cases had more meandering of the plume and a distinct bifurcation in the plume with the smaller branch transported to the east. On this day, the plume footprint using the NEXRAD wind retrievals was significantly different than Case 2, which employed the radar wind-profiler data. Cases 3 and 4 were more similar to one another than to Case 2. As with the previous two periods, the plume footprint from Cases 5 and 6 (Figure 5.8e,f) were similar to Cases 3 and 4. 


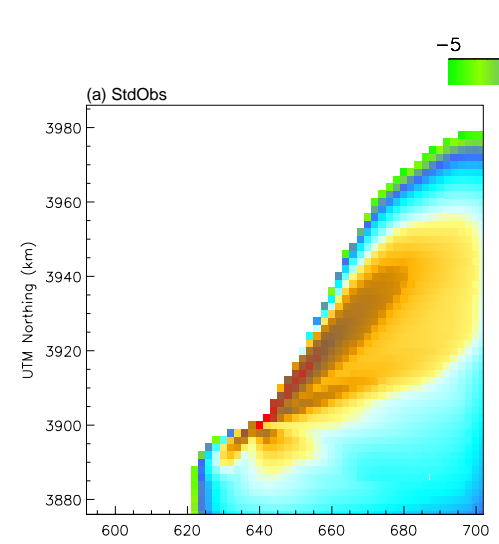

$\operatorname{PM}_{-4} \operatorname{LOG}_{10}\left(\right.$ Exposure $\left._{-3}\left(\mathrm{gram} \mathrm{m}_{-2}^{-3} \mathrm{~s}\right)\right)$
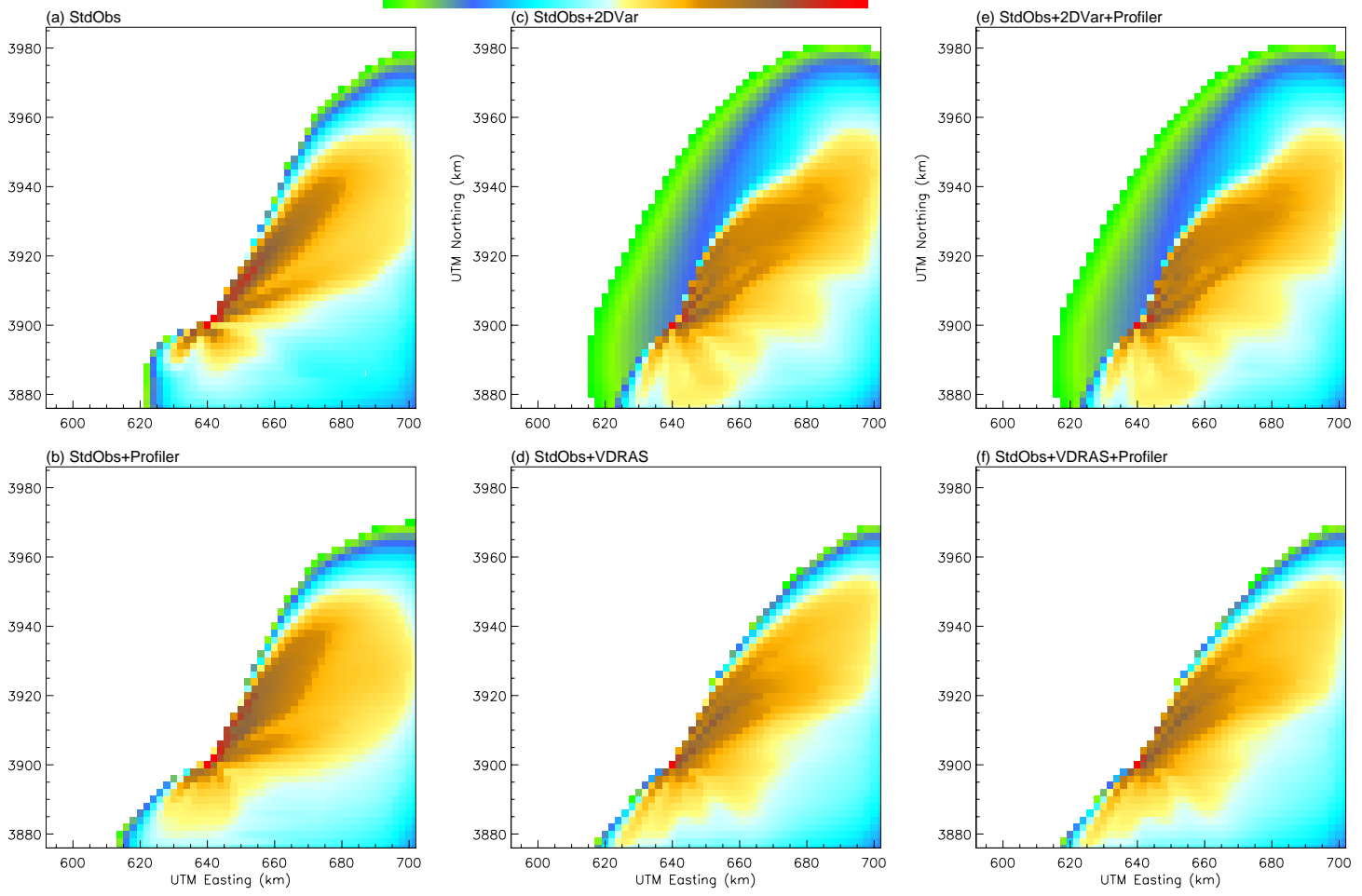

Figure 5.7. Same as Figure 5.6, Except for July 10, 2003

We have also quantified the differences in the dispersion predictions by computing the plume centerline direction and plume width among the various cases. Figure 5.9 shows examples of these quantities as a function of downwind distance for July 5, 10, and 12. For July 5 (Figure 5.9a), the plume centerline direction for Cases 3 and 4 included the wind retrievals that were very similar to each other, and Case 2 included the radar wind-profiler data. Cases 2, 3, and 4 differ from Case 1, which included only the standard observations, by as much as 10 degrees. The differences in the plume width among the cases were small and became as large as $2 \mathrm{~km}$ at $50 \mathrm{~km}$ downwind of the release site (Figure 5.9b). For July 10 during the frontal passage (Figure 5.9c), the plume centerline from Cases 3 and 4 with the wind retrievals was located further to the south than Cases 1 and 2, especially near the release site. In contrast to July 5, the plume width on July 10 was much larger (Figure 5.9d), and larger differences in the plume width among the cases were produced. Differences in the plume width between Cases 1 and 4 were as much as $8 \mathrm{~km}$ at $22 \mathrm{~km}$ downwind of the release site. The centerline of the plume predicted by Cases 3 and 4 were again further south of Cases 1 and 2 on July 12 (Figure 5.9e). On this day, the plume width from Case 1 was narrow and only $3 \mathrm{~km}$ wide and $50 \mathrm{~km}$ downwind of the release site. However, the plume widths from the other cases were much larger. 

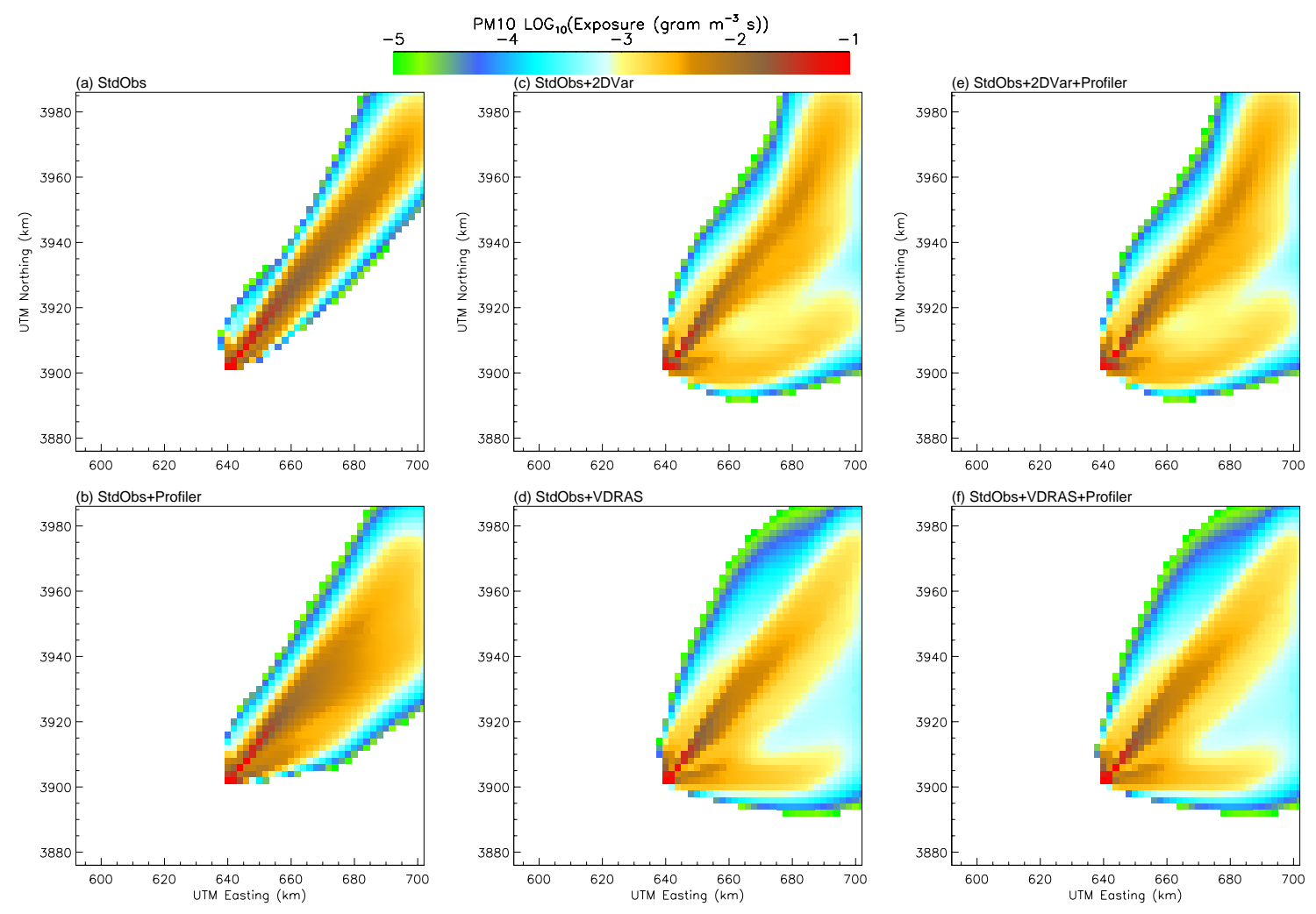

Figure 5.8. Same as Figure 5.6, Except for July 12, 2003

For all of the CALPUFF simulations, the plume widths from Case 1 were narrower than those from Case 2, which included radar wind profiler data in addition to the standard observations. The inclusion of hourly wind profiles introduced more temporal variability into the CALMET wind fields that spread out the plume. The plume widths were even wider for Cases 3 and 4, demonstrating that the additional spatial variations in the winds derived from the NEXRAD data resulted in increased dispersion downwind of the release site that was not produced by inclusion of the radar wind-profiler data alone in CALMET.

The way in which the NEXRAD retrievals increase the downwind dispersion of a plume is reasonable, but would need a tracer experiment to adequately quantify the improvement in the representation of dispersion. The $\mathrm{SF}_{6}$ tracer experiment conducted during JU2003 made measurements only up to $5 \mathrm{~km}$ downwind of the downtown release site. The spatial extent of this experiment was not large enough to examine how the spatial variations in the NEXRAD wind retrievals would affect dispersion. 

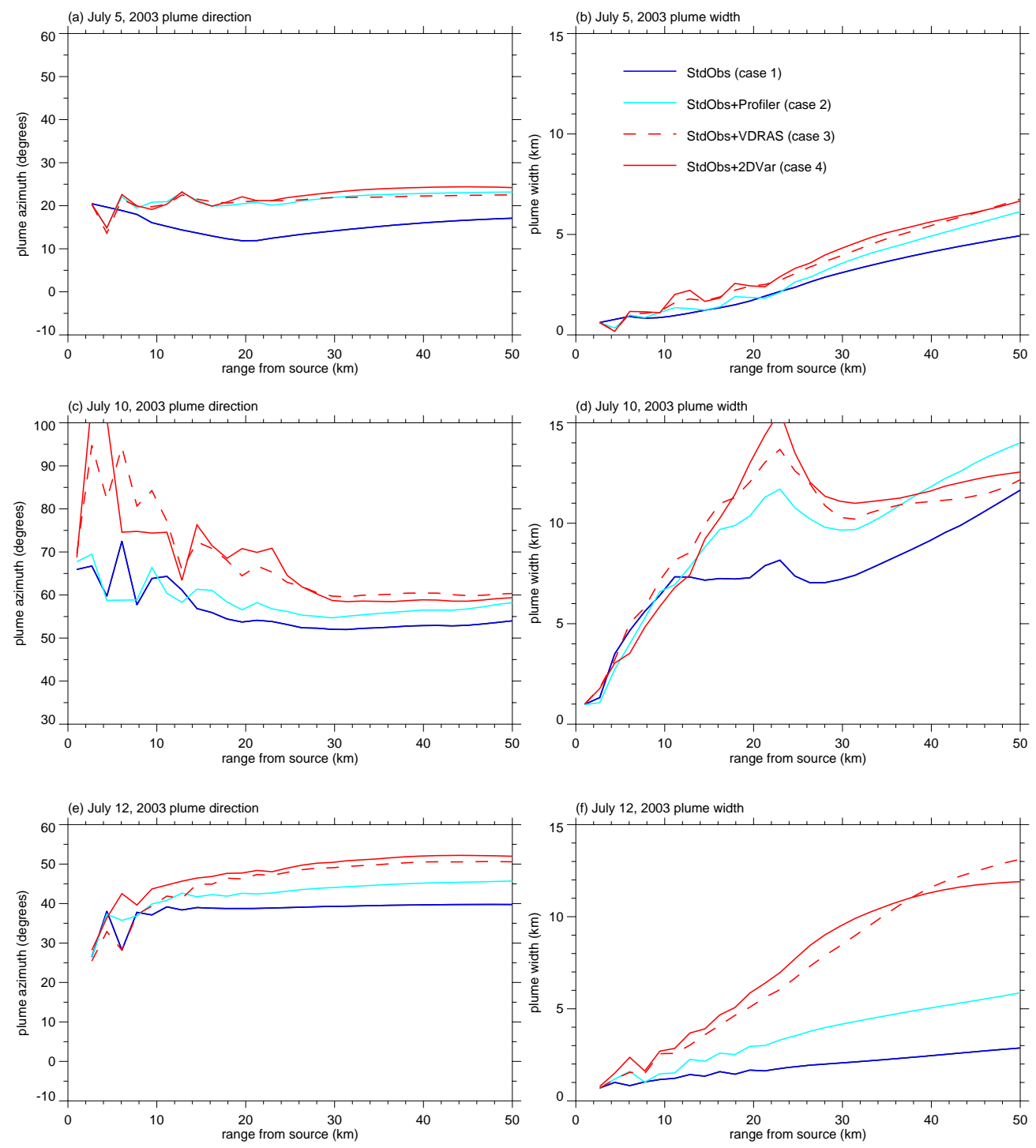

Figure 5.9. Direction of the Plume Produced by CALMET/CALPUFF Simulations Using Either Standard Observations (blue), Standard Observations + Profiler (light blue), Standard Observations + 2DVar Wind Retrievals (red), and Standard Observations + VDRAS Wind Retrievals (dashed red) for (a) July 5, (c) July 10, and (e) July 12. Plume widths for July 5, 10 , and 12 are shown in (b), (d), and (f), respectively. 


\subsection{Comparison of CALPUFF and SCIPUFF}

CALMET and CALPUFF are U.S. Environmental Protection Agency (EPA)-approved models that have been used for a wide range of regulations and research related to atmospheric dispersion. To assess whether the conclusions regarding the effect of the NEXRAD wind retrievals on the overall dispersion presented in Section 5.3 were specific to CALPUFF, we also performed a series of simulations using the Second-order Closure Integrated PUFF (SCIPUFF) model (Sykes et al. 1993, 2004). The SCIPUFF model performs the dispersion predictions as part of the Defense Threat Reduction Agency's (DTRA's) Hazard Prediction and Assessment Capability (HPAC) used by the U.S. Department of Defense (DTRA 2001; Warner et al. 2004; Chang et al. 2003, 2005). CALMET and SCIPUFF are also being used to represent dispersion for the Biological Warning and Incident Characterization (BWIC) system currently being developed by DHS.

We used the same meteorological fields on July 5, 10, and 12 to drive both CALPUFF and SCIPUFF to assess differences in the simulated concentration fields that result from differences in the treatment of transport and diffusion. This was achieved by converting the CALMET files into a format that could be used by SCIPUFF (Rishel et al. 2007). It was also necessary to modify the source-term parameters from those used previously because of differences in the way the source terms are handled between the two models. For this comparison, material was released at the surface with the exit velocity and buoyancy set to zero; therefore, the exposure produced by CALPUFF is somewhat different than in Figure 5.6 to Figure 5.8. Simulations were performed for Case 1 (standard observations), Case 3 (standard observations with 2DVar wind retrievals), and Case 4 (standard observations with VDRAS wind retrievals) as described in Section 5.1.

The resulting exposures from SCIPUFF and CALPUFF for Case 3, which used the 2DVar wind retrievals, are shown in Figure 5.10. The direction of the downwind plume predicted by SCIPUFF and CALPUFF was similar because of the identical mean wind fields; however, the footprint of the plumes differed somewhat. The SCIPUFF results exhibited a bit more fine-scale spatial variability, especially for the cases that employed the NEXRAD wind retrievals. Table C.7 quantifies the differences in the predicted surface exposures produced by CALPUFF and SCIPUFF. The maximum exposures predicted by CALPUFF were higher in nearly every simulation. In most cases, the CALPUFF exposure values were 2 to 4 times larger than those predicted by SCIPUFF. This is consistent with Figure 5.10, which showed that regions of maximum exposure tended to be more concentrated in the CALPUFF plume.

A similar comparison of the resulting exposures from SCIPUFF and CALPUFF for Case 4, which used the VDRAS wind retrievals, is shown in Figure 5.11. As with the CALPUFF predictions shown previously in Figure 5.6 to Figure 5.8, the SCIPUFF predictions between Cases 3 and 4 were more similar to each other than to the SCIPUFF prediction from Case 1 (not shown). Therefore, most of the differences between the exposure patterns between CALPUFF and SCIPUFF resulted from the different treatments of diffusion. 

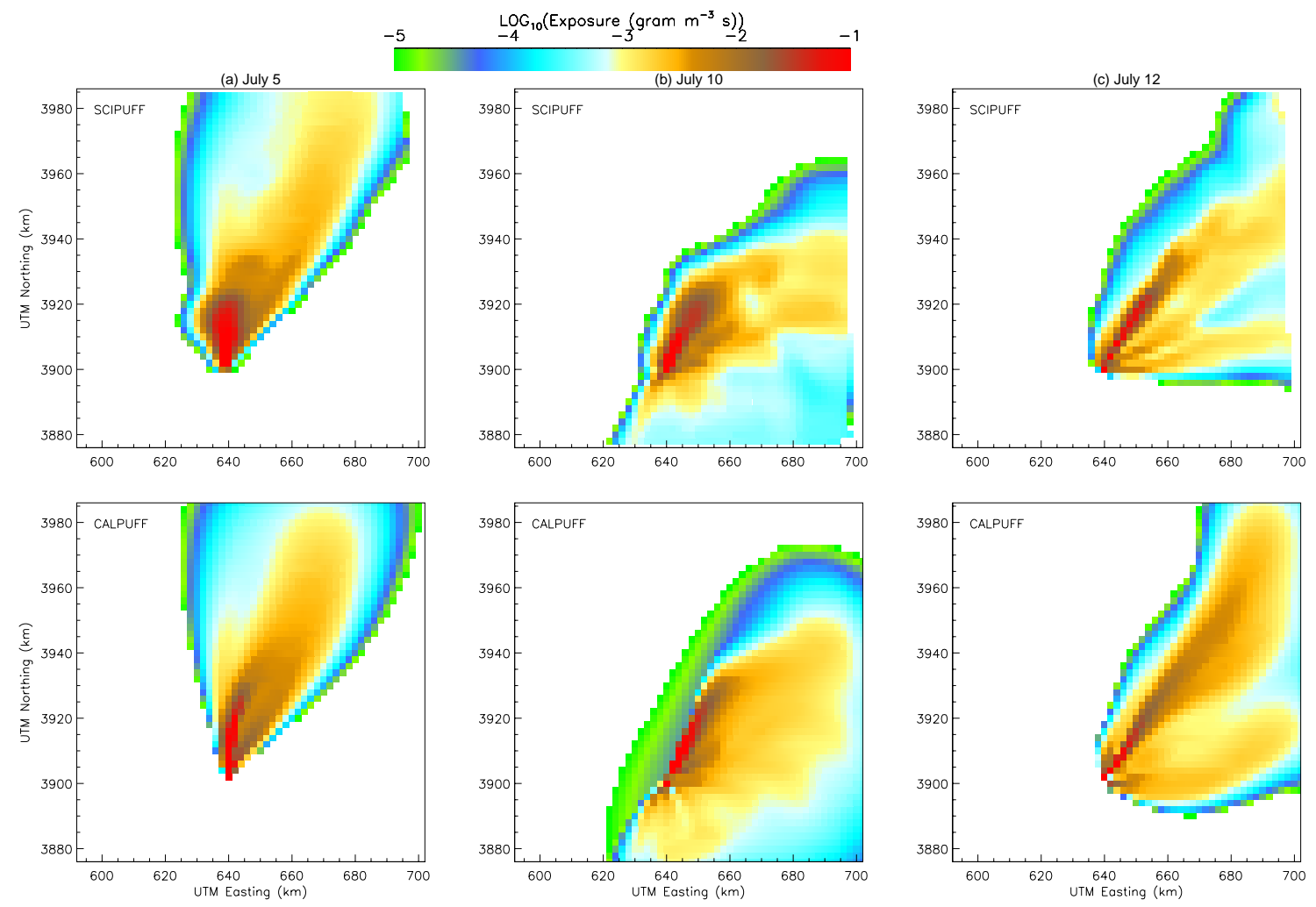

Figure 5.10. Comparison of CALPUFF and SCIPUFF Exposures for (a) July 5, (b) July 10, and (c) July 12 Using StdObs + 2DVar CALMET Wind Fields

\subsection{Effect of Temporal Resolution of Meteorology}

To be consistent with most operational dispersion model simulations, CALMET wind fields were produced at hourly intervals, and wind retrievals were averaged over each 1-hour period for the six cases listed in Section 5.1. CALPUFF subsequently linearly interpolated the wind fields in time to the time step employed by the dispersion calculations. As will be discussed in Section 6, the NEXRAD wind retrievals can be computed in near real-time; therefore, it is possible to obtain wind retrievals at a rate of approximately once every 10 minutes. Dispersion models should be configured to take advantage of this higher temporal resolution.

To examine the effects of the time-varying NEXRAD wind retrievals on the simulated dispersion patterns, the CALPUFF simulations were repeated for July 5, 10, and 12, which were based on CALMET wind fields at 15-min intervals. Either a single wind retrieval was used or two wind retrievals were averaged over the 15-min period. The resulting CALPUFF simulations were compared to those produced by hourly averaged wind fields. 

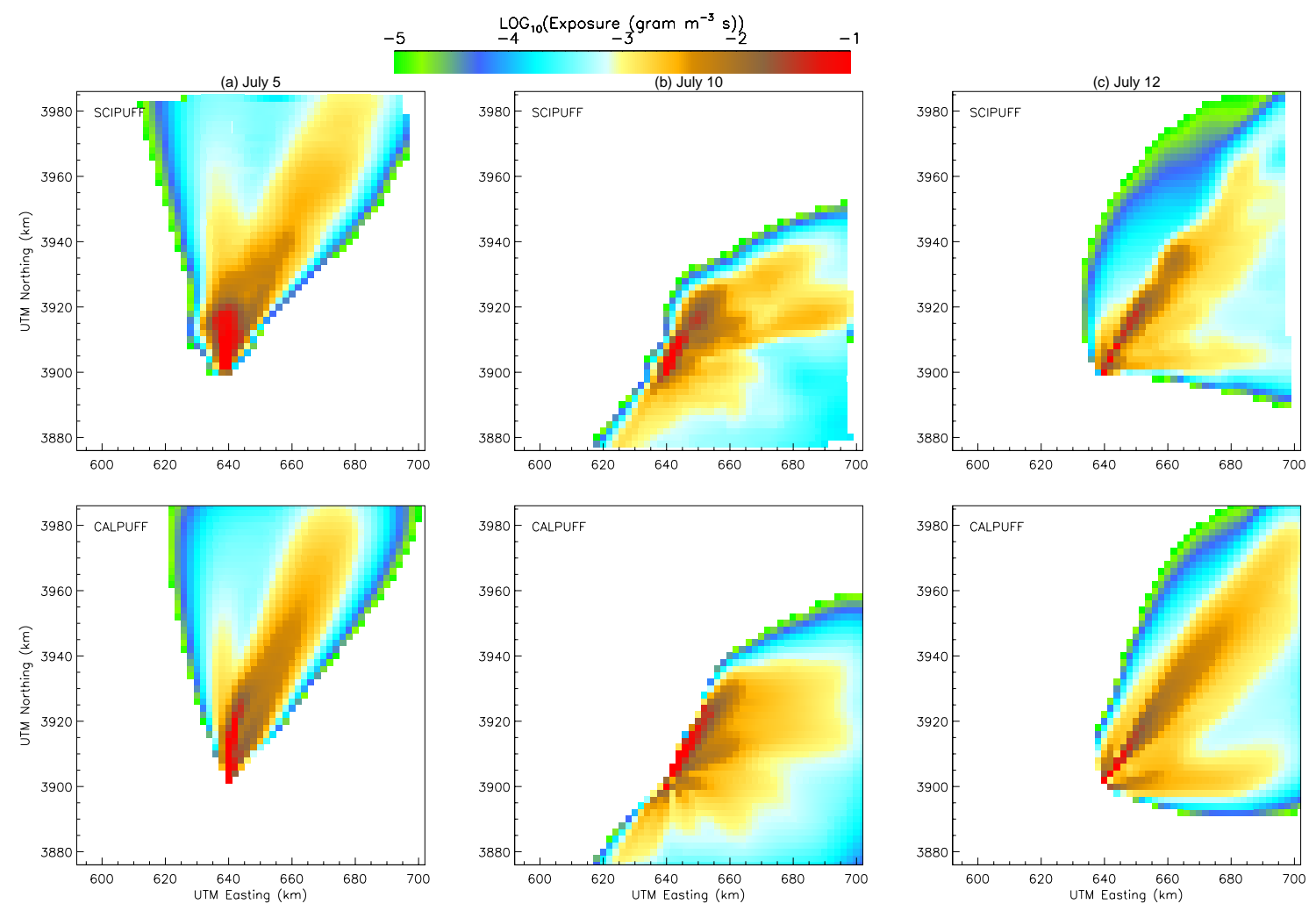

Figure 5.11. Comparison of CALPUFF and SCIPUFF Exposures for (a) July 5, (b) July 10, and (c) July 12 Using StdObs + VDRAS CALMET Wind Fields

The spatial distribution and magnitude of the predicted surface concentrations and exposure that employed the 15-min wind fields were very similar to the 1-h wind fields. Table C.8 summarizes the differences in the predicted exposure resulting from wind fields at 15-min or 1-h intervals. The difference in the maximum exposure was less than $\sim 6 \%$. The similar dispersion patterns are consistent with Figure 4.4 and Figure 4.5, which show gradual changes in wind speed and direction from both 2DVar and VDRAS wind retrievals. The number of periods with rapidly changing winds over sub-hourly intervals was relatively few. This indicates that the sub-hourly variations in winds had a small effect on the overall downwind dispersion for the present cases. However, there are likely to be meteorological conditions in which sub-hourly wind fields would significantly improve the transport and mixing of atmospheric contaminants. The current time period in Oklahoma was too short to fully evaluate the utility of subhourly wind fields in dispersion calculations.

\subsection{Dispersion Discussion}

The ambient daytime winds observed during JU2003 were rather simple, except on a few days. Therefore, interpolation of standard meteorological conditions in space and in time may be adequate for emergency-response dispersion calculations. At night, the formation of a low-level jet results in strong vertical wind shears that cannot be adequately represented by standard observations. If atmospheric contaminants are lofted into this jet, they could be transported large distances in a relatively short period 
of time. Measurements from either radar wind profilers or the NEXRAD wind retrievals are needed to obtain this information.

The simple meteorological conditions during the daytime resulted in dispersion patterns that were similar for wind fields based on the standard observations and those that included the NEXRAD wind retrievals. However, there were still subtle differences in the surface concentration magnitude and the plume footprint that would affect decisions regarding the actions taken by emergency responders. To get a better picture on how the NEXRAD wind retrievals would affect ADM predictions, additional tests are needed over a wider range of meteorological conditions. During periods with large spatial and time variations of the winds, such as those observed in regions of complex terrain and during rapidly propagating synoptic systems, the effect of including the NEXRAD wind retrievals on dispersion could be much larger than demonstrated in this study. 


\subsection{Computational Time}

An important consideration in determining whether NEXRAD wind retrievals should be computed routinely for emergency-response applications is the computational time needed to obtain the wind retrievals from the raw NEXRAD radial velocities. The information needs to be generated in near-real time for use in ADMs.

Computational requirements for the JU2003 simulations were recorded by NSSL and NCAR investigators, based on their respective computers. NSSL reported that 2DVar required 1 to 2 minutes to obtain one wind retrieval so that the total computational time was about 4 times as fast as the real-time data flow. NCAR reported that VDRAS required $\sim 5$ minutes to obtain one wind retrieval so that the total computational time was slightly faster than the real-time data flow. Differences in computer hardware and software would affect how those numbers should be compared. Therefore, PNNL obtained 2DVar and VDRAS so that the codes could be run using the same hardware and software.

The 2DVar and VDRAS codes were ported to a Redhat Linux cluster at PNNL that consisted of 2.4 GHz dual P4 processors with Myrinet interconnect and $3 \mathrm{~Gb}$ of memory per node. The 2DVar method was compiled with version 6.0 of the Portland compiler (pgf90), and VDRAS was compiled using Version 9.0 of the Intel compiler (ifort). We encountered problems when VDRAS was compiled with pgf90; but we expect differences in computer time not to be affected significantly by the different compilers. NEXRAD radial velocities from the KTLX radar for a 1-hour period between 23 UTC July 4 and 00 UTC July 5 were selected to compare the computational times. Table 6.1 shows the wall-clock times, the total time required to run the codes.

On average, a single wind retrieval from 2DVar was completed in a little over 2 minutes while a single wind retrieval from VDRAS was completed a little over 5 minutes. The variation in computational time for both systems did not vary significantly among the wind retrievals during this time period. The

difference in computational times is a direct result of the different variational approaches employed by the systems as described in Section 3. The combination of 2DVar's simpler approach and computing wind retrievals only along the elevation scans results in less computer time than VDRAS. 
Table 6.1. Computational Time Required to Execute 2DVAR and VDRAS for the JU2003 Configuration for a One Hour Period Staring at 2300 UTC July 4

\begin{tabular}{|c|c|c|c||}
\hline $\begin{array}{c}\text { KTLX Scan Time } \\
\text { (hours, minutes, } \\
\text { seconds) }\end{array}$ & $\begin{array}{c}\text { Wall-Clock Time for } \\
\text { 2DVar } \\
\text { (seconds) }\end{array}$ & $\begin{array}{c}\text { KTLX Scan Time } \\
\text { (hours, minutes, } \\
\text { seconds) }\end{array}$ & $\begin{array}{c}\text { Wall-Clock Time for } \\
\text { VDRAS } \\
\text { (seconds) }\end{array}$ \\
\hline 230254 & 128.67 & $230248^{\text {(a) }}$ & - \\
\hline 230841 & 127.78 & 230835 & 299.98 \\
\hline 231429 & 131.82 & 231423 & 310.48 \\
\hline 232016 & 125.11 & 232010 & 298.96 \\
\hline 232603 & 122.76 & 232558 & 308.57 \\
\hline 233151 & 121.45 & 233145 & 399.49 \\
\hline 233739 & 120.39 & 233733 & 299.62 \\
\hline 234346 & 119.03 & 234320 & 310.06 \\
\hline 234913 & 118.23 & 234908 & 299.30 \\
\hline 235501 & 116.72 & 235455 & 304.14 \\
\hline \multicolumn{2}{|c|}{ Average } & 123.20 & Average \\
\hline (a) Times not computed since 2 to 3 volumes needed to obtain retrieval. \\
\hline
\end{tabular}




\subsection{NEXRAD Data Availability}

An important consideration for using NEXRAD wind retrievals for ADMs is availability of the data. As described in Section 1.2, the range of the radar depends on the size, number-density, and physical properties of scattering material in the atmosphere. Therefore, the amount of radial-velocity data varies in time and among NEXRAD sites. We computed radial-velocity data availability at five WSR-88D radars near large metropolitan areas (that also represent different geophysical areas), including KSOX near Los Angeles, KMTX near Salt Lake City, KTLX near Oklahoma City, KBOX near Boston, and KLWX near Washington DC. Measurements from each of these radars over a 1-week period during each season (Table 7.1) have been sampled to check temporal variability of the data.

NSSL's QC package was applied to filter out the bad Doppler velocity measurements that include migrating bird contamination, aliasing problems, noisy data, etc. Then, the coverage (valid data/total possible observation) is estimated at the lowest five elevation angles for each volume scan. The number of possible observations is 331,200 (360 beams $\times 920$ range gates) along each elevation angle. Each range gate extends $\sim 250 \mathrm{~m}$ so that the maximum distance from the radar is $\sim 230 \mathrm{~km}$. Therefore a $30 \%$ coverage implies valid data that extend as far as $\sim 70 \mathrm{~km}$ from the radar. In most cases, the lowest five elevation angles are $0.5^{\circ}, 1.5^{\circ}, 2.5^{\circ}, 3.5^{\circ}$, and $4.5^{\circ}$ and depend on different volume-coverage patterns. Sometimes the elevation angles were $0.5^{\circ}, 1.5^{\circ}, 2.4^{\circ}, 3.4^{\circ}$, and $4.3^{\circ}$ or $0.5^{\circ}, 0.9^{\circ}, 1.3^{\circ}, 1.8^{\circ}$, and $2.4^{\circ}$.

Table 7.1. Sampling Period of NEXRAD Data to Compute Available Coverage from Five Radars

\begin{tabular}{||c|c|c|c|c|c||}
\hline \hline & Location & $\begin{array}{c}\text { Winter } \\
\mathbf{2 0 0 6}\end{array}$ & $\begin{array}{c}\text { Spring } \\
\mathbf{2 0 0 5}\end{array}$ & $\begin{array}{c}\text { Summer } \\
\mathbf{2 0 0 6}\end{array}$ & $\begin{array}{c}\text { Fall } \\
\mathbf{2 0 0 6}\end{array}$ \\
\hline KBOX & $\begin{array}{c}\text { Boston } \\
41^{\circ} 57^{\prime},-71^{\circ} 8\end{array}$ & Jan. 1-7 & May 20-26 & Aug. 20-26 & Oct. 20-26 \\
\hline KLWX & $\begin{array}{c}\text { Washington DC } \\
38^{\circ} 58^{\prime},-77^{\circ} 28^{\prime} \\
\text { Kalt Lake City } \\
41^{\circ} 15^{\prime},-112^{\circ} 26^{\prime}\end{array}$ & Jan. 1-7 & May 20-26 & Aug. 20-26 & Oct. 20-26 \\
\hline KTLX & $\begin{array}{c}\text { Oklahoma City } \\
35^{\circ} 19^{\prime},-97^{\circ} 16^{\prime}\end{array}$ & Jan. 1-7 & May 20-26 & Aug. 20-26 & Oct. 20-26 \\
\hline KSOX & $\begin{array}{c}\text { Los Angeles } \\
33^{\circ} 49^{\prime},-117^{\circ} 38^{\prime}\end{array}$ & Jan. 1-7 & May 20-26 $20-26$ & Oct. 20-26 \\
\hline \hline
\end{tabular}

Table 7.2 lists two types of data availability defined as $A_{\text {time }}$ and $A_{\text {space }} . A_{\text {time }}$ is the percentage of volume scans that contain valid radial velocities passing QC checks, and $\mathrm{A}_{\text {space }}$ is the percentage of the total possible 331,200 points along the lowest elevation angle with valid radial velocities. In general, the temporal availability of valid observations $\left(\mathrm{A}_{\text {time }}\right)$ averaged over the 1-week-long sampling periods was relatively high in spring, summer, and fall, but relatively low in winter. The KTLX radar (Oklahoma City) had the highest value of $\mathrm{A}_{\text {time }}$ of $73.9 \%$, representing 1325 of the 1792 volume scans containing valid radial velocities that passed the QC check during the summer sampling period. $A_{\text {space }}$ ranged from 11.2 to $36.3 \%$. The KSOX radar (Los Angeles) had the lowest values of $\mathrm{A}_{\text {time }}$ and $\mathrm{A}_{\text {space }}$ among the five radars, except during the winter period. 
Table 7.2. Availability of NEXRAD Data Expressed as Percentage of the Volume Scans Containing Valid Radial Velocities that Pass QC Checks During each Sampling Period $\left(\mathrm{A}_{\text {time }}\right)$ and Average Percentage of the Lowest Elevation Scan Containing Valid Radial Velocities During each Sampling Period $\left(\mathrm{A}_{\text {space }}\right)$

\begin{tabular}{|c|c|c|c|c|c|c|c|c|}
\hline & \multicolumn{2}{|c|}{ Winter } & \multicolumn{2}{|c|}{ Spring } & \multicolumn{2}{|c|}{ "Summer } & \multicolumn{2}{|c|}{ Fall } \\
\hline & $\begin{array}{c}\text { A }_{\text {time }} \\
\text { Volume } \\
(\%) \\
\end{array}$ & $\begin{array}{c}\text { A }_{\text {space }} \\
\text { Lowest } \\
\text { Elevation } \\
\text { Angle } \\
(\%) \\
\end{array}$ & $\begin{array}{c}\text { Volume } \\
\text { Coverage } \\
(\%) \\
\end{array}$ & $\begin{array}{c}\text { Lowest } \\
\text { Elevation } \\
\text { Angle } \\
\text { Coverage } \\
(\%) \\
\end{array}$ & \begin{tabular}{|c} 
Volume \\
Coverage \\
$(\%)$
\end{tabular} & $\begin{array}{c}\text { Lowest } \\
\text { Elevation } \\
\text { Angle } \\
\text { Coverage } \\
(\%) \\
\end{array}$ & $\begin{array}{c}\text { Volume } \\
\text { Coverage } \\
(\%) \\
\end{array}$ & $\begin{array}{c}\text { Lowest } \\
\text { Elevation } \\
\text { Angle } \\
\text { Coverage } \\
(\%) \\
\end{array}$ \\
\hline KBOX & 39.3 & 40.3 & 61.8 & 27.9 & 36.3 & 24.8 & 23.5 & 33.6 \\
\hline KLWX & 21.0 & 30.0 & 50.0 & 35.1 & 36.5 & 17.7 & 15.9 & 36.3 \\
\hline KMTX & 37.3 & 32.9 & 51.9 & 20.4 & 67.0 & 20.5 & 27.2 & 21.3 \\
\hline KTLX & 5.9 & 11.2 & 56.7 & 26.4 & 73.9 & 33.3 & 36.4 & 29.6 \\
\hline KSOX & 26.1 & 19.8 & 55.2 & 16.2 & 23.3 & 14.7 & 10.5 & 15.0 \\
\hline
\end{tabular}

The spatial data availability for each elevation angle among the five radars is shown in Figure 7.1 to Figure 7.3 to illustrate their variations during the day. In these figures, the average, maximum, and minimum values for all the scans during each hour are shown. The KBOX radar (Boston) has the highest availability among the five sites, with hourly-averaged values from 5 to $25 \%$ for most hours. On some days, the availability was as high as $60 \%$. All stations had zero availability for at least one scan during each hour during the 1-week sampling period. In general, the availability was highest at the lowest elevation angle and lowest at the highest elevation angle. The data from the lowest elevation angle is most useful for emergency response.

Lack of targets for the radar in clear-air is the main reason for lower availability in winter because insects are less active during the cold periods (Zhang et al. 2006). Observations at night during the spring and fall are more likely to be contaminated by bird migrations that produce strong echoes in the Doppler velocity coverage; therefore, the radial velocities for these cases cannot be used to retrieve air motion. For example, bird contamination is the reason for the low availability during the night at KTLX during spring and fall (Figure 7.2). The highest data coverage usually occurred in the presence of stratiform rain. This is one reason that KBOX had the highest available data. 

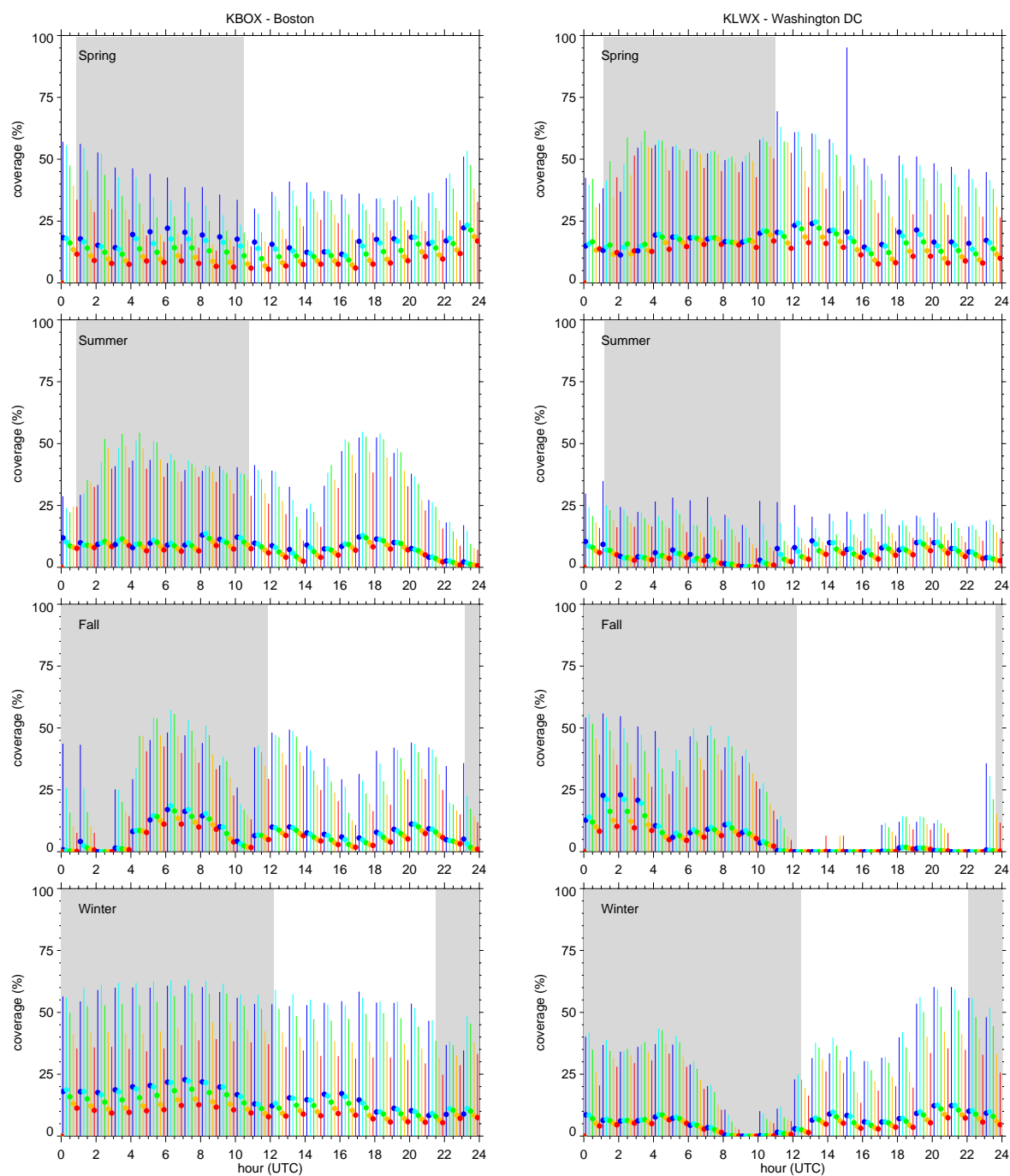

Figure 7.1. Availability of Radial Velocities from the KBOX and KLWX Radars as a Function of Time of Day and Season. Color denotes elevation angle where blue $=0.5^{\circ}$, light blue $=1.5^{\circ}$, green $=2.5^{\circ}$, orange $=3.5^{\circ}$, and red $=4.5^{\circ}$. Dots denote hourly-averaged quantities, and vertical lines denote the range of values during each hour. Gray shading denotes nighttime periods. 

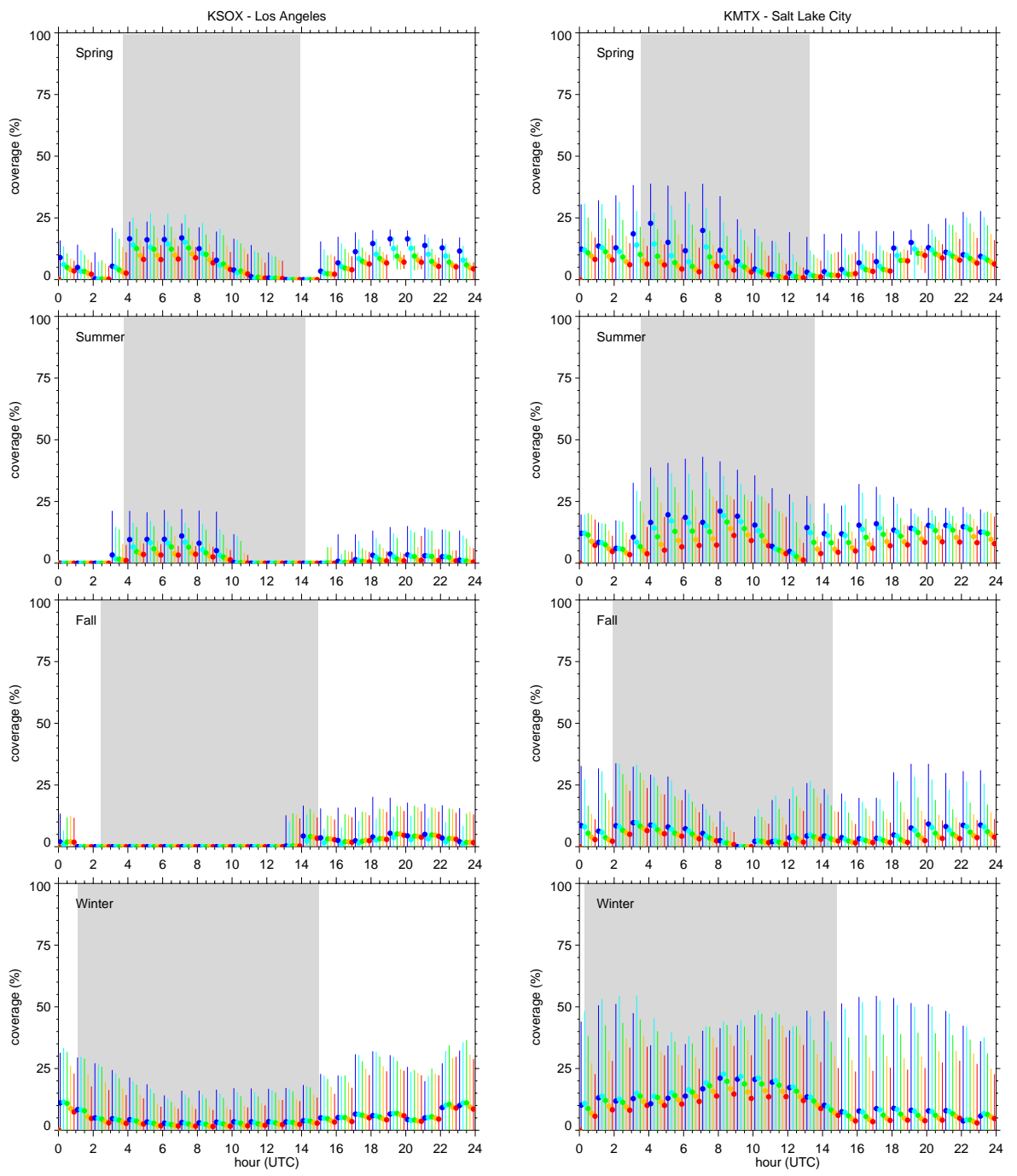

Figure 7.2. Same as Figure 7.1, Except for KSOX and KMTX Radars 


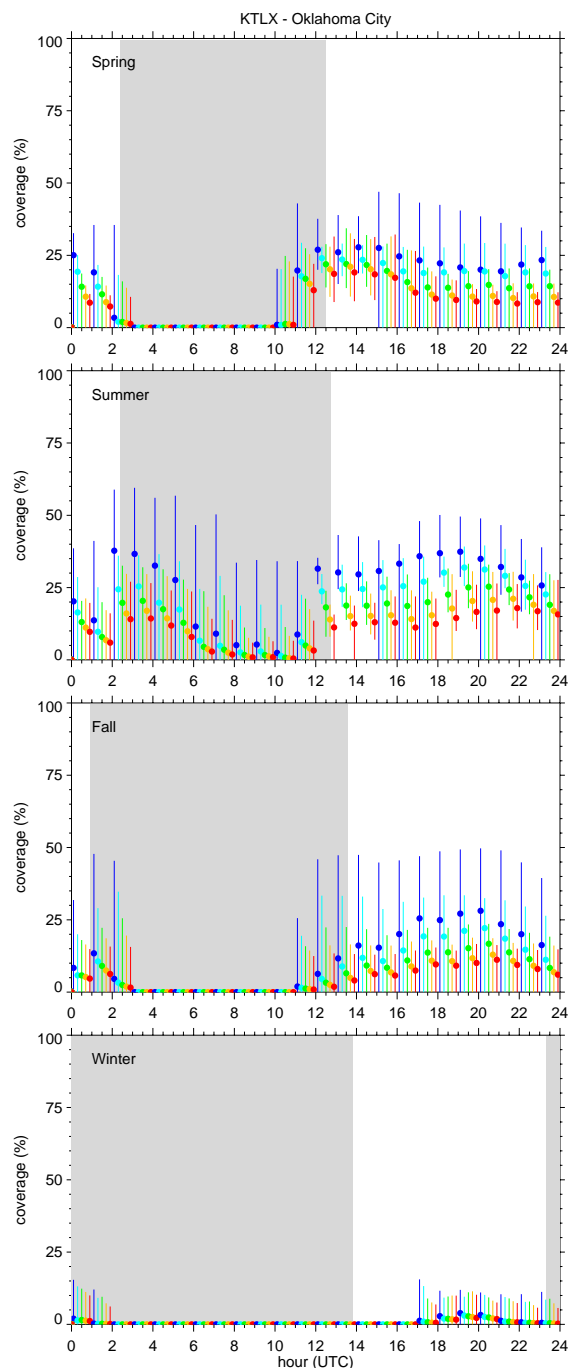

Figure 7.3. Same as Figure 7.1, Except for KTLX Radar 


\subsection{Recommendations}

In this section, we describe the rationale for the operational implementation of NEXRAD wind retrievals for use by ADMs, which is based on the advantages and disadvantages of the two available variational models. Our recommendation is based on the accuracy of the wind retrievals, computational requirements, and capabilities of each system. We also examine the costs of deploying additional instrumentation in urban areas to obtain spatial and temporal coverage of data that would be similar to the NEXRAD wind retrievals.

\subsection{Quantitative Considerations}

The most important question for evaluating 2DVAR and VDRAS is whether the wind retrievals provide data that are accurate enough to be used by ADMs. The Office of the Federal Coordinator for Meteorology defines standards for the accuracies of various operational meteorological measurements based on realistic instrument-performance expectations. The standards for the accuracy of wind-speed measurements are $\pm 1.5 \mathrm{~m} \mathrm{~s}^{-1}$ for radiosondes (FCM-H3-1997 1997), and $\pm 0.5 \mathrm{~m} \mathrm{~s}^{-1}$ for surface stations (FCM-H1-2005 2005). The accuracy of wind speeds measured by radar wind profilers is difficult to pin down because the profiler essentially measures a spatial average at a given height, and estimates of the accuracy vary widely, depending on the type of radar wind profiler and atmospheric conditions.

Nevertheless, it is reasonable to assume an accuracy of about $1 \mathrm{~m} \mathrm{~s}^{-1}$ for wind-speed measurements from a radar profiler (FCM-R14-1998 1998). The accuracy of the wind-profiler measurements, including their height dependence, must be taken into account in the evaluation of the 2DVar and VDRAS wind retrievals presented in Sections 4.5 and 4.6.

With this consideration, it is evident from Figure 4.4 and Figure 4.5 that the wind speeds from both 2DVar and VDRAS were often within a few meters per second of the radar wind-profiler data. Both systems reproduced the observed diurnal and multi-day trends in the wind speeds and direction. The periods in which large differences were produced $\left(>5 \mathrm{~m} \mathrm{~s}^{-1}\right)$ were usually relatively short. Within a few hundred meters of the surface, both algorithms had the tendency to over-estimate the wind speeds associated with the nocturnal low-level jet. Farther aloft from 1 to $2 \mathrm{~km}$ AGL, either the 2DVar or VDRAS wind retrieval would be closer to the profiler data. The statistical performance of both systems, listed in Tables C.3 and C.4, were similar as well. Statistically, 2DVar performed better at certain locations and altitudes, while VDRAS performed better at other locations and altitudes. Thus, neither system out-performed the other. The statistical measures suggest that the wind retrievals are less accurate than conventional instrumentation.

The results of the CALPUFF simulations indicated that the wind fields based on wind retrievals from 2DVar and VDRAS and the radar wind profiler data produced similar dispersion patterns. This suggests that the operational NEXRAD data could provide valuable information for a location that does not have any radar wind-profiler data or other routine wind-profile measurements aloft, even if it did contain somewhat larger uncertainties than other remote-sensing instruments.

For emergency-response applications, the uncertainties in the wind retrievals need to be weighed against having no other wind information aloft. Clearly, in most situations, the wind retrievals would provide better information aloft than simply interpolating standard rawinsonde information in time. 


\subsection{Operational Considerations}

As with any modeling system, the computational requirements of 2DVar and VDRAS depend on how they are configured. For this study, both systems were run with a 2-km grid spacing and approximately the same number of horizontal grid points. The 2DVar technique executed significantly faster than VDRAS for two reasons. First, the variational approach employed in 2DVAR is simpler than VDRAS. Second, VDRAS computations were performed on 14 vertical levels while 2DVar computations were performed along the five NEXRAD elevation scan angles.

For the grid configuration used in this study, both models could be run to produce output in near-real time using a single computer with a dual-processor. The number of grid points could be increased by a factor of three, and 2DVar could still be run in real-time. However, increasing the number of grid points would not be possible for VDRAS without also employing additional computational resources. The problem is compounded by the fact that VDRAS uses a prognostic model. Thus, a reduction in the grid spacing may also require a decrease in the time step to maintain numerical stability. This is not an issue with 2DVar.

The number of grid points employed in this study may be more than needed for regional dispersion applications. As described in Appendix D, we found that the CALMET and CALPUFF results were not significantly affected by decreasing the horizontal grid resolution of the NEXRAD wind retrievals. Thus, 2DVar could be executed even faster without having a significant negative impact on the dispersion predictions. It may also be possible to reduce the execution time of VDRAS by degrading the grid resolution; however, this could increase the influence of the boundary conditions in the interior of the domain (Chai et al. 2004). This is not an issue with 2DVar. In situations where the meteorology is more variable, such as for cities located along the coast or in areas of complex terrain, and when the synoptic and mesoscale conditions vary rapidly in time, it may be necessary to retain the full horizontal resolution.

The 2DVar method is basically a stand-alone system that only requires input from the NEXRAD radar. In contrast, VDRAS requires additional input to generate the wind retrievals, and the output is a combination of NEXRAD data and model predictions. For example, VDRAS depends upon vertical temperature profiles from another operational model. The code has been configured to employ default values if the external operational model output is unavailable. The VDRAS code has evolved over many years and has been used operationally for several applications; however, running the code operationally requires some effort to configure the model for a specific location. From an operational standpoint, the simplicity and computational efficiency in 2DVar is more desirable than VDRAS because it requires no such configuration for each location. On the other hand, 2DVar is a new code that has not been run operationally like VDRAS.

\subsection{System-Capability Considerations}

ADMs currently ingest meteorological measurements from surface monitoring stations, meteorological towers, rawinsondes, and radar wind profilers. The amount of meteorological information above the surface is limited at most locations. For example, rawinsondes are only available twice per day, and radar wind profilers are usually not located near urban areas. Gridded prognostic model output is often used to supplement the available meteorological measurements aloft; however, model predictions contain uncertainties. The operational production of NEXRAD wind retrievals would significantly increase the amount of upper-air information on winds over the United States, potentially decreasing the uncertainty in transport and mixing of atmospheric contaminants made by emergency-response ADMs. 
However, the output from 2DVar and VDRAS does not neatly fit the "measurement" (i.e., data at points) or "model” (i.e., data on a three-dimensional grid) input category types employed by ADMs.

While the output of 2DVar is produced on a regular horizontal grid, the vertical grid varies spatially as a result of the NEXRAD scans. Thus, the wind retrievals cannot be employed as a "model" input category by an ADM. Nor can they be considered as a large number of rawinsondes because other meteorological quantities (temperature, pressure, humidity) are not available. The 2DVar wind retrievals most closely resemble information that is produced by radar wind profilers. As we found with CALMET, the default number of profiles in ADMs are probably set to a relatively low number. ADMs would need to increase the default number of profiles to a few thousand. As shown in Appendix D, the significantly larger number of "measurement" wind profiles can increase the computational time needed to generate the diagnostic three-dimensional wind fields needed as input by dispersion models. Emergency-response personnel would need to decide what is an acceptable number of wind profiles to be employed or modify their codes to be more computationally efficient so that all the available information can be used.

Since VDRAS is based on a prognostic meteorological model, its output is similar to other meteorological models that drive ADMs. Therefore, it could be used directly by ADMs as a "model" input category type after the ADM has been configured to recognize the coordinate system and variables employed by VDRAS. A disadvantage of this approach is that users will likely wish to drive their ADM with the prognostic model output that they are currently using. But then users would not be able to take advantage of winds derived from NEXRAD radar data. Another disadvantage of this approach is that VDRAS could potentially produce large errors in the near-surface winds over regions of complex topography (much of the western United States) that is taken into account by existing prognostic models. Therefore, VDRAS output should be treated as a "measurement" input category as a large number of wind profiles, like 2DVAR output.

For these reasons, some modifications to existing ADMs are likely needed to accommodate NEXRAD wind retrievals. Because the wind retrievals contain more uncertainties than standard meteorological measurements, it would be prudent for ADMs to assign a weighting of the wind-retrieval data (either 2DVar or VDRAS) to be less than standard meteorological measurements. In addition, wind retrievals above $2 \mathrm{~km}$ AGL should not be used because the uncertainties are currently too high.

\subsection{Future Model Development}

Additional research could lead to improvements in 2DVar and VDRAS that would reduce the uncertainties in the wind retrievals. An area of research that needs to be addressed by both models is the capability to handle complex terrain applications. The 2DVar method makes assumptions regarding horizontal homogeneity and isotropy that would not be valid for regions where the terrain affects the nearsurface meteorology, such as in Los Angeles, San Francisco, Denver, and Phoenix. A number of assumptions in the four-dimensional variational technique in VDRAS, including the lack of topography, have been made in VDRAS so that it can be executed in near-real time. VDRAS, in its current form, is unlikely to produce realistic near-surface wind fields in areas of complex terrain without significant modifications. Either the governing equations need to be changed, or some sort of terrain-masking is needed.

One of the strengths of VDRAS is its capability to assimilate observations from a diverse array of instrumentation in a dynamically consistent manner, including the capability of assimilating observations from two or more Doppler radars. However, tests with VDRAS that also assimilated standard surface and 
rawinsonde measurements actually produced results that were worse near the surface than the version of VDRAS that employed only the NEXRAD radar data. Thus, additional research is needed how to best assimilate other operational measurements into the model to produce the best wind fields. By adding terrain and land-use variations, VDRAS could then be used to drive the "model" input category for ADMs.

The performance of 2DVar and VDRAS in this study was based on a limited number of upper-air observation sites, located primarily to the northwest of the KTLX radar; therefore, a more extensive study would be useful to evaluate the spatial variations in the wind retrievals surrounding a radar site. Larger spatial variations in the winds are expected over metropolitan areas located in complex terrain or along oceans or large lakes. This would require finding a location with a sufficient number of upper-air observations that are not available operationally. Other field campaigns that employ a large number of radar wind profilers may be suitable candidates for evaluating NEXRAD wind retrievals. Another approach is to perform an Observing System Simulation Experiment (OSSE) (e.g., Xue et al. 2006) in which a mesoscale model is used to generate a "true" atmosphere that varies in space and time. Radial velocities can then be extracted from the mesoscale model output to drive the retrieval schemes, and the OSSE framework would permit a full quantification of the skill of the retrieval schemes.

It would be also useful to test 2DVar and VDRAS using Terminal Doppler Weather Radar (TDWR). TDWR's are deployed at 44 airports across the country to provide wind-shear detection and precipitation information to air traffic controllers and supervisors. The range of this type of radar is less than the NEXRAD radar; however, the lower elevation angles permit wind retrievals at altitudes closer to the surface and more relevant for ADM applications. Therefore, operational versions of 2DVar and VDRAS in the future should employ both NEXRAD and TDWR data.

\subsection{Wind Retrieval Versus Additional Instrumentation Considerations}

Another consideration of whether to develop NEXRAD wind retrievals operationally is the cost associated with deploying additional meteorological instrumentation. Radar wind profilers or sodars could be deployed in urban areas or other areas of interest to provide the needed wind information aloft. Radar wind profilers cost $\sim \$ 200,000$ to $\$ 250,000$; therefore, deploying at least one in every major metropolitan area in the United States with a population greater than one million ( 50$)$ would cost between $\$ 7.5$ and $\$ 10$ million. Additional funding would be required to cover costs associated with maintaining the radar wind-profiler network and an archive of data.

The NEXRAD wind retrievals have the potential of providing horizontally varying wind fields that also contain vertical wind profiles comparable to radar wind profilers. The cost of obtaining the wind retrievals would include dedicating computing resources, maintaining the software, and managing a data archive. For a grid configuration employed by this study, the number of computers needed would be $\sim 47$ and $\sim 141$ for 2DVar and VDRAS, respectively. Assuming that each computer costs $\sim \$ 2,000$, the total computational resources needed for a nation-wide network would be approximately $\$ 94,000$ to $\$ 282,000$. Additional funding would be required for maintaining the computer cluster and an archive of data. These costs are significantly lower than deploying additional meteorological measurements. The costs are also relatively low considering the potential benefit of providing meteorological information needed to more accurately predict the transport and diffusion of atmospheric contaminates during an emergency. It may also be prudent to deploy radar wind profilers for a small number of cities and/or where there are critical gaps in NEXRAD coverage over a metropolitan area. 


\subsection{Recommended Implementation}

Despite being a relatively new algorithm, we propose that 2DVar be implemented operationally to produce routine wind fields associated with NEXRAD radar data. We base our decision on the fact that the wind retrievals from the technique in 2DVar can be considered a type of observation that is similar to other types of data (e.g., radar wind profiler). The derived winds are produced at the same locations as the radial velocities observed along the NEXRAD elevation scans. This form of the wind retrieval complements the other data sources available to ADM users. Its simplicity also makes it potentially easier to implement computationally.

VDRAS is a more sophisticated model and is therefore more computationally expensive. Despite the complexity of the four-dimensional variational approach, the wind retrievals were not significantly different than 2DVar. Some effort would also be required to set up VDRAS for each location. Its complexity also requires a careful consideration on how it is configured so that it can be run in real time. Nevertheless, we recommend that additional research be performed to refine the system so that it can be used several years in the future. VDRAS could potentially provide more accurate wind retrievals by tuning the model parameters, accounting for terrain variations, and ingesting other types of meteorological data.

The following section describes the steps that should be taken next to develop an operational NEXRAD wind-retrieval capability designed for ADMs. 


\subsection{Path Forward}

We propose a phased approach of making NEXRAD wind retrievals available in real time for ADMs that is summarized as:

Phase 1: Development of the NEXRAD data center

1) identify organization responsible for managing the NEXRAD data center

2) obtain dedicated computer cluster to produce NEXRAD wind retrievals

3) establish links to real-time NEXRAD radial-velocity products

4) develop a detailed budget

Phase 2: Evaluation of an operational beta version of 2DVar

1) run 2Dvar operationally for select radars and archive the wind retrievals

2) evaluate 2DVar over longer period of time

3) consult with ADM developers on the type of wind-retrieval products and their format

4) develop updated versions of 2DVar and compare performance with previous versions

Phase 3: Implementation of 2DVar operationally

1) run 2DVar operationally for all NEXRAD radars

2) make wind retrievals available in real-time as part of the standard measurement network

3) archive NEXRAD wind-retrieval products

Phase 4: Maintenance of operational NEXRAD wind-retrieval products

1) monitor wind-retrieval products to verify their availability in near real-time

2) ongoing development of 2DVar and implementation of updated versions if needed

Phase 5: Further development of VDRAS

1) incorporate effects of complex terrain into VDRAS

2) evaluate VDRAS with terrain effects

Phase 6: Evaluation of an operational beta version of VDRAS

1) run VDRAS operationally for select radars and archive the wind retrievals

2) evaluate VDRAS over longer period of time

3) adapt VDRAS output to be consistent with 2DVar wind-retrieval products

4) develop updated versions of VDRAS and compare performance with previous versions

Phase 7: Implementation of VDRAS operationally

1) run VDRAS operationally for all NEXRAD radars

2) make wind retrievals available in real-time as part of the standard measurement network

3) archive NEXRAD wind-retrieval products

These steps are described in more detail in the following sections. Phases 1 to 4 are needed at a minimum to develop NEXRAD wind retrieval products, whereas Phases 5 to 7 are optional. Since 2DVar and VDRAS are complementary approaches, we strongly recommend that Phases 5 to 7 be implemented to have a more robust NEXRAD data center for long-term use. Phases 5 to 7 could be performed in 
parallel to Phases 1 to 4; however, we recommend that 2DVar be run operationally for some time before VDRAS is implemented operationally.

\subsection{Phase 1: Development of the NEXRAD Data Center}

The NEXRAD Data Center would consist of a dedicated Linux computer cluster that has access to real-time radar velocity data, which are required to generate wind retrievals using either 2DVar or VDRAS. One approach in designing the computer cluster is to obtain the minimum amount of computer resources needed to produce wind retrievals in near real-time. In this approach, one processor could handle three to four radar sites for 2DVAR and one radar site for VDRAS. A minimum of 48 processors for 2DVar and 160 processors for VDRAS would be needed; however, this is an upper estimate since processor speeds continue to increase. This estimate includes a few extra processors that are desired in an operational environment to replace processors that fail temporarily. Another approach is to dedicate a single processor for each radar so that $\sim 160$ processors would be needed for either 2DVar or VDRAS. Although this approach increases the one-time hardware cost, dedicating a processor for each radar site would minimize potential computational bottlenecks so that problems with one radar site would not interfere with obtaining wind retrievals from other radar sites.

Software needed to create the wind retrievals would reside on the NEXRAD Data Center computer cluster. License agreements, or other arrangements, with NSSL and NCAR would have to be arranged for permission to use the code on this cluster. Code-management software would be necessary to identify which versions of the code are being used and document any updates to the code. Other necessary software would include one or more Fortran compilers. Execution scripts would need to be developed to execute 2DVar and VDRAS operationally.

The amount of storage needed to archive the wind retrievals on the NEXRAD Data Center computer cluster would be determined during this phase of development. The amount of storage would depend on the needs of ADM users. For emergency-response applications, storage would only be needed for recent wind retrievals (up to a week-long period). Older wind retrievals could be archived in a long-term storage facility, such as NOAA's NCDC. The capability to store a large quantity of meteorological data is another reason NOAA would be the ideal partner in developing operational NEXRAD wind-retrieval products. The costs associated with storage would likely be much smaller than the rest of the hardware costs associated with the computer cluster.

An organization that would be responsible for managing the NEXRAD Data Center would be identified during this phase. Since NOAA also provides a wide variety of meteorological products (including other NEXRAD products) available in real time, NOAA would be the logical choice for leading the effort to make NEXRAD wind retrievals routinely available. NOAA is part of the Interagency Modeling and Atmospheric Assessment Center (IMAAC) consortium; therefore, it should have an interest in contributing to the development of meteorological products needed by homeland security applications. During Phase 1, NOAA program directors need to be informed about the need of NEXRAD wind retrievals for emergency-response ADMs. The relative role of DHS and NOAA in funding the implementation of the NEXRAD Data Center, as well as other phases proposed here, would need to be worked out. 


\subsection{Phase 2: Evaluation of an Operational Beta Version of 2DVar}

In this study, we have evaluated wind retrievals produced by 2DVar for one NEXRAD radar over a 2-week period. Before wind retrievals are produced operationally for the nationwide NEXRAD radar network, it would be desirable to run 2DVar operationally for a subset of radars ( $\sim 20)$ over a relatively long period of time ( months). In this way, its performance for a wider range of meteorological conditions and locations would be determined, and any problems associated with ingesting NEXRAD radial velocities and executing 2DVar operationally would be resolved before going into full production.

As 2DVar is run operationally for a limited number of radars, it would be useful for NSSL developers to refine the code. An example of research that could lead to an improved code includes modifications to the background error covariance to account for inhomogeneity and anisotropy of the velocity statistics due to terrain. Another example of needed research is testing the method of successive corrections that may enhance the computational efficiency and increase the flexibility of the variational approach to produce three-dimensional winds easily on any grid system. Assumptions associated with filtering out data above $2 \mathrm{~km}$ AGL also need to be revisited. Additional evaluations that employ previous field campaign data could be performed at this time.

During this phase, updated versions of 2DVar could be evaluated by comparing their performance with the preliminary operational version. We propose that updates to the code be implemented in a manner similar to National Aeronautics and Space Administration (NASA) satellite products and named as v0, v1, v2, etc. When NASA develops retrievals from its satellite measurements, some degree of uncertainty is expected. As research is conducted that compares the satellite measurements with other independent data sources, newer products are developed with smaller uncertainties that are also better understood.

ADM developers need to be advised of the new wind-retrieval products that will become available operationally. Current ADMs may not be set up to easily ingest and utilize NEXRAD wind-retrieval products; therefore, ADM codes may need to be modified to fully utilize the wind retrievals. The output format of 2DVar and VDRAS will be decided based on the needs of the ADM developers. We also recommend that a series of products be produced, including wind retrievals for each volume scan at approximately every 6 min (as in this study) as well as wind retrievals that are based on 15-min and 1-h averages of several volume scans. The 15-min and 1-h averages would be more consistent with other types of meteorological measurements currently ingested by ADMs. Another parameter to be defined in consultation with ADM developers is a relative weight applied to the NEXRAD wind retrievals versus data obtained from traditional instrumentation. The specific products will depend on the needs of the ADM developers.

The products will be put in the operational meteorological data stream so that ADM developers will have time to test and evaluate the wind retrievals in their models during the beta operational system for Phase 2. Feedback from the ADM developers will be used to refine the NEXRAD wind-retrieval products for the fully operational version in the next phase.

\subsection{Phase 3: Implementation of 2DVar Operationally}

After 2DVar has been run operationally for a small number of radars, and additional evaluations of its performance have been completed, a fully-operationally version will be defined. The operational scripts that execute 2DVar on the Data Center computer cluster will be modified to produce wind-retrieval 
products from all of the NEXRAD radars across the United States. These products will be made available as part of the standard meteorological data stream.

The additional number of radars will increase the computational requirements by fully utilizing the processors on the computer cluster. Therefore, a short period of time will be needed at the beginning of the fully operational capability to make sure that the system runs smoothly. The need for additional computer resources will be determined at this time. The additional number of radar wind-retrieval products will also increase the local storage needed for real-time use as well as the remote storage associated with long-term archival of the wind-retrieval products.

\subsection{Phase 4: Maintenance of Operational NEXRAD Wind-Retrieval Products}

After the wind-retrieval products have become fully operational, some monitoring will be necessary to verify availability of the data for all sites. We expect this to consist of computer-support personnel for hardware and software issues associated with the NEXRAD Data Center. The organization that manages the NEXRAD Data Center also needs personnel that become familiar with all aspects of the 2DVar code. Both computational and scientific support for the wind retrievals is needed; however, these duties would likely only be part-time activities. One approach for the scientific support is to provide the original developers support for long-term issues associated with 2DVar.

Since computer clusters become obsolete over time, newer hardware and software will be needed after $\sim 5$ years to replace the original computer cluster in the NEXRAD Data Center and enable long-term use of the wind-retrieval products. During this phase, the contributors to the NEXRAD Data Center will need to decide whether additional research support is needed to improve the performance of 2DVar.

\subsection{Phase 5: Further Development of VDRAS}

The relatively simple variational approach employed by 2DVAR results in output that can be considered to be a derived-data product. In contrast, VDRAS is a prognostic mesoscale model that employs a more complex four-dimensional variational approach so that the forecasts are constrained by the meteorological measurements. For this reason, it is probably more appropriate to use 2DVar wind retrievals as a "measurement" source that drives ADMs and to use VDRAS output as a three-dimensional "model” source that drives ADMs.

The performance of VDRAS in the present study was similar to 2DVar; therefore, it is not apparent that the increased numerical complexity, higher computational cost, and additional effort associated with setting up the code for specific locations is warranted. However, the capabilities of the code make it more flexible than 2DVar and suggests that it could provide more accurate wind fields and a wider range of products in the future. Additional research is desirable to improve the performance of VDRAS before it is implemented within the framework of the NEXRAD Data Center to operationally produce threedimensional wind fields for all of the NEXRAD radars sites. Areas of research that are needed include 1) terrain effects, 2) treatment of surface observations, 3) multiple radars, and 4) down-scaling of mesoscale wind fields to urban scales.

Two of the assumptions employed by VDRAS to make the code run quickly are the flat lower boundary and uniform surface characteristics. However, many large metropolitan areas are located in regions of complex terrain (e.g., Salt Lake City, Phoenix) or adjacent to the ocean (e.g., New York, 
Houston) or both (e.g., Los Angeles, San Francisco). The dynamic and thermodynamic effects of terrain produce slope flows, valley circulations, mountain waves, and other types of circulations that complicate the near-surface wind fields. Sea/land breeze circulations are produced as a result of differential heating of the land and water surfaces. All of these effects are currently neglected in the prognostic model of VDRAS, but they can be included to some extent if there are sufficient meteorological measurements that can be assimilated. Some research is needed to determine whether variable terrain and land-use can be added to the model without significantly increasing the overall computational time. As with 2DVAR, other assumptions specific to the treatment of NEXRAD radial velocities also needs to be examined.

Assimilating surface measurements is especially important for emergency-response ADM applications because the attitude of the NEXRAD elevation scans becomes higher above the surface farther away from the radar. VDRAS has the potential to provide near-surface winds that cannot be provided by 2DVar, except very close to the radar site. VDRAS runs that included surface measurements, however, significantly increased the errors in the wind fields aloft. Additional work is needed to properly constrain the model with winds both at the surface and aloft.

Because of the simple variational approach employed by 2DVar, it only uses radial velocities from one NEXRAD radar site. NEXRAD scans from multiple radars often overlap. VDRAS has the capability to ingest data from multiple radars so that extra information could lead to more accurate threedimensional wind fields. However, as indicated in Figure 1.1, the lowest elevation scans do not begin to overlap with one another until $\sim 100 \mathrm{~km}$ from the radar at some locations. At this distance, the elevation scan is above $1 \mathrm{~km}$ AGL. Despite the altitude of the overlapping scans, the improvement in the upperlevel winds may indirectly improve the near-surface winds.

Obtaining high-resolution wind fields within the urban canopy at street level is needed by some ADM applications. The winds produced by VDRAS can be considered roof-top winds that may not be the most useful for ADM calculations at street level. One area of research is to use the three-dimensional VDRAS wind fields to drive the QUICUrb model (Gowardhan et al. 2006) that computes building-aware winds. The operational Pentagon Shield system (Warner 2006) employs QUICUrb and its associated ADM, QUICPlume, in this way. Coupling VDRAS and QUICUrb could provide more complete threedimensional wind fields both at street level and above the urban canopy so that tracking the dispersion of atmospheric contaminates from their source to downwind locations would be treated more realistically and more accurately. A preliminary demonstration of such a coupling has already been done for Pentagon Shield. The computational requirements as well as the performance of such a coupling of models for more generic urban settings still need to be evaluated.

\subsection{Phase 6: Evaluation of an Operational Beta Version of VDRAS}

The tasks associated with this phase would be very similar to Phase 2, except for VDRAS. It should be performed only after Phase 2 has been completed. The updated version of VDRAS produced during Phase 5 should be run for the same period and by radars employed by 2DVAR during Phase 2 so that the performance of 2DVar and VDRAS can be directly compared again. Since VDRAS is more sophisticated and requires more computational resources that 2DVar, the benefits of its use need to be demonstrated. 


\subsection{Phase 7: Implementation of VDRAS Operationally}

The tasks associated with this phase would be very similar to Phase 3, except for VDRAS. We anticipate that this version may not be made available operationally a year or more after 2DVar has been running operationally. 


\subsection{References}

Allwine KJ, MJ Leach, LW Stockham, JH Shinn, RP Hosker, JF Bowers, and J Pace. 2004. "Overview of Joint Urban 2003 - An Atmospheric Dispersion Study in Oklahoma City.” Preprints, Symposium on Planning, Nowcasting and Forecasting in the Urban Zone. American Meteorological Society, January 11-15, 2004, Seattle, WA.

Brown RA, VT Wood, and D Sirmans. 2000. "Improved WSR-88D scanning strategies for convective storms.” Wea. Forecasting 15:208-220.

Brown RA, and JM Lewis. 2005. “Path to NEXRAD.” Bull. Amer. Meteor. Soc. 86:1459-1470.

Browning KA, and R Wexler. 1968. "The determination of kinematic properties of a wind field using Doppler radar.” J. Appl. Meteor. 7:105-113.

Chai T, CL Lin, and RK Newsom. 2004. "Retrieval of microscale flow structures from high resolution Doppler Lidar using an adjoint model.” J. Atmos. Sci. 61:1500-1520.

Chang JC, P Franzese, K Chayantrakom, and SR Hanna. 2003. "Evaluations of CALPUFF, HPAC, and VLSTRACK with two mesoscale field datasets.” J. Appl. Meteor. 42:453-466.

Chang JC, SR Hanna, Z Boybeyi, and P Franzese. 2005. "Use of Salt Lake City URBAN 2000 field data to evaluate the Urban Hazard Prediction Assessment Capability (HPAC) dispersion model.” J. Appl. Meteor. 44:485-501.

Crook NA, and J Sun. 2004. "Analysis and Forecasting of the Low-Level Wind During the Sydney 2000 Forecast Demonstration Project.” Wea. Forecasting 19:151-167.

Crum T, and RL Alberty. 1993. “The WSR-88D and the WSR-88D Operational Support Facility.” Bull. Amer. Meteor. Soc. 74:1669-1687.

Crum TD, RE Saffle, and JW Wilson. 1998. "An update on the NEXRAD program and future WSR88D support to Operations.” Wea. Forecasting 13:253-262.

Daley R. 1991. Atmospheric Data Analysis. Cambridge University Press, New York, NY.

Defense Threat Reduction Agency (DTRA). 2001. “The HPAC users's guide,” Version 4.0.3. Prepared for DTRA, Contract DSWA01-98-C-0110, by Science Applications International Corporation, Rep. HPAC-UGUIDE-02-U-RAC0.

FCM-H1-2005. 2005. "Federal Meteorological Handbook No. 1 - Surface Weather Observations and Reports.” Office of the Federal Coordinator for Meteorology, Silver Spring, MD.

FCM-H3-1997. 1997. "Federal Meteorological Handbook No.3 - Rawinsonde and Pibal Observations.” Office of the Federal Coordinator for Meteorology, Silver Spring, MD.

FCM-R14-1998. 1998. “U.S. Wind Profilers: A Review.” Office of the Federal Coordinator for Meteorology Services and Supporting Research, Silver Spring, MD. 
Gong J, L Wang, and Q Xu. 2003. “A three-step dealiasing method for Doppler velocity data quality control.” J. Atmos. Oceanic Technol. 20:1738-1748.

Gowardhan A, M Brown, M Williams, and E Pardyjak. 2006. "Evaluation of the QUIC urban dispersion model using the Salt Lake City Urban 2000 tracer experiment data.” Sixth Symposium on the Urban Environment, Atlanta, GA, Amer. Meteor. Soc., J6.3.

Liu S, Q Xu, and P Zhang. 2005. "Quality control of Doppler velocities contaminated by migrating birds. Part II: Bayes identification and probability tests.” J. Atmos. Oceanic Technol. 22:1114-1121.

Liu S, P Zhang, L Wang, J Gong, and Q Xu. 2003. "Problems and solutions in real-time Doppler wind retrievals.” Preprints, 31th Conference on Radar Meteorology, 6-12 August 2003, Seattle, WA, Amer. Meteor. Soc., 308-309.

Qiu C, and Q Xu. 1992. “A simple adjoint method of wind analysis for single-Doppler data.” J. Atmos. \& Oceanic Technology 9:588-598.

Rishel JP, FC Rutz, WJ Shaw, and KJ Allwine. 2007. Transforming CALMET Gridded Meteorological Fields for Use in HPAC's SCIPUFF Dispersion Model. In press, Pacific Northwest National Laboratory, Richland, WA.

Scire JS, FR Robe, ME Fernau, EM Insley, and RJ Yamartino. 1997. “A user’s guide for the CALMET meteorological model (Version 5.).” Earth Tech. Inc., Concord, MA.

Scire JS, DG Strimaitis, and RJ Yamartino. 2000. “A user's guide for the CALPUFF dispersion model (Version 5.).” Earth Tech. Inc., Concord, MA.

Sykes RI, SF Parker, DS Henn, and WS Lewellen. 1993. "Numerical simulation of ANATEX tracer data using a turbulence closure model for long-range dispersion.” J. Appl. Met. 32:929-947.

Sykes RI, SF Parker, and DS Henn. 2004. “SCIPUFF Version 2.2 Technical Documentation.” Titan/ARAP Report No. 729.

Sun J, D Flicker, and DK Lilly. 1991. "Recovery of three-dimensional wind and temperature from simulated single-Doppler radar data.” J. Atmos. Sci. 48:876-890.

Sun J, and NA Crook. 1994. "Wind and thermodynamic retrieval from single-Doppler measurements of a gust front observed during Phoenix-II.” Mon. Wea. Rev. 122:1075-1091.

Sun J, and NA Crook. 1997. "Dynamical and microphysical retrieval from Doppler radar observations using a cloud model and its adjoint: Part I. model development and simulated data experiments.”

J. Atmos. Sci. 54:1642-1661.

Sun J, and NA Crook. 1998. "Dynamical and microphysical retrieval from Doppler radar observations using a cloud model and its adjoint: Part II.” Retrieval experiments of an observed Florida convective storm. J. Atmos. Sci. 55:835-852.

Sun J, and NA Crook. 2001. "Real-time low-level wind and temperature analysis using single WSR-88D data.” Wea. Forecasting 16:117-132. 
Warner S, N Platt, and JF Heagy. 2004. "Comparisons of transport and dispersion model predictions of the URBAN 2000 field experiment.” J. Appl. Meteor. 43:829-46.

Warner TT. 2006. “An operational building-scale urban forecasting system: Pentagon Shield.” Sixth Symposium on the Urban Environment, Atlanta, GA, Amer. Meteor. Soc., J4.2.

Xu Q, H Gu, and C Qiu. 2001a. "Simple adjoint retrievals of wet-microburst winds and gustfront winds from single-Doppler radar data.” J. Appl. Meteor. 40:1485-1499.

Xu Q, H Gu, and S Yang. 2001b. "Simple adjoint method for three-dimensional wind retrievals from single-Doppler radar.” Quart. J. Roy. Meteor. Soc. 127:1053-1067.

Xu Q, C Qiu, H Gu, and J Yu. 1995. “Simple adjoint retrievals of microburst winds from single-Doppler radar data.” Mon. Wea. Rev. 123:1822-1833.

Xu Q, S Liu, and M Xue. 2007. "Background error covariance functions for vector wind analyses using Doppler radar radial-velocity observations.” In press, Q. J. R. Meteorol. Soc.

Xue M, M Tong, and KK Droegemeier. 2006. “An OSSE framework based on the ensemble root Kalman filter for evaluating the impact of data from radar networks on thunderstorm analysis and forecasting.” J. Atmos. Oceanic Technol. 23:46-66.

Zhang P, S Liu, and Q Xu. 2005. "Quality control of Doppler velocities contaminated by migrating birds. Part I: Feature extraction and quality control parameters.” J. Atmos. Oceanic Technol. 22:1105-1113.

Zhang P, A Ryzhkov, and D Zrnic. 2006. "Polarimetric prototype of the WSR-88D radar observations of insects and birds." Preprints, 12th Conference on Aviation, Range, and Aerospace Meteorology, Atlanta, GA, Amer. Meteor. Soc., CD-ROM, P6.4. 

Appendix A

Additional Description of VDRAS 


\section{Appendix A: Additional Description of VDRAS}

The most salient features of the forward model include the basic advection, diffusion, pressure gradient, and buoyancy forcing terms. The pressure Poisson equation is solved using the Harlow-Welch scheme to suppress divergence. Diffusion terms use prescribed constants for the coefficients of eddy viscosity and heat diffusivity. The forward model is integrated using a second-order Adams-Bashforth scheme on a staggered Cartesian grid. At the top and bottom of the domain, the vertical velocity and the vertical derivatives of the horizontal velocities are set to zero. The perturbation potential temperature gradient is set to zero at the top and bottom of the domain. The lower boundary of the domain is assumed to be flat. Thus, terrain effects are not incorporated into VDRAS.

The optimal fit between the output of the forward model and the observations is achieved by minimizing a cost function using a conjugate gradient algorithm. When using only radial velocity information from a single Doppler radar, the cost function takes the following form:

$$
J=\sum \frac{\left(u_{r}-u_{r}^{o b s}\right)^{2}}{\sigma^{2}}+J_{b}+J_{p}
$$

The first term of Eq. (A.1) represents the misfit between the observed radial velocities from the radar, $u_{r}$ obs , and the radial component of the velocity field produced by the forward model, $u_{r}$. The summation is carried out over the model domain and the assimilation time. The observational error is denoted by $\sigma$. The background term, $J_{b}$, provides a measure of the misfit between the model output and the prescribed background fields. Background fields are typically horizontally homogeneous profiles of the mean potential temperature and the mean winds. In this study, the background fields are also used as the first guess. The penalty term, $J_{p}$, is used to control the degree of spatial and temporal smoothness in the model output.

The crux of the wind-retrieval method in VDRAS involves minimizing the cost function (Eq. A.1), subject to the constraint that the retrieved velocity field be a solution to the forward model. This minimization process is computationally intensive. For example, for a modestly sized simulation using $50 \times 50 \times 10$ grid points, there will be approximately $4 \times 50 \times 50 \times 10=100,000$ control variables to adjust, corresponding to the initial temperature and velocity at each node of the grid. VDRAS uses the full adjoint of the forward model to efficiently compute the gradient of the cost function with respect to the initial state of the forward model.

The adjoint is a powerful tool that can be used to determine the sensitivity of a model's output to changes in its input parameters (Talagrand and Courtier 1987; Talagrand 1997; Thacker 1988; Errico 1997). In the current version of VDRAS, the adjoint of the forward is used to determine the change in the cost function, which depends on the model output, with respect to changes in the initial state of the forward model. The adjoint can be represented by a system of equations that are obtained by converting the constrained minimization problem into an unconstrained problem through the use of the Lagrange function. The Lagrangian, $L$, is constructed by appending the model equations to the cost function. The minimum of $J$ is found by determining the stationary points of $L$ with respect to the forward model's prognostic and diagnostic variables.

The minimization of the cost function requires first integrating the forward model over the assimilation time. The adjoint equations are then integrated backwards in time from the end to the start of 
the assimilation time. The result of the adjoint integration is used to determine the gradient of the cost function with respect to every velocity and temperature variable at the initial time at each grid point in the domain. This gradient information and a conjugate gradient algorithm are used to determine a "downgradient" search direction. The conjugate gradient algorithm adds the appropriate perturbations to each of the initial velocity and temperature variables, and the whole process repeats until the change in cost function, from one iteration to the next, falls below some preset tolerance.

VDRAS was run at NCAR on a dual processor (Intel 3.06GHz Xeon) Linux workstation running Debian/Sarge with $4 \mathrm{~Gb}$ of RAM. Typical execution time for a VDRAS retrieval was 5 minutes; however, the execution time varied by as much as 2 minutes in different cycles based on the amount of input data. The addition of synoptic information resulted in negligible increases in execution time.

\section{References}

Errico RM. 1997. “What is an adjoint model?” Bull. Amer. Meteor. Soc. 78:2577-2591.

Talagrand O. 1997. “Assimilation of observations, an introduction.” J. Meteorol. Soc. Japan 75:191-209.

Talagrand O, and P Courtier. 1987. "Variational assimilation of meteorological observations with the adjoint vorticity equation. I: Theory.” Q. J. R. Meteor. Soc. 113:1311-1328.

Thacker WC. 1988. "Fitting models to inadequate data by enforcing spatial and temporal smoothness." J. Geophys. Res. 93:10655-10665. 
Appendix B

Additional Description of 2DVar 


\section{Appendix B: Additional Description of 2DVar}

Unlike 4DVar, the 2DVar technique does not assume a specific deterministic model for the flow. Instead, the 2DVar method uses estimates of the background error covariance functions for the radial and azimuthal components of the velocity field, relative to the radar. In particular, the background error covariance is formulated first as a $2 \times 2$ tensor function for the horizontal vector velocity in the Cartesian coordinates. This tensor function is assumed to be locally homogeneous and isotropic in the horizontal, so its canonical form is diagonal and depends only on the horizontal distance between the two correlated points. The two diagonal terms of the canonical form are modeled by Gaussian functions (Xu and Gong 2003). The above covariance tensor function is then transformed into (non-isotropic) background error covariance functions for the radial and azimuthal components of the velocity field in the polar coordinates on each conical surface of the radar scans. These transformed covariance functions can be readily used by the 2DVar.

The background error covariances are used in a cost function, and the cost function is minimized with respect to perturbations (from the background) in the radial and azimuthal components of the velocity field. The analysis is performed on the conical surfaces of the radar scans. Minimizing the cost function results in the following optimal solutions for the radial, $u_{r}$, and azimuthal, $u_{\phi}$, velocity components:

$$
u_{r}(\mathbf{r})=u_{r b}(\mathbf{r})+\sum_{n=1}^{N} C_{r r}\left(\mathbf{r}, \mathbf{r}_{n}\right) z_{n}
$$

and

$$
u_{\phi}(\mathbf{r})=u_{\phi b}(\mathbf{r})+\sum_{n=1}^{N} C_{\phi r}\left(\mathbf{r}, \mathbf{r}_{n}\right) z_{n}
$$

where $\quad u_{r b}=$ background radial component

$u_{\phi b}=$ the background azimuthal component

$C_{r r}\left(\mathbf{r}, \mathbf{r}_{\mathrm{n}}\right)=$ covariance between radial velocities at points $\mathbf{r}$ and $\mathbf{r}_{\mathrm{n}}$

$C_{\phi r}\left(\mathbf{r}, \mathbf{r}_{\mathrm{n}}\right)=$ covariance between radial and azimuthal velocities at points $\mathbf{r}$ and $\mathbf{r}_{\mathrm{n}}$.

Specific expressions for $C_{r r}\left(\mathbf{r}, \mathbf{r}_{\mathrm{n}}\right)$ and $C_{\phi r}\left(\mathbf{r}, \mathbf{r}_{\mathrm{n}}\right)$ are given in (Xu et al. 2007). The radial and azimuthal components of the background field $\left(u_{r b}, u_{\phi b}\right)$ are determined from a VAD analysis. The summations in Equations (B.1) and (B.2) are carried out over all the observations in the scan ( $N$ observations). The vector $\mathbf{z}$ is given by the solution to the following linear system:

$$
\left(\mathbf{C}+\sigma_{\text {obs }}^{2} \mathbf{I}\right) \mathbf{z}=\mathbf{d}
$$

where $\sigma_{o b s}=$ radial velocity observational error

$\mathbf{I}=$ identity matrix

$\mathbf{d}=$ so-called observation innovation vector

$\mathbf{C}=N \times N$ matrix whose elements are given by $C_{n m}=C_{r r}\left(\mathbf{r}_{\mathrm{m}}, \mathbf{r}_{\mathrm{n}}\right)$. 
The observation innovation vector represents the difference between the observed radial velocity and the radial component of the background velocity field. The radial velocity errors are assumed to be normally distributed, unbiased, and spatially uncorrelated. Equations (1) and (2), together with Eq. (3) are used to

construct optimal estimates of the radial and azimuthal velocity components over the surface of the radar conical scan.

\section{Reference}

Xu Q, and J Gong, J. 2003. "Background error covariance function for Doppler radar radial-wind analysis.” Quart. J. Roy. Meteor. Soc. 129:1703-1720. 
Appendix C

Statistical Measures 


\section{Appendix C: Statistical Measures}

The bias, the root-mean-square difference, RMSE, index of agreement, $I A$, and correlation coefficient, $R$, employed by this study are defined as:

$$
\begin{gathered}
\text { bias }=\frac{1}{N} \sum_{i=1}^{N} \frac{p_{i}-o_{i}}{o_{i}} \\
R M S E=\left[\frac{1}{N} \sum_{i=1}^{N}\left(p_{i}-o_{i}\right)^{2}\right]^{1 / 2} \\
I A=\frac{\sum_{i-1}^{N}\left(p_{i}-o_{i}\right)^{2}}{\sum_{i=1}^{N}\left(\left|p_{i}-\bar{o}\right|+\left|o_{i}-\bar{o}\right|\right)^{2}} \\
R(p, o)=\frac{\frac{(p-\bar{p})(o-\bar{o})}{\sqrt{(p-\bar{p})^{2}}} \sqrt{(o-\bar{o})^{2}}}{\sqrt{\overline{(p-\bar{c}}}}
\end{gathered}
$$

where $p$ is a predicted value, and $o$ is an observed value. The index of agreement is a relative measure of the difference between the observed and predicted values (Willmott 1982). It is bounded such that $0 \leq I A \leq 1$, where $I A=1$ indicates perfect agreement. We should point out that these statistical metrics were also used to compare two "predicted" values—in which case it is a bit misleading to use the term "observed" value to describe $o$.

A percent difference, $D$, was also used when comparing CALPUFF and SCIPUFF predictions such that

$$
D=100 \frac{\left|\left\langle E_{\text {Scipuff }}\right\rangle-\left\langle E_{\text {Calpuff }}\right\rangle\right|}{0.5\left(\left\langle E_{\text {Scipuff }}\right\rangle+\left\langle E_{\text {Calpuff }}\right\rangle\right)}
$$

where the brackets indicate an average over the surface of the simulation domain. D is also used to compare exposures from different time resolutions.

The subsequent tables quantify the performance of the NEXRAD wind retrievals using Eqs. (C.1) to (C.5), and the results are described in the text. 
Table C.1. Radar Wind-Profiler Range Gates and Model Levels Used to Evaluate 2DVar NEXRAD Wind Retrievals

\begin{tabular}{|c|c|c|c|c||}
\hline $\begin{array}{c}\text { ANL Profiler } \\
\text { Range Gate }\end{array}$ & $\begin{array}{c}\text { ANL Profiler } \\
\text { Height (m AGL) }\end{array}$ & $\begin{array}{c}\text { 2DVar Model } \\
\text { Level }\end{array}$ & $\begin{array}{c}\text { Model Height } \\
\text { (m AGL) }\end{array}$ & $\begin{array}{c}\text { Height } \\
\text { Difference (m) }\end{array}$ \\
\hline 6 & 357 & 1 & 327 & -30 \\
\hline 15 & 852 & 2 & 847 & -5 \\
\hline 24 & 1347 & 3 & 1367 & 20 \\
\hline 34 & 1897 & 4 & 1888 & -9 \\
\hline 43 & 2392 & 5 & 2411 & 19 \\
\hline
\end{tabular}

\begin{tabular}{|c|c|c|c|c||}
\hline \hline $\begin{array}{c}\text { PNNL Profiler } \\
\text { Range Gate }\end{array}$ & $\begin{array}{c}\text { PNNL Profiler } \\
\text { Height (m AGL) }\end{array}$ & $\begin{array}{c}\text { 2DVar Model } \\
\text { Level }\end{array}$ & $\begin{array}{c}\text { Model Height } \\
\text { (m AGL) }\end{array}$ & $\begin{array}{c}\text { Height } \\
\text { Difference (m) }\end{array}$ \\
\hline 5 & 302 & 1 & 285 & -17 \\
\hline 13 & 742 & 2 & 754 & 12 \\
\hline 22 & 1237 & 3 & 1224 & -13 \\
\hline 30 & 1677 & 4 & 1694 & 17 \\
\hline 39 & 2172 & 5 & 2165 & -7 \\
\hline
\end{tabular}

\begin{tabular}{|c|c|c|c|c|}
\hline $\begin{array}{c}\text { OU Profiler } \\
\text { Range Gate }\end{array}$ & $\begin{array}{c}\text { OU Profiler } \\
\text { Height (m AGL) }\end{array}$ & $\begin{array}{c}\text { 2DVar Model } \\
\text { Level }\end{array}$ & $\begin{array}{c}\text { Model Height } \\
\text { (m AGL) }\end{array}$ & $\begin{array}{c}\text { Height } \\
\text { Difference (m) }\end{array}$ \\
\hline 4 & 247 & 1 & 239 & -8 \\
\hline 11 & 632 & 2 & 611 & -21 \\
\hline 17 & 962 & 3 & 983 & 24 \\
\hline 24 & 1347 & 4 & 1356 & 9 \\
\hline 31 & 1732 & 5 & 1729 & -4 \\
\hline
\end{tabular}

\begin{tabular}{|c|c|c|c|c||}
\hline $\begin{array}{c}\text { NOAA Profiler } \\
\text { Range Gate }\end{array}$ & $\begin{array}{c}\text { NOAA Profiler } \\
\text { Height (m AGL) }\end{array}$ & $\begin{array}{c}\text { 2DVar Model } \\
\text { Level }\end{array}$ & $\begin{array}{c}\text { Model Height } \\
\text { (m AGL) }\end{array}$ & $\begin{array}{c}\text { Height } \\
\text { Difference (m) }\end{array}$ \\
\hline 2 & 500 & 1 & 547 & 47 \\
\hline 5 & 1250 & 2 & 1329 & 78 \\
\hline 8 & 2000 & 3 & 2111 & 111 \\
\hline 11 & 2750 & 4 & 2896 & 146 \\
\hline 15 & 3750 & 5 & 3682 & -68 \\
\hline
\end{tabular}


Table C.2. Radar Wind-Profiler Range Gates and Model Levels Used to Evaluate VDRAS NEXRAD Wind Retrievals

\begin{tabular}{|c|c|c|c|c||}
\hline $\begin{array}{c}\text { ANL Profiler } \\
\text { Range Gate }\end{array}$ & $\begin{array}{c}\text { ANL Profiler } \\
\text { Height (m AGL) }\end{array}$ & Model Level & $\begin{array}{c}\text { Model Height } \\
\text { (m AGL) }\end{array}$ & $\begin{array}{c}\text { Height } \\
\text { Difference (m) }\end{array}$ \\
\hline 3 & 192 & 1 & 188 & -4 \\
\hline 10 & 577 & 2 & 563 & -14 \\
\hline 16 & 907 & 3 & 938 & 31 \\
\hline 23 & 1292 & 4 & 1313 & 21 \\
\hline 30 & 1677 & 5 & 1688 & 11 \\
\hline 37 & 2062 & 6 & 2063 & 1 \\
\hline 44 & 2447 & 7 & 2438 & -9 \\
\hline 50 & 2777 & 9 & 2813 & 36 \\
\hline
\end{tabular}

\begin{tabular}{|c|c|c|c|c||}
\hline $\begin{array}{c}\text { PNNL Profiler } \\
\text { Range Gate }\end{array}$ & $\begin{array}{c}\text { PNNL Profiler } \\
\text { Height (m AGL) }\end{array}$ & Model Level & $\begin{array}{c}\text { Model Height } \\
\text { (m AGL) }\end{array}$ & $\begin{array}{c}\text { Height } \\
\text { Difference (m) }\end{array}$ \\
\hline $5^{*}$ & 302 & 1 & 192 & -110 \\
\hline 10 & 577 & 2 & 567 & -10 \\
\hline 17 & 962 & 3 & 942 & -20 \\
\hline 23 & 1292 & 4 & 1317 & 25 \\
\hline 30 & 1677 & 5 & 1692 & 15 \\
\hline 37 & 2062 & 6 & 2067 & 5 \\
\hline 44 & 2447 & 7 & 2442 & -5 \\
\hline 50 & 2777 & 9 & 2817 & 40 \\
\hline
\end{tabular}

\begin{tabular}{|c|c|c|c|c|}
\hline $\begin{array}{c}\text { OU Profiler } \\
\text { Range Gate }\end{array}$ & $\begin{array}{c}\text { OU Profiler } \\
\text { Height (m AGL) }\end{array}$ & Model Level & $\begin{array}{c}\text { Model Height } \\
\text { (m AGL) }\end{array}$ & $\begin{array}{c}\text { Height } \\
\text { Difference (m) }\end{array}$ \\
\hline 3 & 192 & 1 & 191 & -1 \\
\hline 10 & 577 & 2 & 566 & -11 \\
\hline 16 & 907 & 3 & 941 & 34 \\
\hline 23 & 1292 & 4 & 1316 & 24 \\
\hline 30 & 1677 & 5 & 1690 & 13 \\
\hline 37 & 2062 & 6 & 2067 & 5 \\
\hline 44 & 2447 & 7 & 2441 & 6 \\
\hline 50 & 2777 & 9 & 2816 & 39 \\
\hline
\end{tabular}


Table C.2 (Contd)

\begin{tabular}{|c|c|c|c|c||}
\hline $\begin{array}{c}\text { NOAA Profiler } \\
\text { Range Gate }\end{array}$ & $\begin{array}{c}\text { NOAA Profiler } \\
\text { Height (m AGL) }\end{array}$ & Model Level & $\begin{array}{c}\text { Model Height } \\
\text { (m AGL) }\end{array}$ & $\begin{array}{c}\text { Height } \\
\text { Difference (m) }\end{array}$ \\
\hline- & - & 1 & 222 & - \\
\hline 2 & 500 & 2 & 597 & 97 \\
\hline 4 & 1000 & 3 & 972 & -28 \\
\hline 5 & 1250 & 4 & 1347 & 97 \\
\hline 7 & 1750 & 5 & 1721 & -29 \\
\hline 8 & 2000 & 6 & 2097 & 97 \\
\hline 10 & 2500 & 7 & 2472 & -28 \\
\hline 11 & 2750 & 8 & 2847 & 97 \\
\hline 13 & 3250 & 9 & 3222 & -8 \\
\hline 14 & 3500 & 10 & 3597 & -28 \\
\hline 16 & 4000 & 11 & 3972 & 97 \\
\hline 17 & 4250 & 12 & 4347 & -28 \\
\hline 19 & 4750 & 13 & 4722 & \\
\hline
\end{tabular}

Table C.3. Statistics that Quantify the Performance of the 2DVar Wind Retrievals Using Radar Wind-Profiler Measurements

Wind Speed: 2DVar versus ANL profiler

\begin{tabular}{|c|c|c|c|c|c|c|c|}
\hline Level & Number & Ave obs & Ave mdl & bias & RMSE & IA & R \\
\hline 1 & 633 & 10.97 & 13.56 & 2.59 & 4.32 & 0.83 & 0.80 \\
\hline 2 & 628 & 11.16 & 9.94 & -1.21 & 3.07 & 0.84 & 0.76 \\
\hline 3 & 593 & 9.65 & 8.26 & -1.38 & 3.86 & 0.69 & 0.49 \\
\hline 4 & 417 & 8.18 & 8.24 & 0.06 & 3.99 & 0.71 & 0.50 \\
\hline 5 & 203 & 6.67 & 8.56 & 1.89 & 4.68 & 0.55 & 0.29 \\
\hline
\end{tabular}

Wind direction: 2DVar versus ANL profiler

\begin{tabular}{|c|c|c|c|c|c|c|c||}
\hline Level & Number & Ave obs & Ave mdl & bias & RMSE & IA & R \\
\hline 1 & 633 & 194.4 & 194.2 & -1.3 & 23.7 & 0.91 & 0.80 \\
\hline 2 & 628 & 200.8 & 194.6 & -8.5 & 23.6 & 0.93 & 0.69 \\
\hline 3 & 593 & 202.7 & 204.5 & -2.5 & 32.7 & 0.92 & 0.71 \\
\hline 4 & 417 & 198.5 & 199.3 & 0.7 & 52.8 & 0.90 & 0.61 \\
\hline 5 & 203 & 172.0 & 171.9 & -10.8 & 64.4 & 0.91 & 0.67 \\
\hline
\end{tabular}

Wind Speed: 2DVar versus PNNL profiler

\begin{tabular}{|c|c|c|c|c|c|c|c||}
\hline Level & Number & Ave obs & Ave mdl & bias & RMSE & IA & R \\
\hline 1 & 641 & 10.32 & 12.96 & 2.65 & 3.89 & 0.84 & 0.84 \\
\hline 2 & 641 & 11.23 & 9.91 & -1.32 & 2.71 & 0.88 & 0.82 \\
\hline 3 & 641 & 9.88 & 8.96 & -0.91 & 2.88 & 0.82 & 0.69 \\
\hline 4 & 598 & 8.80 & 8.50 & -0.31 & 3.66 & 0.75 & 0.58 \\
\hline 5 & 497 & 7.78 & 8.92 & 1.15 & 4.35 & 0.66 & 0.46 \\
\hline
\end{tabular}


Table C.3 (Contd)

Wind direction: 2DVar versus PNNL profiler

\begin{tabular}{|c|c|c|c|c|c|c|c|}
\hline Level & Number & Ave obs & Ave mdl & bias & RMSE & IA & R \\
\hline 1 & 641 & 191.5 & 191.5 & -0.5 & 17.6 & 0.95 & 0.84 \\
\hline 2 & 641 & 198.4 & 195.9 & -3.8 & 17.5 & 0.96 & 0.88 \\
\hline 3 & 641 & 203.2 & 206.1 & 1.8 & 23.3 & 0.95 & 0.87 \\
\hline 4 & 598 & 202.2 & 210.9 & 6.9 & 40.9 & 0.91 & 0.76 \\
\hline 5 & 497 & 194.7 & 198.1 & 0.5 & 60.4 & 0.89 & 0.77 \\
\hline
\end{tabular}

Wind speed: 2DVar versus OU profiler

\begin{tabular}{|c|c|c|c|c|c|c|c|}
\hline Level & Number & Ave obs & Ave mdl & bias & RMSE & IA & R \\
\hline 1 & 639 & 9.6 & 9.3 & -0.2 & 2.4 & 0.89 & 0.80 \\
\hline 2 & 582 & 11.1 & 11.7 & 0.6 & 2.4 & 0.94 & 0.91 \\
\hline 3 & 415 & 10.1 & 10.9 & 0.8 & 3.1 & 0.87 & 0.82 \\
\hline 4 & 340 & 9.0 & 9.7 & 0.7 & 3.1 & 0.81 & 0.71 \\
\hline 5 & 170 & 9.3 & 9.8 & 0.5 & 3.1 & 0.78 & 0.61 \\
\hline
\end{tabular}

Wind direction: 2DVar versus OU profiler

\begin{tabular}{|c|c|c|c|c|c|c|c||}
\hline Level & Number & Ave obs & Ave mdl & bias & RMSE & IA & R \\
\hline 1 & 639 & 195.9 & 1188.2 & -9.3 & 23.2 & 0.91 & 0.75 \\
\hline 2 & 582 & 202.4 & 202.4 & -3.1 & 17.5 & 0.95 & 0.73 \\
\hline 3 & 415 & 201.0 & 198.8 & -3.9 & 20.3 & 0.96 & 0.87 \\
\hline 4 & 340 & 195.0 & 194.8 & -1.2 & 22.8 & 0.96 & 0.86 \\
\hline 5 & 170 & 179.1 & 174.7 & -2.2 & 25.1 & 0.98 & 0.94 \\
\hline
\end{tabular}

Wind speed: 2DVar versus NOAA profiler

\begin{tabular}{|c|c|c|c|c|c|c|c|}
\hline Level & Number & Ave obs & Ave mdl & bias & RMSE & IA & R \\
\hline 1 & 323 & 10.86 & 11.51 & 0.65 & 3.10 & 0.89 & 0.81 \\
\hline 2 & 325 & 8.94 & 10.13 & 1.19 & 3.01 & 0.83 & 0.73 \\
\hline 3 & 275 & 7.23 & 8.27 & 1.04 & 4.35 & 0.66 & 0.44 \\
\hline 4 & 195 & 6.15 & 11.42 & 5.27 & 8.12 & 0.36 & 0.07 \\
\hline 5 & 137 & 9.50 & 14.75 & 5.24 & 8.53 & 0.52 & 0.45 \\
\hline
\end{tabular}

Wind direction: 2DVar versus NOAA profiler

\begin{tabular}{|c|c|c|c|c|c|c|c||}
\hline Level & Number & Ave obs & Ave mdl & bias & RMSE & IA & R \\
\hline 1 & 323 & 195.9 & 199.3 & 1.2 & 23.0 & 0.91 & 0.68 \\
\hline 2 & 325 & 198.6 & 203.6 & -1.7 & 21.7 & 0.95 & 0.53 \\
\hline 3 & 275 & 191.8 & 182.4 & -16.0 & 52.5 & 0.91 & 0.57 \\
\hline 4 & 195 & 165.9 & 107.5 & -14.2 & 66.8 & 0.92 & 0.50 \\
\hline 5 & 137 & 103.3 & 70.0 & -7.0 & 35.9 & 0.94 & 0.27 \\
\hline
\end{tabular}


Table C.4. Statistics that Quantify the Performance of the VDRAS Wind Retrievals Using Radar Wind-Profiler Measurements

Wind speed: VDRAS (NEXRAD data only) versus ANL profiler

\begin{tabular}{|c|c|c|c|c|c|c|c|}
\hline Level & Number & Ave PRO & Ave NEX & bias & RMSE & IA & R \\
\hline 1 & 574 & 8.23 & 10.64 & 2.41 & 3.81 & 0.71 & 0.67 \\
\hline 2 & 571 & 11.84 & 9.79 & 2.05 & 3.53 & 0.82 & 0.83 \\
\hline 3 & 561 & 11.07 & 9.14 & -1.93 & 3.27 & 0.77 & 0.75 \\
\hline 4 & 538 & 9.56 & 8.63 & -1.60 & 2.96 & 0.82 & 0.75 \\
\hline 5 & 474 & 9.13 & 8.10 & -1.03 & 2.91 & 0.84 & 0.74 \\
\hline 6 & 320 & 8.50 & 7.84 & -0.66 & 3.07 & 0.84 & 0.71 \\
\hline 7 & 246 & 6.86 & 7.38 & 0.53 & 2.80 & 0.81 & 0.69 \\
\hline 8 & 204 & 6.50 & 7.25 & 0.76 & 2.92 & 0.78 & 0.63 \\
\hline
\end{tabular}

Wind direction: VDRAS (NEXRAD data only) versus ANL profiler

\begin{tabular}{|c|c|c|c|c|c|c|c||}
\hline Level & Number & Ave PRO & Ave NEX & bias & RMSE & IA & R \\
\hline 1 & 574 & 187.7 & 188.6 & -1.0 & 27.7 & 0.88 & 0.68 \\
\hline 2 & 571 & 196.8 & 191.7 & -6.4 & 22.1 & 0.94 & 0.84 \\
\hline 3 & 561 & 202.6 & 195.5 & -8.4 & 21.7 & 0.95 & 0.83 \\
\hline 4 & 538 & 203.5 & 196.6 & -10.9 & 26.0 & 0.95 & 0.80 \\
\hline 5 & 474 & 201.3 & 197.1 & -10.3 & 29.1 & 0.96 & 0.75 \\
\hline 6 & 320 & 189.7 & 188.3 & -11.5 & 36.6 & 0.96 & 0.75 \\
\hline 7 & 246 & 188.4 & 182.0 & -16.7 & 42.4 & 0.95 & 0.83 \\
\hline 8 & 204 & 191.0 & 187.5 & -21.1 & 55.5 & 0.91 & 0.63 \\
\hline
\end{tabular}

Wind speed: 2DVAR (NEXRAD data + standard observations) versus ANL profiler

\begin{tabular}{|c|c|c|c|c|c|c|c||}
\hline \hline Level & Number & Ave PRO & Ave NEX & bias & RMSE & IA & R \\
\hline 1 & 574 & 8.23 & 8.89 & 0.66 & 2.99 & 0.68 & 0.46 \\
\hline 2 & 571 & 11.84 & 8.62 & -3.22 & 5.09 & 0.62 & 0.61 \\
\hline 3 & 561 & 11.07 & 8.39 & -2.68 & 4.16 & 0.66 & 0.60 \\
\hline 4 & 538 & 9.56 & 7.94 & -2.02 & 3.34 & 0.77 & 0.71 \\
\hline 5 & 474 & 9.13 & 8.23 & -0.90 & 2.91 & 0.84 & 0.74 \\
\hline 6 & 320 & 8.50 & 7.96 & -0.54 & 3.02 & 0.84 & 0.72 \\
\hline 7 & 246 & 6.86 & 7.47 & 0.62 & 2.79 & 0.82 & 0.70 \\
\hline 8 & 204 & 6.50 & 7.31 & 0.82 & 2.95 & 0.77 & 0.63 \\
\hline
\end{tabular}

Wind direction: 2DVAR (NEXRAD data + standard observations) versus ANL profiler

\begin{tabular}{|c|c|c|c|c|c|c|c|}
\hline Level & Number & Ave NEX & Ave PRO & bias & RMSE & IA & R \\
\hline 1 & 574 & 187.7 & 185.9 & -1.8 & 27.4 & 0.88 & 0.72 \\
\hline 2 & 571 & 196.8 & 191.3 & -6.7 & 22.3 & 0.94 & 0.84 \\
\hline 3 & 561 & 202.6 & 195.2 & -8.7 & 22.1 & 0.95 & 0.83 \\
\hline 4 & 538 & 203.5 & 195.3 & -11.6 & 26.3 & 0.95 & 0.83 \\
\hline 5 & 474 & 201.3 & 197.6 & -9.0 & 27.9 & 0.96 & 0.74 \\
\hline 6 & 320 & 189.7 & 189.7 & -10.1 & 36.6 & 0.95 & 0.75 \\
\hline 7 & 246 & 188.4 & 185.5 & -14.5 & 42.5 & 0.94 & 0.80 \\
\hline 8 & 204 & 191.0 & 178.3 & -20.5 & 54.2 & 0.91 & 0.64 \\
\hline
\end{tabular}


Table C.4 (Contd)

Wind speed: VDRAS (NEXRAD data only) versus PNNL profiler

\begin{tabular}{|c|c|c|c|c|c|c|c|}
\hline \hline Level & Number & Ave PRO & Ave NEX & bias & RMSE & IA & R \\
\hline 1 & 587 & 10.33 & 10.49 & 0.15 & 2.26 & 0.92 & 0.86 \\
\hline 2 & 587 & 11.50 & 9.75 & -1.74 & 2.98 & 0.87 & 0.85 \\
\hline 3 & 587 & 10.63 & 9.05 & -1.58 & 2.68 & 0.85 & 0.80 \\
\hline 4 & 587 & 9.88 & 8.38 & -1.50 & 2.71 & 0.85 & 0.79 \\
\hline 5 & 587 & 9.10 & 7.95 & -1.14 & 2.71 & 0.86 & 0.78 \\
\hline 6 & 587 & 8.43 & 7.98 & -.0 .46 & 2.48 & 0.87 & 0.78 \\
\hline 7 & 587 & 7.65 & 7.92 & 0.28 & 2.56 & 0.83 & 0.72 \\
\hline 8 & 587 & 7.15 & 8.03 & 0.88 & 2.97 & 0.78 & 0.64 \\
\hline \hline
\end{tabular}

Wind direction: VDRAS (NEXRAD data only) versus PNNL profiler

\begin{tabular}{|c|c|c|c|c|c|c|c|}
\hline \hline Level & Number & Ave PRO & Ave NEX & bias & RMSE & IA & R \\
\hline 1 & 587 & 191.8 & 190.6 & -1.8 & 18.5 & 0.94 & 0.84 \\
\hline 2 & 587 & 198.1 & 194.6 & -2.9 & 17.7 & 0.96 & 0.87 \\
\hline 3 & 587 & 200.8 & 198.3 & -4.3 & 18.5 & 0.96 & 0.82 \\
\hline 4 & 587 & 204.6 & 198.9 & -7.0 & 21.1 & 0.96 & 0.90 \\
\hline 5 & 587 & 203.8 & 200.1 & -6.8 & 30.8 & 0.94 & 0.82 \\
\hline 6 & 587 & 203.6 & 198.8 & -3.5 & 39.8 & 0.93 & 0.84 \\
\hline 7 & 587 & 200.8 & 198.0 & -22.8 & 44.5 & 0.93 & 0.79 \\
\hline 8 & 587 & 201.0 & 197.4 & 0.1 & 49.1 & 0.92 & 0.78 \\
\hline
\end{tabular}

Wind speed: 2DVAR (NEXRAD data + standard observations) versus PNNL profiler

\begin{tabular}{|c|c|c|c|c|c|c|c||}
\hline Level & Number & Ave PRO & Ave NEX & bias & RMSE & IA & R \\
\hline 1 & 587 & 10.33 & 8.70 & -1.63 & 4.25 & 0.62 & 0.46 \\
\hline 2 & 587 & 11.50 & 8.56 & -2.94 & 4.63 & 0.65 & 0.62 \\
\hline 3 & 587 & 10.63 & 8.63 & -2.27 & 3.45 & 0.74 & 0.69 \\
\hline 4 & 587 & 9.88 & 8.01 & -1.82 & 2.95 & 0.82 & 0.77 \\
\hline 5 & 587 & 9.10 & 8.18 & -0.92 & 2.67 & 0.86 & 0.78 \\
\hline 6 & 587 & 8.43 & 8.14 & -0.30 & 2.49 & 0.87 & 0.78 \\
\hline 7 & 587 & 7.65 & 8.00 & 0.36 & 2.58 & 0.83 & 0.73 \\
\hline 8 & 587 & 7.15 & 8.07 & 0.92 & 3.00 & 0.78 & 0.65 \\
\hline
\end{tabular}

Wind direction: 2DVAR (NEXRAD data + standard observations) versus PNNL profiler

\begin{tabular}{|c|c|c|c|c|c|c|c|}
\hline Level & Number & Ave PRO & Ave NEX & bias & RMSE & IA & R \\
\hline 1 & 587 & 191.8 & 189.2 & -1.4 & 18.5 & 0.95 & 0.80 \\
\hline 2 & 587 & 198.1 & 194.9 & -2.9 & 18.0 & 0.96 & 0.88 \\
\hline 3 & 587 & 200.8 & 198.2 & -3.8 & 18.4 & 0.96 & 0.87 \\
\hline 4 & 587 & 204.6 & 199.1 & -6.8 & 22.0 & 0.96 & 0.89 \\
\hline 5 & 587 & 203.8 & 201.3 & -5.6 & 27.6 & 0.95 & 0.83 \\
\hline 6 & 587 & 203.6 & 201.1 & -2.5 & 39.1 & 0.93 & 0.85 \\
\hline 7 & 587 & 200.8 & 200.4 & -2.9 & 43.5 & 0.93 & 0.78 \\
\hline 8 & 587 & 201.0 & 197.2 & 0.4 & 47.2 & 0.92 & 0.77 \\
\hline
\end{tabular}


Table C.4 (Contd)

Wind speed: VDRAS (NEXRAD data only) versus OU profiler

\begin{tabular}{|c|c|c|c|c|c|c|c||}
\hline Level & Number & Ave PRO & Ave NEX & bias & RMSE & IA & R \\
\hline 1 & 575 & 8.89 & 9.77 & 0.87 & 2.69 & 0.85 & 0.77 \\
\hline 2 & 535 & 11.17 & 9.60 & -1.57 & 2.80 & 0.89 & 0.88 \\
\hline 3 & 389 & 10.37 & 9.25 & -1.12 & 2.41 & 0.89 & 0.84 \\
\hline 4 & 305 & 9.54 & 8.55 & -0.99 & 2.26 & 0.89 & 0.83 \\
\hline 5 & 178 & 9.62 & 8.08 & -1.54 & 2.80 & 0.83 & 0.77 \\
\hline 6 & 63 & 9.62 & 8.11 & -1.51 & 2.58 & 0.84 & 0.79 \\
\hline 7 & 30 & 7.55 & 6.13 & -1.41 & 2.85 & 0.78 & 0.69 \\
\hline 8 & 14 & 7.75 & 7.63 & -0.12 & 4.02 & 0.72 & 0.57 \\
\hline
\end{tabular}

Wind direction: VDRAS (NEXRAD data only) versus OU profiler

\begin{tabular}{|c|c|c|c|c|c|c|c|}
\hline Level & Number & Ave PRO & Ave NEX & bias & RMSE & IA & R \\
\hline 1 & 575 & 193.2 & 184.2 & -10.2 & 23.6 & 0.91 & 0.76 \\
\hline 2 & 535 & 203.2 & 191.2 & -10.0 & 21.4 & 0.94 & 0.77 \\
\hline 3 & 389 & 200.2 & 191.8 & -9.3 & 23.8 & 0.95 & 0.84 \\
\hline 4 & 305 & 197.3 & 192.7 & -7.1 & 28.4 & 0.95 & 0.76 \\
\hline 5 & 178 & 177.3 & 168.5 & -12.9 & 25.9 & 0.97 & 0.86 \\
\hline 6 & 63 & 198.2 & 188.9 & -6.4 & 26.8 & 0.96 & 0.94 \\
\hline 7 & 30 & 163.4 & 155.1 & -8.3 & 42.0 & 0.96 & 0.93 \\
\hline 8 & 14 & 219.4 & 237.9 & 18.4 & 85.0 & 0.79 & 0.75 \\
\hline
\end{tabular}

Wind speed: 2DVAR (NEXRAD data + standard observations) versus OU profiler

\begin{tabular}{|c|c|c|c|c|c|c|c||}
\hline Level & Number & Ave PRO & Ave NEX & bias & RMSE & IA & R \\
\hline 1 & 575 & 8.89 & 8.99 & 0.10 & 2.74 & 0.80 & 0.64 \\
\hline 2 & 535 & 11.17 & 9.24 & -1.93 & 3.16 & 0.86 & 0.86 \\
\hline 3 & 389 & 10.37 & 9.15 & -1.22 & 2.33 & 0.90 & 0.85 \\
\hline 4 & 305 & 9.54 & 8.47 & -1.08 & 2.15 & 0.90 & 0.86 \\
\hline 5 & 178 & 9.62 & 8.16 & -1.46 & 2.76 & 0.84 & 0.78 \\
\hline 6 & 63 & 9.62 & 8.19 & -1.44 & 2.43 & 0.86 & 0.81 \\
\hline 7 & 30 & 7.55 & 6.14 & -1.41 & 2.84 & 0.77 & 0.69 \\
\hline 8 & 14 & 7.75 & 7.30 & -0.45 & 4.08 & 0.69 & 0.55 \\
\hline
\end{tabular}

Wind direction: 2DVAR (NEXRAD data + standard observations) versus OU profiler

\begin{tabular}{|c|c|c|c|c|c|c|c|}
\hline \hline Level & Number & Ave PRO & Ave NEX & bias & RMSE & IA & R \\
\hline 1 & 575 & 193.2 & 187.8 & -6.0 & 20.76 & 0.93 & 0.81 \\
\hline 2 & 535 & 203.2 & 193.6 & -8.3 & 21.9 & 0.94 & 0.76 \\
\hline 3 & 389 & 200.2 & 192.6 & -8.4 & 23.7 & 0.95 & 0.87 \\
\hline 4 & 305 & 197.3 & 192.8 & -7.1 & 26.3 & 0.95 & 0.77 \\
\hline 5 & 178 & 177.3 & 171.2 & -12.2 & 26.2 & 0.97 & 0.81 \\
\hline 6 & 63 & 198.2 & 188.4 & -6.8 & 25.9 & 0.97 & 0.94 \\
\hline 7 & 30 & 163.4 & 153.3 & -10.1 & 40.6 & 0.96 & 0.93 \\
\hline 8 & 14 & 219.4 & 237.2 & 17.8 & 84.6 & 0.79 & 0.75 \\
\hline
\end{tabular}


Table C.4 (Contd)

Wind speed: VDRAS (NEXRAD data only) versus NOAA profiler

\begin{tabular}{|c|c|c|c|c|c|c|c||}
\hline \hline Level & Number & Ave PRO & Ave NEX & bias & RMSE & IA & R \\
\hline 1 & - & - & - & - & - & - & - \\
\hline 2 & 299 & 10.83 & 10.24 & -0.60 & 2.37 & 0.92 & 0.86 \\
\hline 3 & 301 & 9.54 & 9.45 & -0.10 & 2.30 & 0.90 & 0.82 \\
\hline 4 & 301 & 9.03 & 8.68 & -0.36 & 2.29 & 0.88 & 0.78 \\
\hline 5 & 299 & 8.14 & 7.78 & -0.27 & 2.21 & 0.89 & 0.79 \\
\hline 6 & 301 & 7.55 & 7.63 & 0.78 & 2.43 & 0.87 & 0.77 \\
\hline 7 & 301 & 6.83 & 7.73 & 0.90 & 3.01 & 0.80 & 0.66 \\
\hline 8 & 300 & 6.49 & 8.11 & 1.62 & 3.45 & 0.74 & 0.60 \\
\hline 9 & 299 & 6.90 & 8.38 & 1.48 & 4.13 & 0.63 & 0.40 \\
\hline 10 & 301 & 7.32 & 8.65 & 1.33 & 4.77 & 0.56 & 0.28 \\
\hline 11 & 301 & 8.19 & 8.86 & 0.68 & 5.11 & 0.50 & 0.17 \\
\hline 12 & 300 & 8.91 & 9.05 & 0.14 & 5.22 & 0.47 & 0.08 \\
\hline 13 & 301 & 10.06 & 9.13 & -0.94 & 5.23 & 0.37 & -0.02 \\
\hline
\end{tabular}

Wind direction: VDRAS (NEXRAD data only) versus NOAA profiler

\begin{tabular}{|c|c|c|c|c|c|c|c||}
\hline \hline Level & Number & Ave PRO & Ave NEX & bias & RMSE & IA & R \\
\hline 1 & - & - & - & - & - & - & - \\
\hline 2 & 299 & 196.2 & 194.7 & -1.5 & 18.7 & 0.94 & 0.89 \\
\hline 3 & 301 & 198.7 & 196.1 & -3.8 & 15.3 & 0.97 & 0.86 \\
\hline 4 & 301 & 199.6 & 198.8 & -3.1 & 22.2 & 0.95 & 0.78 \\
\hline 5 & 299 & 198.6 & 199.3 & -5.2 & 36.3 & 0.91 & 0.75 \\
\hline 6 & 301 & 197.1 & 197.2 & -8.2 & 35.5 & 0.94 & 0.74 \\
\hline 7 & 301 & 187.5 & 196.0 & -11.8 & 44.5 & 0.94 & 0.62 \\
\hline 8 & 300 & 183.5 & 187.4 & -14.2 & 52.9 & 0.93 & 0.65 \\
\hline 9 & 299 & 168.8 & 187.7 & -25.6 & 56.4 & 0.93 & 0.51 \\
\hline 10 & 301 & 161.5 & 185.7 & -18.9 & 57.9 & 0.93 & 0.52 \\
\hline 11 & 301 & 146.8 & 184.3 & -9.2 & 62.4 & 0.92 & 0.50 \\
\hline 12 & 300 & 142.9 & 190.4 & -8.9 & 65.7 & 0.91 & 0.38 \\
\hline 13 & 301 & 131.8 & 190.1 & -9.7 & 69.0 & 0.89 & 0.29 \\
\hline
\end{tabular}


Table C.4 (Contd)

Wind speed: 2DVAR (NEXRAD data + standard operations) versus NOAA profiler

\begin{tabular}{|c|c|c|c|c|c|c|c|}
\hline Level & Number & Ave PRO & Ave NEX & bias & RMSE & IA & R \\
\hline 1 & - & - & - & - & - & - & - \\
\hline 2 & 299 & 10.83 & 9.80 & -1.03 & 2.43 & 0.91 & 0.88 \\
\hline 3 & 301 & 9.54 & 9.38 & -0.17 & 2.21 & 0.91 & 0.84 \\
\hline 4 & 301 & 9.03 & 8.59 & -0.44 & 2.23 & 0.88 & 0.80 \\
\hline 5 & 299 & 8.14 & 8.12 & -0.03 & 2.20 & 0.89 & 0.80 \\
\hline 6 & 301 & 7.55 & 7.69 & 0.14 & 2.36 & 0.88 & 0.79 \\
\hline 7 & 301 & 6.83 & 7.76 & 0.93 & 2.99 & 0.80 & 0.66 \\
\hline 8 & 300 & 6.49 & 8.19 & 1.69 & 3.44 & 0.74 & 0.61 \\
\hline 9 & 299 & 6.90 & 8.76 & 1.56 & 4.10 & 0.63 & 0.40 \\
\hline 10 & 301 & 7.32 & 8.71 & 1.39 & 4.75 & 0.57 & 0.28 \\
\hline 11 & 301 & 8.19 & 8.92 & 0.73 & 5.10 & 0.50 & 0.17 \\
\hline 12 & 300 & 8.91 & 9.09 & 0.18 & 5.21 & 0.44 & 0.08 \\
\hline 13 & 301 & 10.06 & 9.16 & -0.90 & 5.20 & 0.36 & -0.03 \\
\hline
\end{tabular}

Wind direction: 2DVAR (NEXRAD data + standard operations) versus NOAA profiler

\begin{tabular}{|c|c|c|c|c|c|c|c|}
\hline \hline Level & Number & Ave PRO & Ave NEX & bias & RMSE & IA & R \\
\hline 1 & - & - & - & - & - & - & - \\
\hline 2 & 299 & 196.2 & 192.1 & -2.9 & 19.9 & 0.93 & 0.77 \\
\hline 3 & 301 & 198.7 & 194.3 & -5.6 & 16.4 & 0.97 & 0.85 \\
\hline 4 & 301 & 199.6 & 198.1 & -5.0 & 22.5 & 0.95 & 0.73 \\
\hline 5 & 299 & 198.6 & 199.1 & -3.1 & 36.1 & 0.91 & 0.77 \\
\hline 6 & 301 & 197.1 & 197.2 & -8.3 & 35.1 & 0.95 & 0.74 \\
\hline 7 & 301 & 187.5 & 196.0 & -11.8 & 44.9 & 0.94 & 0.61 \\
\hline 8 & 300 & 183.5 & 189.1 & -14.9 & 52.7 & 0.93 & 0.63 \\
\hline 9 & 299 & 168.8 & 188.2 & -25.1 & 55.9 & 0.93 & 0.51 \\
\hline 10 & 301 & 161.5 & 182.6 & -18.4 & 57.4 & 0.93 & 0.56 \\
\hline 11 & 301 & 146.8 & 183.5 & -8.8 & 62.0 & 0.92 & 0.51 \\
\hline 12 & 300 & 142.9 & 188.2 & -8.7 & 65.4 & 0.91 & 0.40 \\
\hline 13 & 301 & 131.8 & 190.2 & -8.6 & 68.5 & 0.90 & 0.29 \\
\hline
\end{tabular}


Table C.5. Correlation Coefficients Between Time Series of Velocity Differences at Locations of the NOAA-Purcel and PNNL Profilers. The second (third) column displays the correlation between the difference in $\mathrm{u}(\mathrm{v})$ measured at the profiler locations and the difference in $\mathrm{u}(\mathrm{v})$ from the VDRAS retrieval at the same locations. The fourth (fifth) column displays the correlation between the difference in $\mathrm{u}(\mathrm{v})$ measured at the profiler locations and the difference in $\mathrm{u}(\mathrm{v})$ from the 2DVar retrieval at the same locations.

NOAA-Purcel and PNNL difference

\begin{tabular}{|c|c|c|c|c|}
\hline \multirow{2}{*}{ Elevation (m) } & \multicolumn{2}{|c|}{$R\left(\Delta u_{\text {profiler }}, \Delta u_{\text {Re trieval }}\right)$} & \multicolumn{2}{c|}{$R\left(\Delta v_{\text {profiler }}, \Delta v_{\text {Retrieval }}\right)$} \\
\cline { 2 - 5 } & VDRAS & 2DVar & VDRAS & 2DVar \\
\hline 550 & 0.26 & 0.24 & 0.17 & 0.03 \\
\hline 900 & 0.21 & 0.06 & 0.28 & 0.10 \\
\hline 1400 & 0.31 & 0.11 & 0.23 & 0.02 \\
\hline
\end{tabular}

NOAA-Purcel and ANL difference

\begin{tabular}{|c|c|c|c|c|}
\hline \multirow{2}{*}{ Elevation (m) } & \multicolumn{2}{|c|}{$R\left(\Delta u_{\text {profiler }}, \Delta u_{\text {Retrieval }}\right)$} & \multicolumn{2}{c|}{$R\left(\Delta v_{\text {profiler }}, \Delta v_{\text {Retrieval }}\right)$} \\
\cline { 2 - 5 } & VDRAS & 2DVar & VDRAS & 2DVar \\
\hline 550 & 0.06 & 0.10 & 0.27 & -0.07 \\
\hline 900 & 0.11 & -0.08 & 0.37 & 0.10 \\
\hline 1400 & 0.33 & -0.09 & 0.32 & 0.05 \\
\hline
\end{tabular}

PNNL and ANL difference

\begin{tabular}{|c|c|c|c|c|}
\hline \multirow{2}{*}{ Elevation (m) } & \multicolumn{2}{|c|}{$R\left(\Delta u_{\text {profiler }}, \Delta u_{\text {Re trieval }}\right)$} & \multicolumn{2}{c|}{$R\left(\Delta v_{\text {profiler }}, \Delta v_{\text {Retrieval }}\right)$} \\
\cline { 2 - 5 } & VDRAS & 2DVar & VDRAS & 2DVar \\
\hline 550 & -0.16 & -0.21 & -0.02 & 0.08 \\
\hline 900 & -0.08 & -0.30 & 0.07 & 0.13 \\
\hline 1400 & 0.05 & -0.11 & 0.03 & 0.06 \\
\hline
\end{tabular}


Table C.6. Statistics that Quantify the Performance of the CALMET Wind Fields for the Six Cases Using Radar Wind-Profiler Measurements at the PNNL and ANL sites

PNNL radar wind profiler versus StdObs (case 1)

\begin{tabular}{|r|c|c|c|c|c|c|c|c|c||}
\hline \hline \multicolumn{3}{||c|}{ CALMET Level } & \multicolumn{3}{|c|}{ u-Component } & \multicolumn{3}{c||}{ V-Component } \\
\hline$\#$ & $\begin{array}{c}\text { Height } \\
(\mathbf{m})\end{array}$ & $\begin{array}{c}\text { Bias } \\
\mathbf{( m s}^{-\mathbf{1}} \mathbf{)}\end{array}$ & $\begin{array}{c}\text { RMSE } \\
\mathbf{( m s}^{-\mathbf{1}} \mathbf{)}\end{array}$ & $\mathbf{I A}$ & $\mathbf{R}$ & $\begin{array}{c}\text { Bias } \\
\mathbf{( m s}^{-\mathbf{1}} \mathbf{)}\end{array}$ & $\begin{array}{c}\mathbf{R M S E} \\
\left(\mathbf{m s}^{-\mathbf{1}} \mathbf{)}\right.\end{array}$ & $\mathbf{I A}$ & $\mathbf{R}$ \\
\hline 6 & 450 & 0.42 & 2.63 & 0.86 & 0.79 & 0.29 & 3.91 & 0.81 & 0.75 \\
\hline 7 & 800 & 0.23 & 2.57 & 0.91 & 0.85 & 0.45 & 3.26 & 0.88 & 0.82 \\
\hline 8 & 1250 & 0.1 & 3.18 & 0.89 & 0.82 & 0.03 & 3.04 & 0.9 & 0.87 \\
\hline 9 & 1850 & 0.05 & 2.72 & 0.91 & 0.85 & -0.75 & 3.42 & 0.89 & 0.86 \\
\hline 10 & 2600 & -0.35 & 3.15 & 0.8 & 0.66 & -1.5 & 4.3 & 0.81 & 0.71 \\
\hline
\end{tabular}

PNNL radar wind profiler versus StdObs + profiler (case 2)

\begin{tabular}{|c|c|c|c|c|c|c|c|c|c|}
\hline \multicolumn{2}{|c|}{ CALMET Level } & \multicolumn{4}{|c|}{ 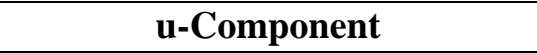 } & \multicolumn{4}{|c|}{ "v-Component } \\
\hline \# & $\begin{array}{c}\text { Height } \\
\text { (m) }\end{array}$ & $\begin{array}{c}\text { Bias } \\
\left(\mathrm{ms}^{-1}\right)\end{array}$ & $\begin{array}{c}\text { RMSE } \\
\left(\mathrm{ms}^{-1}\right)\end{array}$ & IA & $\mathbf{R}$ & $\begin{array}{c}\text { bias } \\
\left(\mathrm{ms}^{-1}\right)\end{array}$ & $\begin{array}{c}\text { RMSE } \\
\left(\mathrm{ms}^{-1}\right)\end{array}$ & IA & $\mathbf{R}$ \\
\hline 6 & 450 & -0.13 & 0.39 & 1 & 1 & -0.11 & 0.47 & 1 & 1 \\
\hline 7 & 800 & -0.05 & 0.41 & 1 & 1 & -0.03 & 0.43 & 1 & 1 \\
\hline 8 & 1250 & -0.02 & 0.47 & 1 & 1 & -0.02 & 0.43 & 1 & 1 \\
\hline 9 & 1850 & 0.02 & 0.59 & 1 & 0.99 & -0.13 & 0.69 & 1 & 0.99 \\
\hline 10 & 2600 & 0.03 & 0.61 & 0.99 & 0.99 & -0.31 & 0.92 & 0.99 & 0.99 \\
\hline
\end{tabular}

ANL radar wind profiler versus StdObs (case 1)

\begin{tabular}{|r|c|c|c|c|c|c|c|c|c||}
\hline \hline \multicolumn{3}{||c|}{ CALMET level } & \multicolumn{3}{|c|}{ u-Component } & \multicolumn{4}{c||}{ v-Component } \\
\hline$\#$ & $\begin{array}{c}\text { Height } \\
\mathbf{( m )}\end{array}$ & $\begin{array}{c}\text { Bias } \\
\mathbf{( m s}^{-\mathbf{1}} \mathbf{)}\end{array}$ & $\begin{array}{c}\text { RMSE } \\
\mathbf{( m s}^{-\mathbf{1}} \mathbf{)}\end{array}$ & $\mathbf{I A}$ & $\mathbf{R}$ & $\begin{array}{c}\text { Bias } \\
\mathbf{( m s}^{-\mathbf{1}} \mathbf{)}\end{array}$ & $\begin{array}{c}\mathbf{R M S E} \\
\left(\mathbf{m s}^{-\mathbf{1}} \mathbf{)}\right.\end{array}$ & $\mathbf{I A}$ & $\mathbf{R}$ \\
\hline 4 & 120 & 0.41 & 1.38 & 0.85 & 0.77 & 0.22 & 2.34 & 0.79 & 0.67 \\
\hline 5 & 230 & 0.7 & 2.15 & 0.79 & 0.68 & -0.07 & 3.13 & 0.76 & 0.66 \\
\hline 6 & 450 & 0.49 & 3.14 & 0.8 & 0.7 & 0.24 & 4 & 0.81 & 0.74 \\
\hline 7 & 800 & 0.19 & 2.85 & 0.89 & 0.81 & 0.56 & 3.45 & 0.87 & 0.81 \\
\hline 8 & 1250 & 0.38 & 3.47 & 0.86 & 0.77 & 0.25 & 3.51 & 0.88 & 0.85 \\
\hline 9 & 1850 & 0.16 & 2.96 & 0.9 & 0.82 & 0.34 & 3.57 & 0.89 & 0.88 \\
\hline 10 & 2600 & 0.99 & 2.92 & 0.81 & 0.71 & 0.29 & 2.87 & 0.93 & 0.88 \\
\hline
\end{tabular}

ANL radar wind profiler versus StdObs + profiler (case 2)

\begin{tabular}{|c|c|c|c|c|c|c|c|c|c|}
\hline \multicolumn{2}{|c|}{ בCALMET Level } & \multicolumn{4}{|c|}{ בu-Component } & \multicolumn{4}{|c|}{ v-Component } \\
\hline$\#$ & $\begin{array}{c}\text { Height } \\
\text { (m) }\end{array}$ & $\begin{array}{c}\text { Bias } \\
\left(\mathrm{ms}^{-1}\right)\end{array}$ & $\begin{array}{c}\text { RMSE } \\
\left(\mathrm{ms}^{-1}\right)\end{array}$ & IA & $\mathbf{R}$ & $\begin{array}{c}\text { Bias } \\
\left(\mathrm{ms}^{-1}\right)\end{array}$ & $\begin{array}{c}\text { RMSE } \\
\left(\mathrm{ms}^{-1}\right)\end{array}$ & IA & $\mathbf{R}$ \\
\hline 4 & 120 & -0.05 & 0.33 & 0.99 & 0.99 & 0.02 & 0.54 & 0.99 & 0.99 \\
\hline 5 & 230 & 0.05 & 0.39 & 0.99 & 0.99 & -0.11 & 0.54 & 1 & 0.99 \\
\hline 6 & 450 & -0.11 & 0.68 & 0.99 & 0.99 & -0.11 & 0.73 & 1 & 0.99 \\
\hline 7 & 800 & -0.09 & 0.88 & 0.99 & 0.98 & 0.09 & 1.01 & 0.99 & 0.99 \\
\hline 8 & 1250 & 0.2 & 1.39 & 0.98 & 0.97 & 0.1 & 1.32 & 0.99 & 0.98 \\
\hline 9 & 1850 & 0.01 & 0.91 & 0.99 & 0.98 & 0.41 & 1.69 & 0.98 & 0.97 \\
\hline 10 & 2600 & 0.82 & 2 & 0.93 & 0.89 & 0.39 & 1.92 & 0.97 & 0.95 \\
\hline
\end{tabular}


Table C.6 (Contd)

PNNL radar wind profiler versus StdObs + 2DVar (case 3)

\begin{tabular}{|c|c|c|c|c|c|c|c|c|c|}
\hline \multicolumn{2}{|c|}{ CALMET Level } & \multicolumn{4}{|c|}{ בu-Component } & \multicolumn{4}{|c|}{ v-Component } \\
\hline \# & $\begin{array}{c}\text { Height } \\
\text { (m) }\end{array}$ & $\begin{array}{c}\text { Bias } \\
\left(\mathrm{ms}^{-1}\right)\end{array}$ & $\begin{array}{c}\text { RMSE } \\
\left(\mathrm{ms}^{-1}\right)\end{array}$ & IA & $\mathbf{R}$ & bias & $\begin{array}{c}\text { RMSE } \\
\left(\mathrm{ms}^{-1}\right)\end{array}$ & IA & $\mathbf{R}$ \\
\hline 6 & 450 & -0.29 & 1.23 & 0.98 & 0.96 & 0.15 & 1.97 & 0.97 & 0.94 \\
\hline 7 & 800 & -0.42 & 1.56 & 0.98 & 0.96 & -0.69 & 2.04 & 0.96 & 0.94 \\
\hline 8 & 1250 & -0.14 & 1.82 & 0.97 & 0.95 & -0.63 & 2.6 & 0.94 & 0.9 \\
\hline 9 & 1850 & 0.07 & 2.26 & 0.95 & 0.91 & -1.03 & 3.33 & 0.91 & 0.86 \\
\hline 10 & 2600 & 0.11 & 2.86 & 0.89 & 0.82 & -1.69 & 4.35 & 0.84 & 0.75 \\
\hline
\end{tabular}

PNNL radar wind profiler versus StdObs + profiler + 2DVar (case 5)

\begin{tabular}{|c|c|c|c|c|c|c|c|c|c|}
\hline \multicolumn{2}{|c|}{ CALMET Level } & \multicolumn{4}{|c|}{ u-Component } & \multicolumn{4}{|c|}{ v-Component } \\
\hline$\#$ & $\begin{array}{c}\text { Height } \\
\text { (m) }\end{array}$ & $\begin{array}{c}\text { Bias } \\
\left(\mathrm{ms}^{-1}\right)\end{array}$ & $\begin{array}{c}\text { RMSE } \\
\left(\mathrm{ms}^{-1}\right)\end{array}$ & IA & $\mathbf{R}$ & $\begin{array}{c}\text { Bias } \\
\left(\mathrm{ms}^{-1}\right)\end{array}$ & $\begin{array}{c}\text { RMSE } \\
\left(\mathrm{ms}^{-1}\right)\end{array}$ & IA & $\mathbf{R}$ \\
\hline 6 & 450 & -0.27 & 1.1 & 0.98 & 0.97 & 0.12 & 1.74 & 0.97 & 0.96 \\
\hline 7 & 800 & -0.38 & 1.37 & 0.98 & 0.97 & -0.61 & 1.8 & 0.97 & 0.96 \\
\hline 8 & 1250 & -0.12 & 1.6 & 0.98 & 0.96 & -0.55 & 2.29 & 0.95 & 0.93 \\
\hline 9 & 1850 & 0.06 & 1.99 & 0.96 & 0.93 & -0.91 & 2.94 & 0.93 & 0.89 \\
\hline 10 & 2600 & 0.1 & 2.52 & 0.91 & 0.85 & -1.5 & 3.85 & 0.88 & 0.8 \\
\hline
\end{tabular}

ANL radar wind profiler versus StdObs + 2DVar (case 3)

\begin{tabular}{|r|c|c|c|c|c|c|c|c|c||}
\hline \hline \multicolumn{3}{||c|}{ CALMET Level } & \multicolumn{4}{c|}{ u-Component } & \multicolumn{4}{c||}{ v-Component } \\
\hline$\#$ & $\begin{array}{c}\text { Height } \\
(\mathbf{m})\end{array}$ & $\begin{array}{c}\text { Bias } \\
\mathbf{( m s}^{-\mathbf{1}} \mathbf{)}\end{array}$ & $\begin{array}{c}\text { RMSE } \\
\mathbf{( m s}^{-\mathbf{1}} \mathbf{)}\end{array}$ & $\mathbf{I A}$ & $\mathbf{R}$ & $\begin{array}{c}\text { Bias } \\
\mathbf{( m s}^{-\mathbf{1}} \mathbf{)}\end{array}$ & $\begin{array}{c}\text { RMSE } \\
\left(\mathbf{m s}^{-\mathbf{1}} \mathbf{)}\right.\end{array}$ & $\mathbf{I A}$ & $\mathbf{R}$ \\
\hline 4 & 120 & 0.2 & 1.28 & 0.89 & 0.8 & 0.44 & 2.27 & 0.84 & 0.72 \\
\hline 5 & 230 & 1.02 & 2.1 & 0.87 & 0.83 & 0.88 & 2.63 & 0.89 & 0.82 \\
\hline 6 & 450 & 0.17 & 2.12 & 0.94 & 0.88 & 0.43 & 2.39 & 0.95 & 0.92 \\
\hline 7 & 800 & -0.65 & 2.19 & 0.95 & 0.91 & -0.33 & 2.24 & 0.95 & 0.93 \\
\hline 8 & 1250 & -0.07 & 2.91 & 0.92 & 0.85 & -0.39 & 2.91 & 0.93 & 0.89 \\
\hline 9 & 1850 & 0.16 & 3.15 & 0.91 & 0.83 & -0.06 & 3.42 & 0.92 & 0.86 \\
\hline 10 & 2600 & 1.24 & 4.31 & 0.74 & 0.62 & -0.26 & 3.29 & 0.92 & 0.86 \\
\hline
\end{tabular}

ANL radar wind profiler versus StdObs + profiler + 2DVar (case 5)

\begin{tabular}{|c|c|c|c|c|c|c|c|c|c|}
\hline \multicolumn{2}{|c|}{ CALMET Level } & \multicolumn{4}{|c|}{ u-Component } & \multicolumn{4}{|c|}{ v-Component } \\
\hline$\#$ & $\begin{array}{c}\text { Height } \\
\text { (m) }\end{array}$ & $\begin{array}{c}\text { Bias } \\
\left(\mathrm{ms}^{-1}\right)\end{array}$ & $\begin{array}{c}\text { RMSE } \\
\left(\mathrm{ms}^{-1}\right)\end{array}$ & IA & $\mathbf{R}$ & $\begin{array}{c}\text { Bias } \\
\left(\mathrm{ms}^{-1}\right)\end{array}$ & $\begin{array}{c}\text { RMSE } \\
\left(\mathrm{ms}^{-1}\right)\end{array}$ & IA & $\mathbf{R}$ \\
\hline 4 & 120 & 0.17 & 1.12 & 0.92 & 0.85 & 0.38 & 1.99 & 0.87 & 0.79 \\
\hline 5 & 230 & 0.88 & 1.83 & 0.9 & 0.86 & 0.76 & 2.29 & 0.92 & 0.86 \\
\hline 6 & 450 & 0.14 & 1.87 & 0.95 & 0.91 & 0.37 & 2.11 & 0.96 & 0.94 \\
\hline 7 & 800 & -0.57 & 1.92 & 0.96 & 0.93 & -0.27 & 2.02 & 0.96 & 0.94 \\
\hline 8 & 1250 & -0.04 & 2.6 & 0.94 & 0.88 & -0.33 & 2.61 & 0.94 & 0.92 \\
\hline 9 & 1850 & 0.13 & 2.77 & 0.93 & 0.86 & 0 & 3.03 & 0.94 & 0.89 \\
\hline 10 & 2600 & 1.18 & 3.9 & 0.77 & 0.66 & -0.19 & 2.9 & 0.94 & 0.89 \\
\hline
\end{tabular}


Table C.6 (Contd)

PNNL radar wind profiler versus StdObs + VDRAS (case 4)

\begin{tabular}{|c|c|c|c|c|c|c|c|c|c|}
\hline \multicolumn{2}{|c|}{ CALMET Level } & \multicolumn{4}{|c|}{ בu-Component } & \multicolumn{4}{|c|}{ v-Component } \\
\hline \# & $\begin{array}{c}\text { Height } \\
\text { (m) }\end{array}$ & $\begin{array}{c}\text { Bias } \\
\left(\mathrm{ms}^{-1}\right)\end{array}$ & $\begin{array}{c}\text { RMSE } \\
\left(\mathrm{ms}^{-1}\right)\end{array}$ & IA & $\mathbf{R}$ & $\begin{array}{c}\text { Bias } \\
\left(\mathrm{ms}^{-1}\right)\end{array}$ & $\begin{array}{c}\text { RMSE } \\
\left(\mathrm{ms}^{-1}\right)\end{array}$ & IA & $\mathbf{R}$ \\
\hline 6 & 450 & -0.66 & 1.92 & 0.94 & 0.91 & -0.93 & 2.96 & 0.91 & 0.89 \\
\hline 7 & 800 & -1.1 & 2.17 & 0.95 & 0.92 & -1.14 & 2.86 & 0.92 & 0.88 \\
\hline 8 & 1250 & -0.46 & 2.08 & 0.96 & 0.93 & -0.78 & 2.69 & 0.94 & 0.9 \\
\hline 9 & 1850 & 0.2 & 2.07 & 0.96 & 0.92 & -0.56 & 2.72 & 0.95 & 0.9 \\
\hline 10 & 2600 & 0.53 & 2.91 & 0.89 & 0.83 & -0.48 & 3.91 & 0.89 & 0.81 \\
\hline
\end{tabular}

PNNL radar wind profiler versus StdObs + profiler + VDRAS (case 6)

\begin{tabular}{|c|c|c|c|c|c|c|c|c|c|}
\hline \multicolumn{2}{|c|}{ CALMET Level } & \multicolumn{4}{|c|}{ u-Component } & \multicolumn{4}{|c|}{ v-Component } \\
\hline$\#$ & $\begin{array}{c}\text { Height } \\
\text { (m) }\end{array}$ & $\begin{array}{c}\text { Bias } \\
\left(\mathrm{ms}^{-1}\right)\end{array}$ & $\begin{array}{c}\text { RMSE } \\
\left(\mathrm{ms}^{-1}\right)\end{array}$ & IA & $\mathbf{R}$ & $\begin{array}{c}\text { Bias } \\
\left(\mathrm{ms}^{-1}\right)\end{array}$ & $\begin{array}{c}\text { RMSE } \\
\left(\mathrm{ms}^{-1}\right)\end{array}$ & IA & $\mathbf{R}$ \\
\hline 6 & 450 & -0.6 & 1.68 & 0.96 & 0.93 & -0.82 & 2.59 & 0.93 & 0.92 \\
\hline 7 & 800 & -0.96 & 1.9 & 0.96 & 0.94 & -0.99 & 2.5 & 0.94 & 0.91 \\
\hline 8 & 1250 & -0.4 & 1.82 & 0.97 & 0.95 & -0.68 & 2.35 & 0.95 & 0.92 \\
\hline 9 & 1850 & 0.18 & 1.82 & 0.97 & 0.94 & -0.49 & 2.38 & 0.96 & 0.93 \\
\hline 10 & 2600 & 0.47 & 2.55 & 0.92 & 0.86 & -0.44 & 3.44 & 0.92 & 0.85 \\
\hline
\end{tabular}

ANL radar wind profiler versus StdObs + VDRAS (case 4)

\begin{tabular}{|r|c|c|c|c|c|c|c|c|c||}
\hline \hline \multicolumn{2}{|c|}{ CALMET Level } & \multicolumn{3}{|c|}{ u-Component } & \multicolumn{4}{|c||}{ V-Component } \\
\hline$\#$ & $\begin{array}{c}\text { Height } \\
(\mathbf{m})\end{array}$ & $\begin{array}{c}\text { Bias } \\
\mathbf{( m s}^{-\mathbf{1}} \mathbf{)}\end{array}$ & $\begin{array}{c}\text { RMSE } \\
\left(\mathbf{m s}^{-\mathbf{1}} \mathbf{)}\right.\end{array}$ & $\mathbf{I A}$ & $\mathbf{R}$ & $\begin{array}{c}\text { Bias } \\
\mathbf{( m s}^{-\mathbf{1}} \mathbf{)}\end{array}$ & $\begin{array}{c}\mathbf{R M S E} \\
\left(\mathbf{m s}^{-\mathbf{1}} \mathbf{)}\right.\end{array}$ & $\mathbf{I A}$ & $\mathbf{R}$ \\
\hline 4 & 120 & 0.76 & 1.85 & 0.82 & 0.73 & 0.87 & 2.28 & 0.86 & 0.77 \\
\hline 5 & 230 & 1.27 & 2.6 & 0.82 & 0.78 & 0.75 & 2.54 & 0.91 & 0.84 \\
\hline 6 & 450 & -0.63 & 2.54 & 0.9 & 0.83 & -0.89 & 2.94 & 0.91 & 0.89 \\
\hline 7 & 800 & -1.25 & 2.55 & 0.92 & 0.89 & -0.94 & 2.9 & 0.92 & 0.88 \\
\hline 8 & 1250 & -0.24 & 2.59 & 0.93 & 0.88 & -0.52 & 2.97 & 0.93 & 0.88 \\
\hline 9 & 1850 & 0.43 & 2.66 & 0.93 & 0.87 & 0.45 & 3.16 & 0.94 & 0.88 \\
\hline 10 & 2600 & 1.58 & 3.98 & 0.78 & 0.72 & 0.76 & 3.26 & 0.93 & 0.89 \\
\hline
\end{tabular}

ANL radar wind profiler versus StdObs + profiler + VDRAS (case 4)

\begin{tabular}{|c|c|c|c|c|c|c|c|c|c|}
\hline \multicolumn{2}{|c|}{ CALMET Level } & \multicolumn{4}{|c|}{ בu-Component } & \multicolumn{4}{|c|}{ "v-Component } \\
\hline$\#$ & $\begin{array}{c}\text { Height } \\
\text { (m) }\end{array}$ & $\begin{array}{c}\text { Bias } \\
\left(\mathrm{ms}^{-1}\right)\end{array}$ & $\begin{array}{c}\text { RMSE } \\
\left(\mathrm{ms}^{-1}\right)\end{array}$ & IA & $\mathbf{R}$ & $\begin{array}{c}\text { Bias } \\
\left(\mathrm{ms}^{-1}\right)\end{array}$ & $\begin{array}{c}\text { RMSE } \\
\left(\mathrm{ms}^{-1}\right)\end{array}$ & IA & $\mathbf{R}$ \\
\hline 4 & 120 & 0.65 & 1.61 & 0.85 & 0.78 & 0.75 & 1.99 & 0.89 & 0.82 \\
\hline 5 & 230 & 1.1 & 2.26 & 0.86 & 0.82 & 0.64 & 2.21 & 0.93 & 0.87 \\
\hline 6 & 450 & -0.56 & 2.24 & 0.92 & 0.87 & -0.78 & 2.59 & 0.94 & 0.92 \\
\hline 7 & 800 & -1.09 & 2.24 & 0.94 & 0.92 & -0.8 & 2.57 & 0.94 & 0.91 \\
\hline 8 & 1250 & -0.18 & 2.34 & 0.95 & 0.9 & -0.44 & 2.65 & 0.94 & 0.91 \\
\hline 9 & 1850 & 0.37 & 2.36 & 0.94 & 0.9 & 0.44 & 2.84 & 0.95 & 0.91 \\
\hline 10 & 2600 & 1.47 & 3.63 & 0.81 & 0.75 & 0.7 & 2.89 & 0.95 & 0.91 \\
\hline
\end{tabular}


Table C.7. Comparisons of the Maximum Surface Exposure Between SCIPUFF and CALPUFF During the Final Hour of Simulation as Well as the Percent Difference (D), Root Mean Squared Difference (RMSD), Index of Agreement (IA), and Correlation (R) Between the SCIPUFF and CALPUFF Results

\begin{tabular}{|c|c|c|c|c|c|c|c|}
\hline Run Type & Date & $\begin{array}{c}\text { SCIPUFF } \\
\text { Max. Exposure } \\
\left(\mathrm{g} \mathrm{s} \mathrm{m}^{-3}\right)\end{array}$ & $\begin{array}{c}\text { CALPUFF } \\
\text { Max. Exposure } \\
\left(\mathrm{g} \mathrm{s} \mathrm{m}^{-3}\right)\end{array}$ & $\begin{array}{c}D \\
(\%)\end{array}$ & $\begin{array}{c}\text { RMSD } \\
\left(\mathrm{g} \mathrm{s} \mathrm{m}^{-3}\right)\end{array}$ & IA & $\mathbf{R}$ \\
\hline Case 1 & 5 July & 0.205 & 0.659 & 0.7 & 0.013 & 0.74 & 0.66 \\
\hline \multirow[t]{2}{*}{ (StdObs) } & 10 July & 0.586 & 1.02 & 18.2 & 0.020 & 0.55 & 0.40 \\
\hline & 12 July & 0.323 & 0.261 & 30.3 & 0.005 & 0.86 & 0.77 \\
\hline Case 3 & 5 July & 0.176 & 0.657 & 0.7 & 0.012 & 0.71 & 0.64 \\
\hline (StdObs + & 10 July & 0.580 & 0.982 & 23.4 & 0.019 & 0.56 & 0.41 \\
\hline 2DVar) & 12 July & 0.150 & 0.292 & 36.7 & 0.005 & 0.71 & 0.61 \\
\hline Case 4 & 5 July & 0.192 & 0.659 & 6.3 & 0.013 & 0.70 & 0.61 \\
\hline (StdObs + & 10 July & 0.542 & 1.06 & 16.0 & 0.020 & 0.58 & 0.45 \\
\hline VDRAS) & 12 July & 0.247 & 0.262 & 25.3 & 0.005 & 0.83 & 0.70 \\
\hline
\end{tabular}

Table C.8. Comparisons of the Maximum Surface Exposure During the Final Hour of Simulation Between the CALPUFF Simulations that Employ Wind Fields at Either the 15-min or 1-h Intervals as Well as the Percent Difference (D), Root Mean Squared Difference (RMSD), Index of Agreement (IA), and Correlation (R) Between the Two CALPUFF Simulations

\begin{tabular}{|c|c|c|c|c|c|c|c|}
\hline Run type & Date & $\begin{array}{c}\text { Max. Exposure } \\
\left(\mathrm{g} \mathrm{s} \mathrm{m}^{-3}\right) \\
\text { 1-h winds }\end{array}$ & $\begin{array}{l}\text { Max. Exposure } \\
\quad\left(\mathrm{g} \mathrm{s} \mathrm{m}^{-3}\right) \\
\text { 15-min winds }\end{array}$ & $\begin{array}{c}\text { D } \\
(\%)\end{array}$ & $\begin{array}{c}\text { RMSD } \\
\left(\mathrm{g} \mathrm{s} \mathrm{m}^{-3}\right)\end{array}$ & IA & $\mathbf{R}$ \\
\hline Case 1 & 5 July & 0.358 & 0.352 & 3.05 & 0.85 & 1.00 & 0.99 \\
\hline (StdObs) & 10 July & 0.196 & 0.184 & 6.12 & 1.35 & 0.98 & 0.96 \\
\hline Case 3 & 5 July & 0.416 & 0.407 & 5.13 & 1.20 & 0.99 & 0.99 \\
\hline (StdObs + & 10 July & 0.134 & 0.152 & 5.22 & 0.89 & 0.98 & 0.97 \\
\hline \multicolumn{8}{|l|}{ 2DVar) } \\
\hline Case 4 & 5 July & 0.482 & 0.491 & 4.85 & 1.82 & 0.99 & 0.98 \\
\hline (StdObs + & 10 July & 0.125 & 0.153 & 5.19 & 1.09 & 0.97 & 0.95 \\
\hline VDRAS) & & & & & & & \\
\hline
\end{tabular}

\section{Reference}

Willmott CJ. 1982. "Some comments on the evaluation of model performance." Bull. Amer. Meteorol. Soc. 63:1309-1313. 

Appendix D

CALMET Configuration 


\section{Appendix D: CALMET Configuration}

There are potentially two methods to configure CALMET to ingest the NEXRAD wind retrievals. The first method involves treating the retrievals as model output. In this approach, the model data are only used as a first guess and not used in subsequent processing. To apply this option, it is necessary for the model data to contain no missing values and to be defined on a Cartesian grid over the entire CALMET domain. Although the VDRAS data fulfill this requirement, the 2DVar data do not. The second option for data ingest involves treating the NEXRAD retrievals as observational upper-air data. This is, in fact, the option that was chosen for this study because it allowed us to evaluate VDRAS and 2DVar on an equal footing. However, this option also presented some practical difficulties.

The upper-air data used by CALMET are read from a series of ASCII files, corresponding to each upper-air station used in the simulation. Each file consists of a series of data records containing vertical profiles of wind speed, wind direction, temperature, pressure, and height above sea level. Each record in the file corresponds to a different sounding time. By contrast, the wind retrievals from both VDRAS and 2DVar are stored as three-dimensional arrays in multiple NetCDF files. Each NetCDF file contains the retrieval for a particular assimilation time.

To prepare the retrievals for ingest into CALMET, it was necessary to treat each horizontal grid point in the retrieval as a separate upper-air station. This required parsing the three-dimensional data stored within multiple NetCDF files into a time series of one-dimensional profiles and then reformatting that information into a series of ASCII files, i.e., one file for every horizontal grid point in the retrieval. With this approach, it would be necessary to create more than 3000 upper-air station files at the full horizontal resolution of the NEXRAD retrievals.

It is clear from inspecting the CALMET source code that the developers had not envisioned applications involving more than 99 upper-air stations. As a result, initial attempts at running CALMET with a large number of upper air stations failed. The problem was corrected by making some slight modifications to the code. These modifications involved redefining maximum array dimensions and changes to a few format statements.

Performing a large number CALMET simulations using the full horizontal resolution of the NEXRAD retrievals was not practical. Tests were conducted to access the impact on the CALMET output by decreasing the number of NEXRAD upper-air stations and thus reducing the execution time. This was done to determine a good trade-off between the density of NEXRAD data and CALMET run time. The original 2- $\times 2$-km 2DVar grid was decimated to produce grids with nominal horizontal resolutions of $4 \times 4,8 \times 8$ and $10 \times 10 \mathrm{~km}$, containing 785, 197, and 122 upper air stations, respectively. The run times for each of these resolutions performed on a Dell Precision $380 \mathrm{PC}$ with a $3.2 \mathrm{GHz}$ Pentium DCPU, and 3.5 Gb of RAM, under Windows XP are shown in Table D.1.

In this comparison, the simulation period was from 0300 to 1500 LST on 5 July 2003. The CALMET runs were performed using the hourly input option, and the CALGRID option was set to false to disable the output of the vertical velocity and temperature fields. The full resolution run $(2 \times 2 \mathrm{~km}$ resolution) took nearly 6 hours to complete, while the $10-\times 10$-km run ran in $85 \mathrm{~s}$. The relationship between execution time and data density is clearly nonlinear. To determine a good trade off between data density and run time, we computed the root-mean-square difference (RMSD) by comparing the 2- $\times 2-\mathrm{km}$ run and the decimated runs. The $4-\times 4$-km run resulted in a relatively small RMSD and executed in a reasonable 
period of time ( $25 \mathrm{~min})$. For this reason, all simulations used in this study are based on the effective 4- $\times 4$-km resolution.

We also evaluated run times for CALMET executables produced with two different Fortran compilers. CALMET was largely developed using the Lahey (LF95) compiler, but the source code can be compiled using the Digital Fortran (DF) compiler. The DF executable ran nearly three times faster than the LF95 executable. The resulting u- and v-components of the wind produced by the two executables differed by only a single precision round-off error of the computer. Thus, a substantial saving in computational time is achieved by using the DF compiled version of CALMET, without sacrificing accuracy.

Table D.1. Execution Times of CALMET for Different Compilers, Resolution, and Number of Input Observations

\begin{tabular}{|l|c|c|c|c|c||}
\hline Compiler & $\begin{array}{c}\text { \# of Upper Air } \\
\text { Stations }\end{array}$ & $\begin{array}{c}\text { Effective } \\
\text { Resolution }\end{array}$ & $\begin{array}{c}\text { RMSD } \\
\mathbf{( m s}^{-\mathbf{1}}\end{array}$ & $\begin{array}{c}\text { Execution Time } \\
\text { Seconds }\end{array}$ & $\begin{array}{c}\text { Execution Time } \\
\text { HH:MM:SS }\end{array}$ \\
\hline LF95 & 3136 & $2 \times 2$ & 0 & 20874 & $05: 47: 54$ \\
\hline LF95 & 785 & $4 \times 4$ & 0.049 & 1443 & $00: 24: 03$ \\
\hline LF95 & 197 & $8 \times 8$ & 0.252 & 149 & $00: 02: 29$ \\
\hline LF95 & 122 & $10 \times 10$ & 0.462 & 85 & $00: 01: 25$ \\
\hline DF & 785 & $4 \times 4$ & - & 597 & $00: 09: 57$ \\
\hline
\end{tabular}


PNNL-16399

\section{Distribution}

No. of

Copies

\section{OFFSITE}

2 National Oceanic and Atmospheric

Administration

National Severe Storms Laboratory

120 David L. Boren Blvd.

Norman, Oklahoma

Attn: Qin Xu

Pengfei Zhang

4 National Center for Atmospheric Research

Research Applications Laboratory

P.O. Box 3000

Boulder, Colorado

Attn: Jeffrey Copeland

Jenny Sun

Scott Swerdlin

Tom Warner

4 U.S. Department of Homeland Security

Ms. Teresa Lustig

Department of Homeland Security

Attn: S\&T/Teresa Lustig/4-5766

Anacosta Naval Annex

245 Murry Lane, SW, Building 410

Washington, DC 20528

(202) 254-5766

Mr. Richard Turville

Department of Homeland Security

Attn: S\&T/Richard Turville/4-5338

Anacosta Naval Annex

245 Murry Lane, SW, Building 410

Washington, DC 20528

(202) 254-5338
No. of

Copies

\section{OFFSITE}

Mr. Lance Brooks

Department of Homeland Security

Attn: S\&T/Lance Brooks/4-5768

Anacosta Naval Annex

245 Murry Lane, SW, Building 410

Washington, DC 20528

(202) 254-5768

Dr. Bruce Davis

Department of Homeland Security

Attn: S\&T/Bruce Davis/4-5893

Anacosta Naval Annex

245 Murry Lane, SW, Building 410

Washington, DC 20528

(202) 254-5893

\section{ONSITE}

7 Pacific Northwest National Laboratory

J. D. Fast K9-30

K. J. Allwine K9-30

R. K. Newsom K9-30

J. C. Doran K9-30

W. J. Shaw K9-30

Information Release (2) 